Review

\title{
Luminescence Spectroscopy and Origin of Luminescence Centers in Bi-Doped Materials
}

\author{
Aleksei Krasnikov ${ }^{1}$, Eva Mihokova ${ }^{2}$, Martin Nikl ${ }^{2}$, Svetlana Zazubovich ${ }^{1, *}$ and \\ Yaroslav Zhydachevskyy ${ }^{3,4}$ (D) \\ 1 Institute of Physics, University of Tartu, W. Ostwaldi 1, 50411 Tartu, Estonia; aleksei.krasnikov@ut.ee \\ 2 Institute of Physics, Czech AS, Cukrovarnicka 10, 16200 Prague, Czech Republic; mihokova@fzu.cz (E.M.); \\ nikl@fzu.cz (M.N.) \\ 3 Institute of Physics, Polish AS, Al. Lotników 32/46, 02-668 Warsaw, Poland; zhydach@ifpan.edu.pl \\ 4 Semiconductor Electronics Department, Lviv Polytechnic National University, Bandera 12, \\ 79013 Lviv, Ukraine \\ * Correspondence: svetlana.zazubovits@ut.ee
}

Received: 21 February 2020; Accepted: 14 March 2020; Published: 17 March 2020

\begin{abstract}
Bi-doped compounds recently became the subject of an extensive research due to their possible applications as scintillator and phosphor materials. The oxides co-doped with $\mathrm{Bi}^{3+}$ and trivalent rare-earth ions were proposed as prospective phosphors for white light-emitting diodes and quantum cutting down-converting materials applicable for enhancement of silicon solar cells. Luminescence characteristics of different $\mathrm{Bi}^{3+}$-doped materials were found to be strongly different and ascribed to electronic transitions from the excited levels of a $\mathrm{Bi}^{3+}$ ion to its ground state, charge-transfer transitions, $\mathrm{Bi}^{3+}$ dimers or clusters, radiative decay of $\mathrm{Bi}^{3+}$-related localized or trapped excitons, etc. In this review, we compare the characteristics of the $\mathrm{Bi}^{3+}$-related luminescence in various compounds; discuss the possible origin of the corresponding luminescence centers as well as the processes resulting in their luminescence; consider the phenomenological models proposed to describe the excited-state dynamics of the $\mathrm{Bi}^{3+}$-related centers and determine the structure and parameters of their relaxed excited states; address an influence of different interactions (e.g., spin-orbit, electron-phonon, hyperfine) as well as the $\mathrm{Bi}^{3+}$ ion charge and volume compensating defects on the luminescence characteristics. The Bi-related luminescence arising from lower charge states (namely, $\mathrm{Bi}^{2+}, \mathrm{Bi}^{+}, \mathrm{Bi}^{0}$ ) is also reviewed.
\end{abstract}

Keywords: Luminescence; excitons; defects; excited states; interactions; Bi-doped compounds; $\mathrm{Bi}^{3+}$, $\mathrm{Bi}^{2+}, \mathrm{Bi}^{+}, \mathrm{Bi}^{0}$ centers; $\mathrm{Bi}^{3+}$ dimers

\section{Introduction}

Luminescence of various $\mathrm{Bi}^{3+}$-doped materials (alkali halides; alkaline-earth oxides, sulfates and phosphates; tungstates; garnets; perovskites; silicates; borates; vanadates; niobates, etc.) was systematically investigated starting from the 1960s (see, e.g., review papers [1-11] and references therein). $\mathrm{Bi}^{3+}$-doped complex oxides, where a trivalent $\mathrm{Bi}^{3+}$ ion substitutes for a trivalent rare-earth ion, became the subject of special interest and extensive research due to their possible applications as scintillator and phosphor materials. For instance, $\mathrm{Bi}^{3+}$-doped garnets [12-19], oxyorthosilicates [20,21], perovskites [22], borates [23] and phosphates [24] were considered as prospective scintillator materials and the materials for $\mathrm{X}$-ray screens due to the presence of an intense and fast $\mathrm{Bi}^{3+}$-related luminescence at room temperature. The materials co-doped with $\mathrm{Bi}^{3+}$ and trivalent rare-earth ions $\left(\mathrm{Ln}^{3+}: \mathrm{Dy}^{3+}\right.$, $\mathrm{Er}^{3+}, \mathrm{Yb}^{3+}, \mathrm{Eu}^{3+}, \mathrm{Sm}^{3+}, \mathrm{Ho}^{3+}, \mathrm{Nd}^{3+}$ ) were found to be potentially applicable as spectral converters for solar cells and solid state light sources of a new generation, so called white light-emitting diodes, 
owing to the presence of broad and intense absorption bands in the ultraviolet region, the intense broad visible $\mathrm{Bi}^{3+}$-related emission band, and an effective energy transfer from the $\mathrm{Bi}^{3+}$-related excited state to $\mathrm{Ln}^{3+}$ ions, giving rise to an intense visible emission from $\mathrm{Ln}^{3+}$ ions (see, e.g., [11,25-45]). Due to an effective $\mathrm{Bi}^{3+} \rightarrow \mathrm{Ln}^{3+}$ energy transfer, the needed luminescence color of the $\mathrm{Bi}^{3+}, \mathrm{Ln}^{3+}$ co-doped compounds can easily be obtained by varying the concentration ratio of $\mathrm{Bi}^{3+}$ and $\mathrm{Ln}^{3+}$ ions in the host material (see, e.g., $[26,39,40,43]$ ). The oxides co-doped with $\mathrm{Bi}^{3+}$ and $\mathrm{Yb}^{3+}$ are of interest as quantum cutting down-converting materials possibly applicable for enhancement of silicon solar cells (see, e.g., [46-48] and references therein). Some $\mathrm{Bi}^{3+}$-doped materials, e.g., $\mathrm{ZnGa}_{2} \mathrm{O}_{4}: \mathrm{Bi}$ [49], $\mathrm{CaGa}_{2} \mathrm{O}_{4}: \mathrm{Bi}$ [50], $\mathrm{SrGa}_{2} \mathrm{O}_{4}: \mathrm{Bi}$ [51], $\mathrm{Ca}_{0.9} \mathrm{Sr}_{0.1} \mathrm{~S}: \mathrm{Bi}$ [52], $\mathrm{KGaGeO}_{4}: \mathrm{Bi}$ [53], $\mathrm{CaWO}_{4}: \mathrm{Bi}$ [54], $\mathrm{CdSiO}_{3}: \mathrm{Bi}$ [55], $\mathrm{Lu}_{2} \mathrm{CaGeO}_{6}: \mathrm{Bi}$ [56], $\mathrm{CaZnGe}_{2} \mathrm{O}_{6}: \mathrm{Bi}$ [57], $\mathrm{Sr}_{3} \mathrm{Ga}_{4} \mathrm{O}_{9}: \mathrm{Bi}$ [58], $\mathrm{NaLuGeO}_{4}: \mathrm{Bi}, \mathrm{Eu}$ [59], $\mathrm{CdSiO}_{3}: \mathrm{Bi}, \mathrm{Gd}$ [60], $\mathrm{CdSiO}_{3}: \mathrm{Bi}$, Dy [61], etc. were found to be long persistent phosphors which may have potential applications in photo-catalysis, anti-counterfeiting, water disinfecting, photochemistry, and dosimetry (see also review [62]).

The drastically increasing interest in the investigation of various bismuth based materials, observed since 2004 and reflecting the increasing importance of these materials in modern technological applications, is clearly illustrated in Figure 1 of Ref. [11]. The quick growth of the number of publications on the bismuth luminescence can be explained by the fact that, owing to a large number of possible valence states, bismuth containing materials exhibit a rich variety of luminescence properties, showing emission from the ultraviolet to infrared. This allows the application of these materials in many areas such as telecommunication, biomedicine, white light illumination, and lasers. An excellent review on different types of bismuth-activated photonic materials, their synthesis, characterization, future research trends and prospective applications in broadband optical amplifiers, fiber lasers, bioimaging, and phosphors for white light-emitting diodes is given in Ref. [8].

In recent years, the interest in $\mathrm{Bi}^{3+}$-doped materials of various types increased drastically not only due to their possible new applications (see, e.g., $[8,11,63]$ and references therein), but also owing to very interesting phenomena appearing under photoexcitation in the $\mathrm{Bi}^{3+}$-related absorption bands. For example, an unusually strong dependence of luminescence characteristics on the host material found many years ago was recently connected with the position of $\mathrm{Bi}^{3+}$ energy levels with respect to the bottom of the host conduction band (see, e.g., $[7,10,64,65])$. To understand the mechanisms of observed features and to clarify the origin of the emission bands in different materials, a detailed spectroscopic study and comparison of various $\mathrm{Bi}^{3+}$-doped compounds are needed.

Absorption spectra of $\mathrm{Bi}^{3+}$ centers in different compounds are caused by the transitions between the electronic configurations of the ground $\left(6 \mathrm{~s}^{2}\right)$ and the excited (6s)(6p) states of $\mathrm{Bi}^{3+}$. The ground state of a free $\mathrm{Bi}^{3+}$ ion is ${ }^{1} \mathrm{~S}_{0}$, and the two lowest-energy excited states are triplet ${ }^{3} \mathrm{P}$ and singlet ${ }^{1} \mathrm{P}$. The triplet state is split due to the spin-orbit interaction into the ${ }^{3} \mathrm{P}_{0},{ }^{3} \mathrm{P}_{1}$, and ${ }^{3} \mathrm{P}_{2}$ states. According to [66], the energies of electronic transitions from the ground ${ }^{1} \mathrm{~S}_{0}$ level to the excited ${ }^{3} \mathrm{P}_{1},{ }^{3} \mathrm{P}_{2}$, and ${ }^{1} \mathrm{P}_{1}$ levels of a free $\mathrm{Bi}^{3+}$ ion $\left(\mathrm{E}_{\text {free }}\right)$ are $9.41 \mathrm{eV}, 11.96 \mathrm{eV}$, and $14.21 \mathrm{eV}$, respectively. Only the dipole ${ }^{1} \mathrm{~S}_{0} \rightarrow{ }^{1} \mathrm{P}_{1}$ transitions are allowed. The ${ }^{1} \mathrm{~S}_{0} \rightarrow{ }^{3} \mathrm{P}_{1}$ transitions are partly allowed due to the mixing of the wave functions of the singlet ${ }^{1} \mathrm{P}_{1}$ and triplet ${ }^{3} \mathrm{P}_{1}$ states by the spin-orbit interaction. In the crystals, the forbidden ${ }^{1} \mathrm{~S}_{0} \rightarrow{ }^{3} \mathrm{P}_{2}$ transitions also become partly allowed due to vibronic mixing of the ${ }^{3} \mathrm{P}_{2}$-related state with the triplet or singlet states by non-totally symmetric lattice vibrations. The ${ }^{1} \mathrm{~S}_{0} \rightarrow$ ${ }^{3} \mathrm{P}_{0}$ transitions are strongly forbidden. Thus, in the crystal, the absorption (excitation) bands labeled as $\mathrm{A}, \mathrm{B}$, and $\mathrm{C}$ and corresponding to the electronic transitions from the ground ${ }^{1} \mathrm{~S}_{0}$ level of a free $\mathrm{Bi}^{3+}$ ion to the excited ${ }^{3} \mathrm{P}_{1},{ }^{3} \mathrm{P}_{2}$, and ${ }^{1} \mathrm{P}_{1}$ levels, respectively, can be observed.

In many cases, only the lowest-energy A band, corresponding to the ${ }^{1} \mathrm{~S}_{0} \rightarrow{ }^{3} \mathrm{P}_{1}$ transition of a free $\mathrm{Bi}^{3+}$ ion, clearly appears in the absorption (excitation) spectra. From the comparison of the A band energy in a $\mathrm{Bi}^{3+}$-doped compound with the ${ }^{1} \mathrm{~S}_{0} \rightarrow{ }^{3} \mathrm{P}_{1}$ transition energy of the free $\mathrm{Bi}^{3+}$ ion $(9.41 \mathrm{eV})$, the approximate positions of the other absorption (excitation) bands of the same compound can be estimated. For example, in $\mathrm{Lu}_{3} \mathrm{Al}_{5} \mathrm{O}_{12}: \mathrm{Bi}$, the $\mathrm{A}$ band is located around $4.63 \mathrm{eV}$, i.e., the transition energy in the crystal $\left(\mathrm{E}_{\text {crys }}\right)$ is about twice as small as in a free $\mathrm{Bi}^{3+}$ ion. Taking into account the fact that 
the $\mathrm{E}_{\text {free }} / \mathrm{E}_{\text {crys }}$ ratio increases with the increasing $\mathrm{E}_{\text {free }}$ according to the approximate equation $\mathrm{E}_{\text {free }} / \mathrm{E}_{\text {crys }}$ $=1+\mathrm{kE}_{\text {free }}$ experimentally found in [67] and confirmed to be valid for all the $\mathrm{ns}^{2}$-ion-doped alkali halides, it was suggested that the $5.95 \mathrm{eV}$ absorption band of $\mathrm{Lu}_{3} \mathrm{Al}_{5} \mathrm{O}_{12}: \mathrm{Bi}$ could arise from the ${ }^{1} \mathrm{~S}_{0} \rightarrow$ ${ }^{1} \mathrm{P}_{1}$ transitions, and the weak $\mathrm{B}$ band should be located at about $5.2 \mathrm{eV}$.

In this paper, mainly luminescence characteristics of $\mathrm{Bi}^{3+}$-doped compounds (collected in Tables 1 and 2) are addressed. As it was noticed many years ago [1,68,69], two types of $\mathrm{Bi}^{3+}$-related emission bands with strongly different characteristics exist in these materials (see, e.g., review papers [4,7,9-11] and references therein). The emission of both types was found to arise from the triplet relaxed excited state (RES) of a luminescence center. For some compounds, not only the characteristics of the triplet luminescence but also the structure and parameters of the corresponding triplet RES were studied (see, e.g., $[3,9,13,16-18,20-22,69-99])$. Due to the spin-orbit interaction, the triplet RES is split and consists of the upper emitting level and the lower metastable level. The energy distance (D) between these levels depends on the spin-orbit interaction energy in the triplet state. The probability of the radiative transitions from the emitting level $\left(\mathrm{k}_{2}\right)$ is much higher as compared to that from the metastable level $\left(\mathrm{k}_{1}\right)$. Due to that, the radiative decay of the emitting and metastable levels can result in the appearance of two different, the fast (FC) and slow (SC), luminescence decay components with characteristic temperature dependences of their decay times and light sums, strongly depending on the $\mathrm{D}$ value.

The main difference between the emissions of the two types is in the Stokes shift (S) and full width at half maximum (FWHM) of the emission band and in the temperature dependence of the luminescence

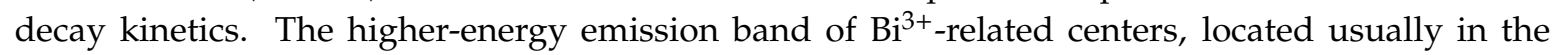
ultraviolet (UV) spectral region, further on called the UV emission, is characterized by relatively small values of FWHM and S. The slow component decay time of this emission is temperature-independent up to rather high temperatures $(40-100 \mathrm{~K})$ indicating a high spin-orbit splitting energy D of the triplet RES of the luminescence center (see Table 1). The FWHM and S values of the lower-energy emission band are much larger, the slow component decay time is temperature-independent only up to $1-5 \mathrm{~K}$, and the D values are 1-2 orders of magnitude smaller as compared to the UV emission (see Table 2). As these bands are usually located in the visible (VIS) spectral range, we denote them the VIS emission.

A clear relation between the energy distance $D$ and the values of the Stokes shift $\mathrm{S}$ was noticed for some $\mathrm{Bi}^{3+}$-containing compounds many years ago (see, e.g., $[5,68,100,101]$ and references therein). It was also discussed in the recent paper [7], but not explained yet. In [68], the authors concluded that the $S$ value depends on the coordination number of a $\mathrm{Bi}^{3+}$ ion and the ionic radius of the crystal lattice ion which $\mathrm{Bi}^{3+}$ is substituted for. However, later studies revealed completely different origin of the UV and VIS emissions of $\mathrm{Bi}^{3+}$-doped materials.

As evident from Tables 1 and 2, in many $\mathrm{Bi}^{3+}$-doped compounds, e.g., in the garnets $\mathrm{Y}_{3} \mathrm{Al}_{5} \mathrm{O}_{12}: \mathrm{Bi}$ and $\mathrm{Lu}_{3} \mathrm{Al}_{5} \mathrm{O}_{12}: \mathrm{Bi}$, silicate $\mathrm{Lu}_{2} \mathrm{SiO}_{5}: \mathrm{Bi}$, borate $\mathrm{LaBO}_{3}: \mathrm{Bi}$, both types of emission bands were found to co-exist (see, e.g., $[9,15-18,20,21,78]$ ). Only the VIS emission was observed, e.g., in $\mathrm{LiLaP}_{4} \mathrm{O}_{12}$ :Bi [72,102], $\mathrm{Sr}_{3} \mathrm{Ga}_{4} \mathrm{O}_{9}: \mathrm{Bi}$ [58], $\mathrm{Li}_{2} \mathrm{BaP}_{2} \mathrm{O}_{7}: \mathrm{Bi}$ [103], $\mathrm{GdBr}_{3} \mathrm{O}_{6}$ :Bi [104], YOCl:Bi [99], GdOCl:Bi [99], $\mathrm{Gd}_{3} \mathrm{Ga}_{5} \mathrm{O}_{12}: \mathrm{Bi}[12,74,75], \mathrm{PbWO}_{4}: \mathrm{Bi}$ [73], rare-earth vanadates [76], and niobates [77], while only the UV emission, in alkali-earth fluorides, oxides, and sulfides [79,84-90,92], $\mathrm{YAlO}_{3}: \mathrm{Bi}$ [22], $\mathrm{Y}_{4} \mathrm{Al}_{2} \mathrm{O}_{9}: \mathrm{Bi}$ [70], $\mathrm{Y}_{2} \mathrm{SiO}_{5}: \mathrm{Bi}[20], \mathrm{Y}_{2} \mathrm{O}_{3}: \mathrm{Bi}$ [71], etc.

Luminescence characteristics of different $\mathrm{Bi}^{3+}$-doped materials were connected in the literature with the single $\mathrm{Bi}^{3+}$ ions and with dimer $\left\{\mathrm{Bi}^{3+}-\mathrm{Bi}^{3+}\right\}$ centers or $\mathrm{Bi}^{3+}$ clusters. The UV emission was usually concluded to arise from the electronic transitions from the excited levels of a single $\mathrm{Bi}^{3+}$ ion to its ground state, corresponding to the ${ }^{3} \mathrm{P}_{1,0} \rightarrow{ }^{1} \mathrm{~S}_{0}$ transitions of a free $\mathrm{Bi}^{3+}$ ion. The VIS emission was ascribed in the literature to the same ${ }^{3} \mathrm{P}_{1,0} \rightarrow{ }^{1} \mathrm{~S}_{0}$ transitions; to $\mathrm{Bi}^{3+}$ pairs or clusters of $\mathrm{Bi}^{3+}$ ions; to charge-transfer (CT) transitions (in particular, to metal-to-metal charge transfer-MMCT, the $\mathrm{Bi}^{3+}$ $\rightarrow \mathrm{Bi}^{3+}$ charge transfer inside a $\left\{\mathrm{Bi}^{3+}-\mathrm{Bi}^{3+}\right\}$ dimer called the intervalence charge transfer-IVCT, and $\mathrm{O}^{-} \rightarrow \mathrm{Bi}^{3+}$ charge transfer); to radiative decay of impurity-trapped exciton; to D-state emission; to radiative decay of an exciton localized around a $\mathrm{Bi}^{3+}$-related center (e.g., a $\mathrm{Bi}^{3+}$ ion, dimer $\left\{\mathrm{Bi}^{3+}-\mathrm{Bi}^{3+}\right\}$ center, $\left\{\mathrm{Bi}^{3+}\right.$ - defect $\}$ center). 
In addition to rich literature dealing with the $\mathrm{Bi}^{3+}$-based luminescence in many kinds of crystalline solids mentioned above, there is an increasing interest in the study of bismuth centers with the valence lower than $3^{+}$for their specific emission characteristics given by radiative transitions within the $6 \mathrm{p}$ shell. Namely, the $\mathrm{Bi}^{2+}$ center was ascribed to red luminescence in $\mathrm{SrB}_{4} \mathrm{O}_{7}$ host in 1994 [105] and other examples can be found in the review paper of Sun et al. in 2014 [8]. More recently, several studies appeared ascribing the near infrared luminescence to $\mathrm{Bi}^{0}$ center, e.g., in $\mathrm{Ba}_{2} \mathrm{P}_{2} \mathrm{O}_{7}$ host [106]. Even the $\mathrm{Bi}^{+}$center was ascribed to new luminescence bands in the visible-near infrared spectral region in $\mathrm{Ba}_{2} \mathrm{~B}_{5} \mathrm{O}_{9} \mathrm{Cl}: \mathrm{Bi}$. These new bands appear among those associated with the $\mathrm{Bi}^{2+}$ and $\mathrm{Bi}^{0}$ centers during the annealing cycles in air and the reduction atmosphere [107].

In this review, we compare the characteristics of the $\mathrm{Bi}^{3+}$-related luminescence in different compounds; discuss the possible origin of the corresponding luminescence centers; consider theoretical models of their RES and phenomenological models allowing to describe the excited-state dynamics of the $\mathrm{Bi}^{3+}$-related centers of different types and determine the structure and parameters of their RES; address an influence of different interactions (e.g., spin-orbit, electron-phonon, hyperfine) as well as the $\mathrm{Bi}^{3+}$ ion charge and volume compensating defects on the luminescence characteristics.

In Section 6 we review the state-of-art regarding emission characteristics of bismuth centers with the valence lower than $3^{+}$.

Table 1. Emission peak positions $\left(\mathrm{E}_{\mathrm{em}}\right)$, full widths at half maxima (FWHM), the Stokes shifts $(S)$, positions of the lowest-energy excitation band $\left(E_{\text {exc }}\right)$, and decay times $\left(\tau_{S C}\right)$ of the slow decay component obtained at $4.2 \mathrm{~K}$ for the triplet emission of $\mathrm{Bi}^{3+}$ centers (denoted in this work the UV emission). The parameters of the triplet relaxed excited state (RES): the spin-orbit splitting energy (D), the probabilities of the radiative decay of the metastable $\left(\mathrm{k}_{1}\right)$ and emitting $\left(\mathrm{k}_{2}\right)$ levels of the triplet RES, and the zero-temperature nonradiative transition rate $(\mathrm{K})$ between the metastable and emitting levels.

\begin{tabular}{|c|c|c|c|c|c|c|c|c|c|c|}
\hline Compound & $\begin{array}{l}E_{e m}, \\
\text { eV }\end{array}$ & $\begin{array}{c}\text { FWHM, } \\
\text { eV }\end{array}$ & $\begin{array}{l}\mathrm{S} \\
\mathrm{eV}\end{array}$ & $\begin{array}{c}\text { Eexc, } \\
\text { eV }\end{array}$ & $\begin{array}{l}\tau_{\mathrm{SC}} \\
\mathrm{ms}\end{array}$ & $\begin{array}{c}\mathrm{D}, \\
\mathrm{meV}\end{array}$ & $\begin{array}{c}\mathbf{k}_{1} \\
\times 10^{3} \\
\mathbf{s}^{-1}\end{array}$ & $\begin{array}{c}\mathbf{k}_{2} \\
\times 10^{8} \\
\mathrm{~s}^{-1}\end{array}$ & $\begin{array}{c}\mathrm{K} \\
\times 10^{8} \\
\mathrm{~s}^{-1}\end{array}$ & Refs. \\
\hline $\mathrm{YAlO}_{3}: \mathrm{Bi}$ & 3.76 & 0.27 & 0.67 & 4.43 & 0.57 & 98 & 1.76 & 1 & 1 & [22] \\
\hline $\mathrm{Lu}_{2} \mathrm{SiO}_{5}: \mathrm{Bi}$ & 3.45 & 0.28 & 0.75 & 4.20 & 0.29 & 65 & 3.51 & 1 & 1 & {$[9,21]$} \\
\hline $\mathrm{Y}_{2} \mathrm{SiO}_{5}: \mathrm{Bi}$ & 3.56 & 0.33 & 0.94 & 4.50 & 0.33 & 60 & 3.05 & 0.2 & 1 & {$[9,20]$} \\
\hline $\mathrm{Lu}_{3} \mathrm{Al}_{5} \mathrm{O}_{12}: \mathrm{Bi}$ & 4.08 & 0.24 & 0.55 & 4.63 & 1.10 & 103 & 0.89 & 0.25 & 5 & [9,16-18] \\
\hline $\mathrm{Y}_{3} \mathrm{Al}_{5} \mathrm{O}_{12}: \mathrm{Bi}$ & 3.99 & 0.24 & 0.58 & 4.57 & 1.05 & 110 & 0.95 & 0.7 & 5 & {$[9,16,17]$} \\
\hline $\mathrm{Y}_{2} \mathrm{O}_{3}: \mathrm{Bi}\left(\mathrm{S}_{6}\right)$ & 3.04 & 0.22 & 0.27 & 3.31 & 0.14 & 39 & 4.8 & 0.45 & 0.9 & [71] \\
\hline $\operatorname{Bi}\left(C_{2}\right)$ & 2.41 & 0.38 & 1.19 & 3.60 & 0.42 & 28 & 1.5 & 0.11 & 0.2 & [71] \\
\hline $\mathrm{Y}_{4} \mathrm{Al}_{2} \mathrm{O}_{9}: \mathrm{Bi}(1)$ & 3.40 & 0.24 & 1.02 & 4.42 & 0.17 & 52 & 6 & 0.9 & 0.7 & [70] \\
\hline $\operatorname{Bi}(2)$ & 3.07 & 0.28 & 1.12 & 4.19 & 0.30 & 53 & 3.3 & 0.6 & 0.3 & [70] \\
\hline $\operatorname{Bi}(3)$ & 2.87 & 0.32 & 1.20 & 4.07 & 0.40 & 50 & 2.5 & 0.4 & 0.3 & [70] \\
\hline $\operatorname{Bi}(4)$ & 3.16 & 0.18 & 0.73 & 3.89 & 0.22 & 50 & 4.4 & 0.7 & 0.6 & [70] \\
\hline \multirow[t]{2}{*}{$\mathrm{Y}_{3} \mathrm{Al}_{5} \mathrm{O}_{12}: \mathrm{Bi}$} & 4.04 & - & 0.49 & 4.53 & - & - & - & - & - & [14] \\
\hline & 4.07 & - & 0.57 & 4.64 & - & - & - & - & - & {$[15,108]$} \\
\hline \multirow[t]{2}{*}{$\mathrm{Lu}_{3} \mathrm{Al}_{5} \mathrm{O}_{12}: \mathrm{Bi}$} & 4.09 & - & 0.47 & 4.56 & - & - & - & - & - & [14] \\
\hline & 4.16 & - & 0.42 & 4.58 & - & - & - & - & - & [19] \\
\hline $\mathrm{GdAlO}_{3}: \mathrm{Bi}$ & 3.72 & 0.30 & 0.52 & 4.24 & - & - & - & - & - & [109] \\
\hline \multirow[t]{3}{*}{$\mathrm{Y}_{3} \mathrm{Ga}_{5} \mathrm{O}_{12}: \mathrm{Bi}$} & 3.88 & - & 0.47 & 4.35 & 1.15 & 90 & 0.87 & 0.21 & 0.23 & [13] \\
\hline & 3.91 & - & 0.35 & 4.26 & - & - & - & - & - & [110] \\
\hline & 3.87 & - & 0.49 & 4.36 & - & - & - & - & - & [14] \\
\hline $\mathrm{MgO}: \mathrm{Bi}$ & 3.50 & - & - & - & 2.9 & 148 & - & 0.2 & - & [79] \\
\hline \multirow[t]{3}{*}{$\mathrm{CaO}: \mathrm{Bi}$} & 3.10 & & 0.40 & & 3.8 & 164 & & 5 & & [79] \\
\hline & 3.10 & 0.14 & 0.40 & 3.50 & 3.25 & 152 & & & & [85] \\
\hline & 3.13 & 0.14 & 0.34 & 3.47 & 3.5 & 147 & - & - & - & {$[84,88,89]$} \\
\hline
\end{tabular}


Table 1. Cont.

\begin{tabular}{|c|c|c|c|c|c|c|c|c|c|c|}
\hline Compound & $\begin{array}{l}E_{\text {em }} \\
\text { eV }\end{array}$ & $\begin{array}{c}\text { FWHM, } \\
\text { eV }\end{array}$ & $\begin{array}{l}\mathrm{S}, \\
\mathrm{eV}\end{array}$ & $\begin{array}{l}E_{\text {exc, }} \\
\text { eV }\end{array}$ & $\begin{array}{l}\tau_{\mathrm{SC}} \\
\mathrm{ms}\end{array}$ & $\begin{array}{c}\text { D, } \\
\text { meV }\end{array}$ & $\begin{array}{c}\mathbf{k}_{1} \\
\times 10^{3} \\
\mathrm{~s}^{-1}\end{array}$ & $\begin{array}{c}\mathbf{k}_{2} \\
\times 10^{8} \\
\mathbf{s}^{-1}\end{array}$ & $\begin{array}{c}\mathrm{K} \\
\times 10^{8} \\
\mathbf{s}^{-1}\end{array}$ & Refs. \\
\hline \multirow[t]{2}{*}{$\mathrm{SrO}: \mathrm{Bi}$} & 2.85 & 0.26 & 0.53 & 3.38 & 3.5 & 128 & - & - & - & [84] \\
\hline & - & - & - & - & 4.2 & 122 & - & - & - & [91] \\
\hline \multirow[t]{2}{*}{$\mathrm{CaS}: \mathrm{Bi}$} & 2.75 & 0.15 & 0.27 & 3.02 & 3.0 & 109 & - & - & - & {$[84,88,89]$} \\
\hline & - & - & 0.13 & - & 3.3 & 100 & 0.32 & 0.21 & - & [87] \\
\hline \multirow[t]{2}{*}{ SrS:Bi } & 2.60 & 0.18 & 0.28 & 2.88 & 1.0 & 93 & - & - & - & {$[84,90]$} \\
\hline & - & - & 0.20 & - & 4.1 & 107 & 0.26 & 1.67 & - & {$[87,90]$} \\
\hline \multirow{2}{*}{$\mathrm{BaS}: \mathrm{Bi}$} & 2.28 & $\approx 0.30$ & 0.49 & 2.77 & - & 61 & - & - & - & [86] \\
\hline & - & - & 0.49 & - & 3.4 & 57 & 0.28 & 0.16 & - & [87] \\
\hline MgS:Bi & - & - & 0.10 & - & 1.7 & 108 & 0.58 & 0.30 & - & [87] \\
\hline $\mathrm{CaF}_{2}: \mathrm{Bi}$ & 5.51 & 0.24 & 0.35 & 5.86 & 4.5 & 265 & - & - & - & [92] \\
\hline $\mathrm{SrF}_{2}: \mathrm{Bi}$ & 5.47 & 0.35 & 0.31 & 5.78 & 5.0 & 110 & - & - & - & [92] \\
\hline $\mathrm{BaF}_{2}: \mathrm{Bi}$ & 4.74 & 0.35 & 1.01 & 5.75 & 1.1 & 65 & - & - & - & [92] \\
\hline \multirow[t]{4}{*}{$\mathrm{KCl}: \mathrm{Bi}$} & 2.68 & 0.38 & 1.13 & 3.81 & 2.8 & - & - & - & - & [85] \\
\hline & 2.84 & - & 0.96 & 3.80 & 1.38 & - & - & - & - & [85] \\
\hline & 3.20 & - & 0.60 & 3.80 & - & - & - & - & - & [94] \\
\hline & 2.88 & - & 0.82 & 3.70 & 0.55 & 59 & 1.85 & 0.625 & - & [94] \\
\hline $\mathrm{ScP}_{3} \mathrm{O}_{9}: \mathrm{Bi}$ & 4.34 & - & 0.56 & 4.90 & - & - & - & - & - & [111] \\
\hline $\mathrm{LuP}_{3} \mathrm{O}_{9}: \mathrm{Bi}$ & 4.29 & - & 0.86 & 5.15 & - & - & - & - & - & [111] \\
\hline $\mathrm{YP}_{3} \mathrm{O}_{9}: \mathrm{Bi}$ & 4.23 & - & 0.92 & 5.15 & - & - & - & - & - & [111] \\
\hline $\mathrm{ScBO}_{3}: \mathrm{Bi}$ & 4.10 & - & 0.22 & 4.32 & 0.87 & 120 & 1.11 & 0.7 & - & [78] \\
\hline $\mathrm{LuBO}_{3}: \mathrm{Bi}$ & 4.08 & - & 0.28 & 4.35 & 0.76 & - & 1.31 & - & - & [78] \\
\hline $\mathrm{YBO}_{3}: \mathrm{Bi}$ & 4.20 & - & 0.64 & 4.86 & - & - & - & - & - & {$[78,95]$} \\
\hline $\mathrm{LaBO}_{3}: \mathrm{Bi}$ & 3.46 & - & 1.16 & 4.62 & 0.22 & 55 & 4.55 & 2.5 & - & {$[78,95]$} \\
\hline $\mathrm{LaB}_{3} \mathrm{O}_{6}: \mathrm{Bi}$ & 3.76 & - & 1.01 & 4.77 & - & - & - & - & - & [104] \\
\hline \multirow[t]{2}{*}{$\mathrm{Y}_{2} \mathrm{O}_{3}: \mathrm{Bi}$} & 3.03 & - & 0.29 & 3.32 & - & - & - & - & - & {$[3,112]$} \\
\hline & 2.35 & - & $\approx 1.25$ & $3.59 ; 3.73$ & - & - & - & - & - & {$[3,112]$} \\
\hline \multirow[t]{2}{*}{$\mathrm{Lu}_{2} \mathrm{O}_{3}: \mathrm{Bi}$} & 3.08 & - & 0.25 & 3.33 & - & - & - & - & - & {$[3,112]$} \\
\hline & 2.42 & - & 1.19 & $3.61 ; 3.77$ & - & - & - & - & - & {$[3,112]$} \\
\hline \multirow[t]{4}{*}{$\mathrm{Gd}_{2} \mathrm{O}_{3}: \mathrm{Bi}$} & 2.98 & - & 0.29 & 3.27 & - & - & - & - & - & [3] \\
\hline & 2.22 & - & $\approx 1.41$ & $3.58 ; 3.68$ & - & - & - & - & - & [3] \\
\hline & 2.97 & - & 0.32 & 3.29 & - & - & - & - & - & [48] \\
\hline & 2.38 & - & 1.38 & 3.76 & - & - & - & - & - & [48] \\
\hline \multirow[t]{2}{*}{$\mathrm{La}_{2} \mathrm{O}_{3}: \mathrm{Bi}$} & 2.58 & - & 1.49 & 4.07 & - & - & - & - & - & [112] \\
\hline & 2.63 & 0.31 & 1.40 & 4.03 & 0.30 & 48 & - & - & - & {$[3,80]$} \\
\hline LaOBr:Bi & 3.37 & - & 1.18 & 4.55 & 0.20 & - & - & - & - & [93] \\
\hline $\mathrm{LaOCl}: \mathrm{Bi}$ & 3.53 & - & 1.06 & 4.59 & 0.24 & 68 & 0.425 & $\approx 1$ & - & {$[93,99]$} \\
\hline \multirow[t]{2}{*}{$\mathrm{YPO}_{4}: \mathrm{Bi}$} & 5.08 & - & 0.43 & 5.51 & - & - & - & - & - & [24] \\
\hline & 5.12 & - & 0.34 & 5.46 & - & - & - & - & - & [113] \\
\hline $\mathrm{LuPO}_{4}: \mathrm{Bi}$ & 5.25 & - & 0.26 & 5.51 & - & - & - & - & - & [24] \\
\hline $\mathrm{CaSnO}_{3}: \mathrm{Bi}$ & 3.44 & - & 0.63 & 4.07 & - & - & - & - & - & [114] \\
\hline $\mathrm{SrSnO}_{3}: \mathrm{Bi}$ & 3.20 & 0.26 & 0.93 & 4.13 & - & - & - & - & - & [115] \\
\hline \multirow[t]{3}{*}{$\mathrm{CaZrO}_{3}: \mathrm{Bi}$} & 3.19 & 0.32 & 0.83 & 4.02 & - & - & - & - & - & [114] \\
\hline & 3.18 & 0.28 & 0.74 & 3.92 & - & - & - & - & - & [63] \\
\hline & 3.17 & - & 0.80 & 3.97 & - & - & - & - & - & [14] \\
\hline
\end{tabular}


Table 1. Cont.

\begin{tabular}{|c|c|c|c|c|c|c|c|c|c|c|}
\hline Compound & $\begin{array}{l}\mathrm{E}_{\mathrm{em}} \\
\mathrm{eV}\end{array}$ & $\begin{array}{c}\text { FWHM, } \\
\text { eV }\end{array}$ & $\begin{array}{c}\text { S, } \\
\text { eV }\end{array}$ & $\begin{array}{c}E_{\text {exc }} \\
\text { eV }\end{array}$ & $\begin{array}{l}\tau_{\mathrm{SC}} \\
\mathrm{ms}\end{array}$ & $\begin{array}{c}\mathrm{D}, \\
\mathrm{meV}\end{array}$ & $\begin{array}{c}\mathbf{k}_{1} \\
\times 10^{3} \\
\mathrm{~s}^{-1}\end{array}$ & $\begin{array}{c}\mathbf{k}_{2} \\
\times 10^{8} \\
\mathbf{s}^{-1}\end{array}$ & $\begin{array}{c}\mathrm{K} \\
\times 10^{8} \\
\mathrm{~s}^{-1}\end{array}$ & Refs. \\
\hline $\mathrm{CaHfO}_{3}: \mathrm{Bi}$ & 3.25 & - & 0.78 & 4.03 & - & - & - & - & - & {$[14]$} \\
\hline $\mathrm{LaGaO}_{3}: \mathrm{Bi}$ & 3.28 & 0.28 & 0.74 & 4.02 & - & - & - & - & - & [116] \\
\hline $\mathrm{LaInO}_{3}: \mathrm{Bi}$ & 2.95 & 0.27 & 0.70 & 3.65 & 0.965 & 62 & - & - & - & [117] \\
\hline $\mathrm{Sr}_{2} \mathrm{GdAlO}_{5}: \mathrm{Bi}$ & 2.74 & - & 1.36 & 4.10 & - & - & - & - & - & [14] \\
\hline $\mathrm{Sr}_{2} \mathrm{GdGaO}_{5}: \mathrm{Bi}$ & 2.63 & - & 1.34 & 3.97 & - & - & - & - & - & [14] \\
\hline $\mathrm{La}_{2} \mathrm{LiSbO}_{6}: \mathrm{Bi}$ & 3.04 & 0.26 & 0.92 & 3.96 & - & - & - & - & - & [118] \\
\hline $\mathrm{Y}_{2} \mathrm{Sn}_{2} \mathrm{O}_{7}: \mathrm{Bi}$ & 3.73 & - & 0.70 & 4.43 & - & - & - & - & - & [119] \\
\hline $\mathrm{La}_{2} \mathrm{Zr}_{2} \mathrm{O}_{7}: \mathrm{Bi}$ & 3.21 & - & 1.07 & 4.28 & - & - & - & - & - & [120] \\
\hline$(\mathrm{Y}, \mathrm{Gd})_{2} \mathrm{O}_{2} \mathrm{SO}_{4}: \mathrm{Bi}$ & 3.87 & - & 0.76 & 4.63 & - & - & - & - & - & [121] \\
\hline $\mathrm{Li}_{6}(\mathrm{Y}, \mathrm{Gd})\left(\mathrm{BO}_{3}\right)_{3}: \mathrm{Bi}$ & 3.65 & - & 1.03 & 4.68 & - & - & - & - & - & [121] \\
\hline $\mathrm{Cs}_{2} \mathrm{NaYBr}_{6}: \mathrm{Bi}$ & 3.08 & - & 0.28 & 3.36 & 0.58 & 80 & - & - & - & [97] \\
\hline $\mathrm{Cs}_{2} \mathrm{NaLaCl}_{6}: \mathrm{Bi}$ & 3.28 & - & 0.48 & 3.76 & 2.40 & 99 & - & - & - & [97] \\
\hline $\mathrm{Cs}_{2} \mathrm{NaYCl}_{6}: \mathrm{Bi}$ & 3.72 & - & 0.12 & 3.84 & - & 143 & - & - & - & {$[98]$} \\
\hline $\mathrm{CaSb}_{2} \mathrm{O}_{6}: \mathrm{Bi}$ & 2.64 & - & 1.00 & 3.64 & 0.75 & 51 & - & - & - & {$[80,81]$} \\
\hline $\mathrm{La}_{2} \mathrm{SO}_{6}: \mathrm{Bi}$ & 3.10 & - & 1.35 & 4.45 & - & 47 & 3 & 0.15 & - & [82] \\
\hline
\end{tabular}

The small Stokes shifts of the UV emission are reported also for $\mathrm{NaGdO}_{2}: \mathrm{Bi}(\mathrm{S}=0.6 \mathrm{eV}), \mathrm{LiScO}_{2}: \mathrm{Bi}$ $(\mathrm{S}=0.9 \mathrm{eV}), \mathrm{NaScO}_{2}: \mathrm{Bi}_{1} \mathrm{YAl}_{3} \mathrm{~B}_{4} \mathrm{O}_{12}: \mathrm{Bi}$, and $\mathrm{Cs}_{2} \mathrm{NaYCl}_{6}: \mathrm{Bi}(\mathrm{S}<0.5 \mathrm{eV})$ (see [68] and references therein).

Table 2. Emission peak positions ( $\left.E_{e m}\right)$, full widths at half maxima (FWHM), the Stokes shifts (S), positions of the lowest-energy excitation band $\left(E_{\text {exc }}\right)$ and decay times $\left(\tau_{\mathrm{SC}}\right)$ of the slow decay component obtained at $\mathrm{LHeT}$ for the lower-energy triplet emission of $\mathrm{Bi}^{3+}$-doped compounds (denoted in this work the VIS emission). The parameters of the triplet RES: the spin-orbit splitting energy (D), the probabilities of the radiative decay of the metastable $\left(\mathrm{k}_{1}\right)$ and emitting $\left(\mathrm{k}_{2}\right)$ levels of the triplet RES, and the zero-temperature nonradiative transition rate $(\mathrm{K})$ between the metastable and emitting levels.

\begin{tabular}{|c|c|c|c|c|c|c|c|c|c|c|}
\hline Compound & $\begin{array}{l}E_{\text {em }}, \\
\text { eV }\end{array}$ & $\begin{array}{c}\text { FWHM, } \\
\text { eV }\end{array}$ & $\begin{array}{l}\mathrm{S} \\
\mathrm{eV}\end{array}$ & $\begin{array}{c}\text { Eexc } \\
\text { eV }\end{array}$ & $\begin{array}{c}\tau_{\mathrm{SC}} \\
\mu \mathrm{s}\end{array}$ & $\begin{array}{c}\text { D, } \\
\text { meV }\end{array}$ & $\begin{array}{c}\mathbf{k}_{1} \\
\times 10^{4} \\
\mathrm{~s}^{-1}\end{array}$ & $\begin{array}{c}\mathbf{k}_{2} \\
\times 10^{5} \\
\mathrm{~s}^{-1}\end{array}$ & $\begin{array}{c}\mathrm{K} \\
\times 10^{6} \\
\mathrm{~s}^{-1}\end{array}$ & Refs. \\
\hline \multirow[t]{4}{*}{$\mathrm{Lu}_{3} \mathrm{Al}_{5} \mathrm{O}_{12}: \mathrm{Bi}$} & 2.60 & 0.87 & 2.00 & 4.60 & 26 & 4 & 3.94 & 7 & 1 & {$[9,16-18]$} \\
\hline & 2.75 & 0.90 & 1.60 & 4.35 & 40 & 2 & 2.56 & 7 & 0.17 & {$[9,16-18]$} \\
\hline & 2.45 & - & 2.13 & 4.58 & - & - & - & - & - & [19] \\
\hline & 2.66 & - & 1.92 & 4.58 & - & - & - & - & - & [19] \\
\hline \multirow[t]{3}{*}{$\mathrm{Y}_{3} \mathrm{Al}_{5} \mathrm{O}_{12}: \mathrm{Bi}$} & 2.63 & 0.85 & 1.92 & 4.55 & 38 & 3 & 2.62 & 7 & 0.2 & {$[9,16,17]$} \\
\hline & 2.75 & 0.85 & 1.57 & 4.32 & 33 & 2 & 2.98 & 7.6 & 0.11 & {$[9,16,17]$} \\
\hline & 2.88 & 0.80 & 1.44 & 4.32 & - & - & - & - & - & [15] \\
\hline \multirow[t]{2}{*}{$\mathrm{Lu}_{2} \mathrm{SiO}_{5}: \mathrm{Bi}$} & 2.30 & 1.00 & 1.75 & 4.05 & 16.8 & 2 & 6.1 & 7.5 & 0.5 & {$[9,21]$} \\
\hline & 2.20 & 1.00 & 1.85 & 4.05 & 2.70 & 1.4 & 33 & 33 & 0.9 & {$[9,21]$} \\
\hline \multirow[t]{3}{*}{$\mathrm{LiLaP}_{4} \mathrm{O}_{12}: \mathrm{Bi}$} & 2.95 & 0.90 & 2.45 & 5.40 & 55 & 5 & 1.82 & 10 & 0.5 & {$[72]$} \\
\hline & 3.02 & 0.63 & 2.25 & 5.27 & - & - & - & - & - & [102] \\
\hline & 2.78 & 0.65 & 2.17 & 4.95 & - & - & - & - & - & [102] \\
\hline \multirow[t]{2}{*}{$\mathrm{PbWO}_{4}: \mathrm{Bi}$} & 2.20 & 0.50 & $\approx 1.8$ & $\approx 4.0$ & $\approx 165$ & 0.45 & 0.6 & 0.3 & $\approx 0.002$ & [73] \\
\hline & 2.20 & 0.50 & $\approx 1.8$ & $\approx 4.0$ & $\approx 165$ & 0.40 & 0.5 & $\approx 0.5$ & 0.03 & [73] \\
\hline \multirow[t]{2}{*}{$\mathrm{CaWO}_{4}: \mathrm{Bi}$} & 2.75 & 0.60 & 1.65 & 4.40 & 74 & - & - & - & - & {$[122,123]$} \\
\hline & 2.65 & - & 1.67 & 4.32 & - & - & - & - & - & [124] \\
\hline
\end{tabular}


Table 2. Cont.

\begin{tabular}{|c|c|c|c|c|c|c|c|c|c|c|}
\hline Compound & $\begin{array}{c}\mathrm{E}_{\mathrm{em}}, \\
\mathrm{eV}\end{array}$ & $\begin{array}{c}\text { FWHM, } \\
\text { eV }\end{array}$ & $\begin{array}{l}\text { S, } \\
\text { eV }\end{array}$ & $\begin{array}{c}E_{\text {exc }} \\
\text { eV }\end{array}$ & $\begin{array}{c}\tau_{\mathrm{SC}} \\
\mu \mathrm{s}\end{array}$ & $\begin{array}{c}\mathrm{D}, \\
\mathrm{meV}\end{array}$ & $\begin{array}{c}\mathrm{k}_{1} \\
\times 10^{4} \\
\mathrm{~s}^{-1}\end{array}$ & $\begin{array}{c}\mathbf{k}_{2} \\
\times 10^{5} \\
\mathbf{s}^{-1}\end{array}$ & $\begin{array}{c}\mathrm{K} \\
\times 10^{6} \\
\mathrm{~s}^{-1}\end{array}$ & Refs. \\
\hline \multirow[t]{2}{*}{$\mathrm{Y}_{3} \mathrm{Ga}_{5} \mathrm{O}_{12}: \mathrm{Bi}$} & 2.58 & - & 1.49 & 4.07 & - & - & - & - & - & [12] \\
\hline & $2.54(2.67)$ & - & $\approx 1.65$ & 4.26 & - & - & - & - & - & [110] \\
\hline \multirow[t]{5}{*}{$\mathrm{Gd}_{3} \mathrm{Ga}_{5} \mathrm{O}_{12}: \mathrm{Bi}$} & 2.58 & - & 1.42 & 4.00 & - & - & - & - & - & [12] \\
\hline & 2.54 & 0.53 & 1.74 & 4.28 & 10 & 5 & 10 & 10 & 0.30 & [74] \\
\hline & 2.46 & 0.58 & $\approx 1.79$ & $\approx 4.25$ & 3 & 1 & 27 & 40 & 0.30 & [74] \\
\hline & 2.55 & 0.56 & 1.73 & 4.28 & 9 & - & - & - & - & [75] \\
\hline & 2.05 & 0.48 & 1.92 & 3.97 & 27 & $\approx 0.45$ & 3.7 & 1 & - & [75] \\
\hline \multirow[t]{3}{*}{$\mathrm{YVO}_{4}: \mathrm{Bi}$} & - & - & 1.57 & - & - & 0.99 & - & - & - & [7] \\
\hline & 2.19 & 0.54 & 1.59 & 3.78 & 85 & 1.20 & - & - & - & [76] \\
\hline & 2.73 & 0.54 & 1.52 & 4.25 & 745 & 0.43 & - & - & - & [76] \\
\hline \multirow[t]{3}{*}{$\mathrm{LuVO}_{4}: \mathrm{Bi}$} & 2.12 & - & 1.61 & 3.73 & 87 & 1.00 & - & - & - & [76] \\
\hline & 2.68 & - & 1.55 & 4.23 & 720 & 0.34 & - & - & - & [76] \\
\hline & 2.16 & - & 1.60 & 3.76 & - & & - & - & - & [28] \\
\hline \multirow[t]{2}{*}{$\mathrm{GdVO}_{4}: \mathrm{Bi}$} & 2.16 & - & 1.63 & 3.79 & 5.6 & - & - & - & - & [76] \\
\hline & 2.69 & - & 1.51 & 4.20 & 214 & - & - & - & - & [76] \\
\hline \multirow[t]{2}{*}{$\mathrm{YNbO}_{4}: \mathrm{Bi}$} & 2.53 & 0.53 & 1.56 & 4.09 & 33 & 0.78 & - & - & - & [77] \\
\hline & 2.41 & 0.55 & 1.65 & 4.06 & 46 & 0.77 & - & - & - & [77] \\
\hline \multirow[t]{2}{*}{$\mathrm{GdNbO}_{4}: \mathrm{Bi}$} & 2.64 & - & 1.20 & 3.84 & - & - & - & - & - & {$[64,65]$} \\
\hline & 2.77 & - & 1.30 & 4.07 & - & - & - & - & - & [125] \\
\hline $\mathrm{GdAlO}_{3}: \mathrm{Bi}$ & 2.58 & 0.82 & 1.69 & 4.27 & - & - & - & - & - & [109] \\
\hline $\mathrm{La}_{2} \mathrm{Zr}_{2} \mathrm{O}_{7}: \mathrm{Bi}$ & 2.41 & 0.95 & 1.86 & 4.27 & - & - & - & - & - & [120] \\
\hline $\mathrm{Y}_{2} \mathrm{Sn}_{2} \mathrm{O}_{7}: \mathrm{Bi}$ & 2.43 & 0.80 & 1.92 & 4.35 & - & - & - & - & - & [119] \\
\hline $\mathrm{Y}_{2} \mathrm{Ti}_{2} \mathrm{O}_{7}: \mathrm{Bi}$ & 2.28 & 0.62 & 1.47 & 3.75 & - & - & - & - & - & {$[126]$} \\
\hline YOCl:Bi & 3.00 & - & 1.87 & 4.87 & 0.93 & - & 7.5 & - & - & {$[1,99]$} \\
\hline $\mathrm{LaOCl}: \mathrm{Bi}$ & 2.65 & 0.90 & 1.83 & 4.48 & - & - & - & - & - & {$[93,99]$} \\
\hline LaOBr:Bi & $\begin{array}{l}2.34 \\
2.96\end{array}$ & - & $\approx 1.76$ & 4.26 & 500 & $<1$ & - & - & - & [93] \\
\hline \multirow[t]{2}{*}{$\mathrm{CaSnO}_{3}: \mathrm{Bi}$} & 2.74 & 0.66 & 1.33 & 4.07 & - & - & - & - & - & [114] \\
\hline & 2.71 & 0.66 & 1.33 & 4.04 & - & - & - & - & - & [63] \\
\hline \multirow[t]{2}{*}{$\mathrm{CaTiO}_{3}: \mathrm{Bi}$} & 2.19 & 0.53 & 1.46 & 3.65 & - & - & - & - & - & [63] \\
\hline & 2.23 & 0.64 & 1.64 & 3.87 & - & - & - & - & - & [127] \\
\hline $\mathrm{SrZrO}_{3}: \mathrm{Bi}$ & 2.87 & 0.42 & 1.22 & 4.09 & - & - & - & - & - & [115] \\
\hline $\mathrm{SrSnO}_{3}: \mathrm{Bi}$ & 2.85 & - & 1.28 & 4.13 & - & - & - & - & - & [115] \\
\hline $\mathrm{LaBO}_{3}: \mathrm{Bi}$ & 2.69 & - & 1.84 & 4.53 & 110 & 5.7 & 0.92 & 3 & - & {$[78,95]$} \\
\hline $\mathrm{YPO}_{4}: \mathrm{Bi}$ & $3.72-3.82$ & 0.95 & $\approx 1.75$ & $5.46-5.56$ & $6-$ & - & - & - & - & $\begin{array}{c}{[1,24,113} \\
128]\end{array}$ \\
\hline $\mathrm{LuPO}_{4}: \mathrm{Bi}$ & 3.72 & 0.95 & 1.79 & 5.51 & - & - & - & - & - & [24] \\
\hline $\mathrm{LaPO}_{4}: \mathrm{Bi}$ & 2.76 & 0.60 & 2.41 & 5.17 & 1000 & 2 & - & - & - & [83] \\
\hline $\mathrm{LaP}_{3} \mathrm{O}_{9}: \mathrm{Bi}$ & 2.72 & - & 2.55 & 5.27 & - & - & - & - & - & {$[111]$} \\
\hline $\mathrm{Sr}_{3} \mathrm{Ga}_{4} \mathrm{O}_{9}: \mathrm{Bi}$ & 2.34 & - & 1.48 & 3.82 & - & - & - & - & - & [58] \\
\hline $\mathrm{Sr}_{3} \mathrm{Ga}_{4} \mathrm{O}_{9}: \mathrm{Bi}$ & 1.82 & - & 1.94 & 3.76 & - & - & - & - & - & [58] \\
\hline $\mathrm{Y}_{2} \mathrm{WO}_{6}: \mathrm{Bi}$ & 2.41 & - & 1.22 & 3.63 & - & - & - & - & - & [1] \\
\hline $\mathrm{Lu}_{2} \mathrm{WO}_{6}: \mathrm{Bi}$ & 2.43 & 0.45 & 1.16 & 3.59 & - & - & - & - & - & [129] \\
\hline $\mathrm{Ca}_{2} \mathrm{MgWO}_{6}: \mathrm{Bi}$ & 2.25 & 0.65 & 1.42 & 3.67 & - & - & - & - & - & [130] \\
\hline
\end{tabular}




\section{Ultraviolet Luminescence of Single $\mathrm{Bi}^{3+}$ Centers in $\mathrm{Bi}^{3+}$-Doped Compounds}

\subsection{Characteristics of the Ultraviolet Luminescence}

The characteristics of the higher-energy (UV) emission in various $\mathrm{Bi}^{3+}$-doped materials are similar (Table 1). Let us demonstrate them at an example of the $\mathrm{Lu}_{3} \mathrm{Al}_{5} \mathrm{O}_{12}: \mathrm{Bi}, \mathrm{Y}_{3} \mathrm{Al}_{5} \mathrm{O}_{12}: \mathrm{Bi}$, and $\mathrm{Lu}_{2} \mathrm{SiO}_{5}: \mathrm{Bi}$ single crystalline films investigated in [16-18,21].

In Figure 1, the emission spectra of $\mathrm{Lu}_{3} \mathrm{Al}_{5} \mathrm{O}_{12}: \mathrm{Bi}$ and $\mathrm{Y}_{3} \mathrm{Al}_{5} \mathrm{O}_{12}: \mathrm{Bi}$ are shown. The absorption and excitation spectra of $\mathrm{Lu}_{3} \mathrm{Al}_{5} \mathrm{O}_{12}$ : $\mathrm{Bi}$ are presented in Figure 2. At low temperatures $(\mathrm{T}<100 \mathrm{~K}$ in $\mathrm{Lu}_{3} \mathrm{Al}_{5} \mathrm{O}_{12}: \mathrm{Bi}$ and $\mathrm{Y}_{3} \mathrm{Al}_{5} \mathrm{O}_{12}: \mathrm{Bi}$ ), the UV emission arises from the radiative decay of the lowest-energy metastable level corresponding to the ${ }^{3} \mathrm{P}_{0}$ level of a free $\mathrm{Bi}^{3+}$ ion. Temperature dependences of the maximum position and FWHM of the UV emission of $\mathrm{Y}_{3} \mathrm{Al}_{5} \mathrm{O}_{12}: \mathrm{Bi}$ and $\mathrm{Lu}_{2} \mathrm{SiO}_{5}: \mathrm{Bi}$ are displayed in Figure 3. As the temperature increases, the UV emission spectrum is shifting to higher energies and becomes broader (see the insets to Figure 1). This effect is caused by the thermally stimulated population of the higher ${ }^{3} \mathrm{P}_{1}$ excited level from the lower ${ }^{3} \mathrm{P}_{0}$ level. Further increase of the temperature results in thermal equilibrium between the ${ }^{3} \mathrm{P}_{0}$ and ${ }^{3} \mathrm{P}_{1}$ levels. As the temperature increases further, a gradual lower-energy shift of the emission band takes place. These processes also appear in the decay kinetics of the UV emission.

At $4.2 \mathrm{~K}$, the slow component with the decay time $\tau_{\mathrm{SC}} \approx 1.1 \mathrm{~ms}$ is observed in the decay kinetics of the UV emission of $\mathrm{Y}_{3} \mathrm{Al}_{5} \mathrm{O}_{12}$ : $\mathrm{Bi}$ (Figure 4a). The decay time remains constant up to $100 \mathrm{~K}$ and then decreases (Figure 5). This dependence is characteristic for the radiative transitions from a triplet RES where the lowest-energy (metastable) level has much smaller radiative decay probability as compared to the upper (emitting) level (see also $[3,68,80]$ ). Indeed, at $\mathrm{T}<100 \mathrm{~K}$, the slow decay component is associated with transitions from the metastable level. As the temperature increases, the decay time shortens exponentially due to thermally stimulated transitions between the metastable and emitting levels and reaches a constant value at the temperatures (around $350 \mathrm{~K}$ ), where the system achieves thermal equilibrium. At higher temperatures, the decay time decreases due to the luminescence thermal quenching. Analogous $\tau_{\mathrm{SC}}(\mathrm{T})$ dependences were obtained, e.g., for the triplet emission of $\mathrm{Pb}^{2+}$ centers in alkali halides [131] and $\mathrm{Bi}^{3+}$ centers in $\mathrm{CaO}$ [85], alkaline-earth sulfides [87], and alkaline-earth fluorides [92]. 


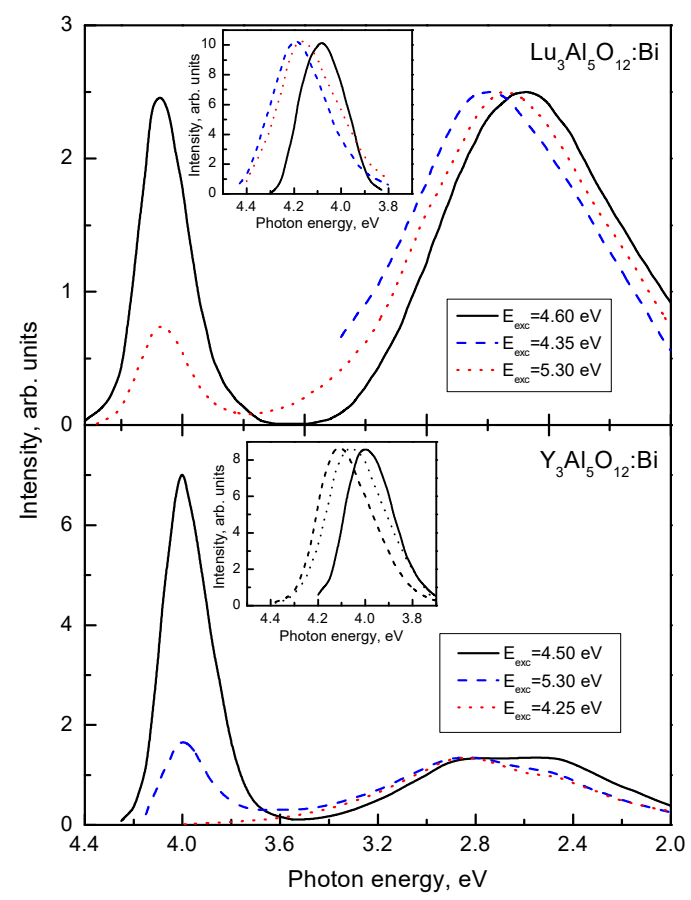

Figure 1. Emission spectra (normalized) of $\mathrm{Lu}_{3} \mathrm{Al}_{5} \mathrm{O}_{12}$ : $\mathrm{Bi}$ and $\mathrm{Y}_{3} \mathrm{Al}_{5} \mathrm{O}_{12}: \mathrm{Bi}$ measured at $80 \mathrm{~K}$ under different excitations shown in the legends. In the insets, the ultraviolet emission spectra of $\mathrm{Bi}^{3+}$ centers (normalized) measured at $80 \mathrm{~K}$ (solid line), $150 \mathrm{~K}$ (dashed line), and $300 \mathrm{~K}$ (dotted line). Based on the data reported in $[17,18]$, presented with the publisher's permission.

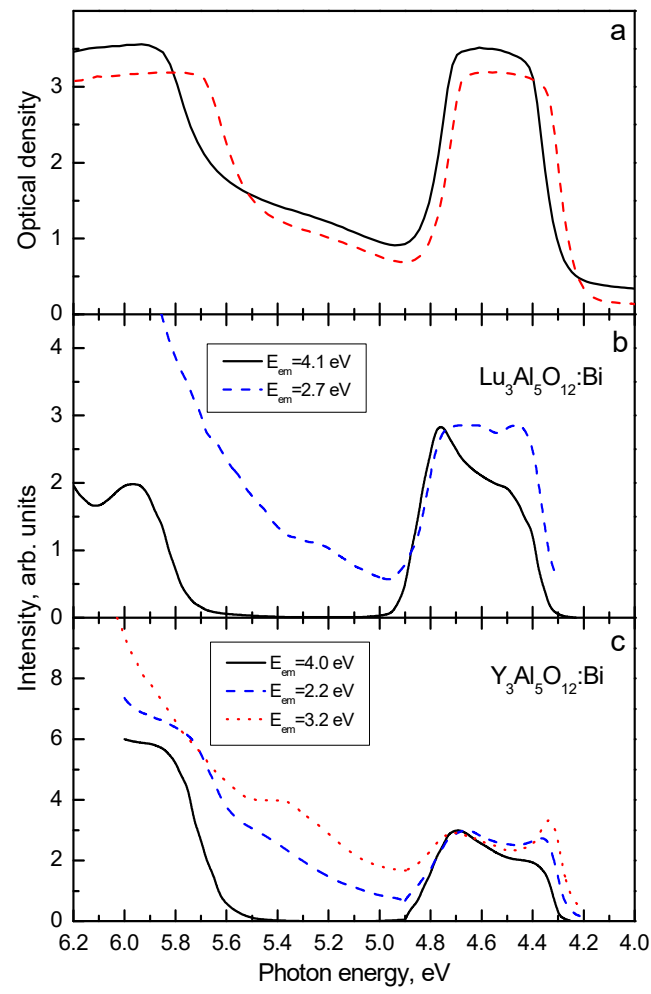

Figure 2. (a) Absorption spectra of $\mathrm{Lu}_{3} \mathrm{Al}_{5} \mathrm{O}_{12}$ : $\mathrm{Bi}$ (solid line) and $\mathrm{Y}_{3} \mathrm{Al}_{5} \mathrm{O}_{12}$ : $\mathrm{Bi}$ (dashed line) at $295 \mathrm{~K}$. Excitation spectra (normalized) of (b) $\mathrm{Lu}_{3} \mathrm{Al}_{5} \mathrm{O}_{12}$ : $\mathrm{Bi}$ and (c) $\mathrm{Y}_{3} \mathrm{Al}_{5} \mathrm{O}_{12}$ : Bi measured at $80 \mathrm{~K}$ for different emission spectra regions shown in the legends. Based on the data reported in [16-18], presented with the publisher's permission. 


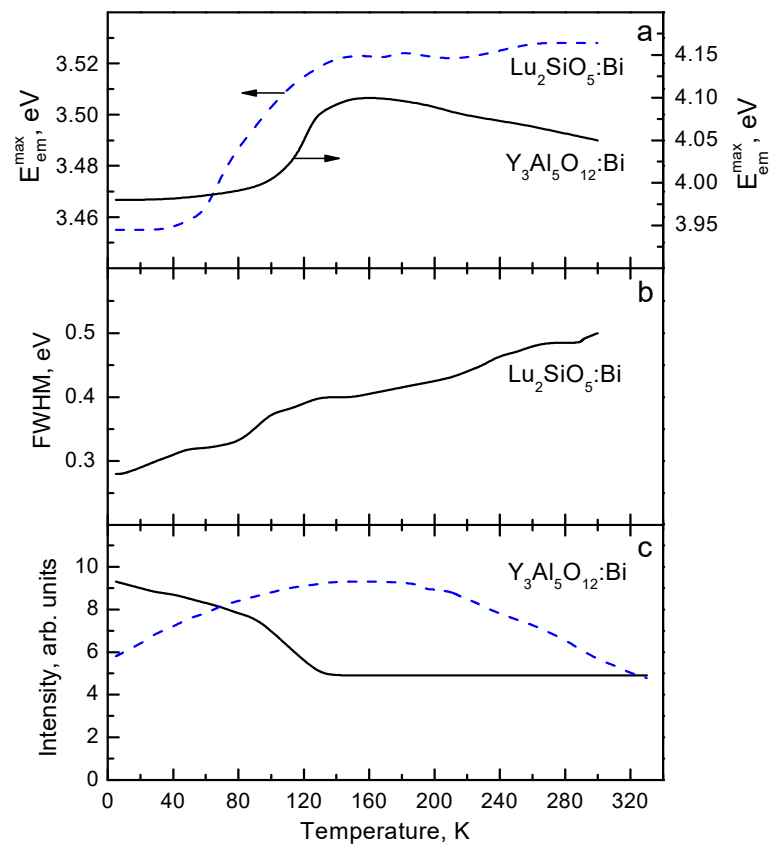

Figure 3. (a) Temperature dependences of the UV emission band maximum position in $\mathrm{Y}_{3} \mathrm{Al}_{5} \mathrm{O}_{12}: \mathrm{Bi}$ (solid line) and $\mathrm{Lu}_{2} \mathrm{SiO}_{5}: \mathrm{Bi}$ (dashed line), (b) the FWHM of the UV emission band in $\mathrm{Lu}_{2} \mathrm{SiO}_{5}: \mathrm{Bi}$, and (c) the maximum intensities of the UV $(4.0 \mathrm{eV}$, solid line) and VIS ( $2.5 \mathrm{eV}$, dashed line) emissions in $\mathrm{Y}_{3} \mathrm{Al}_{5} \mathrm{O}_{12}$ :Bi reported in $[17,18,21]$, presented with the publisher's permission.
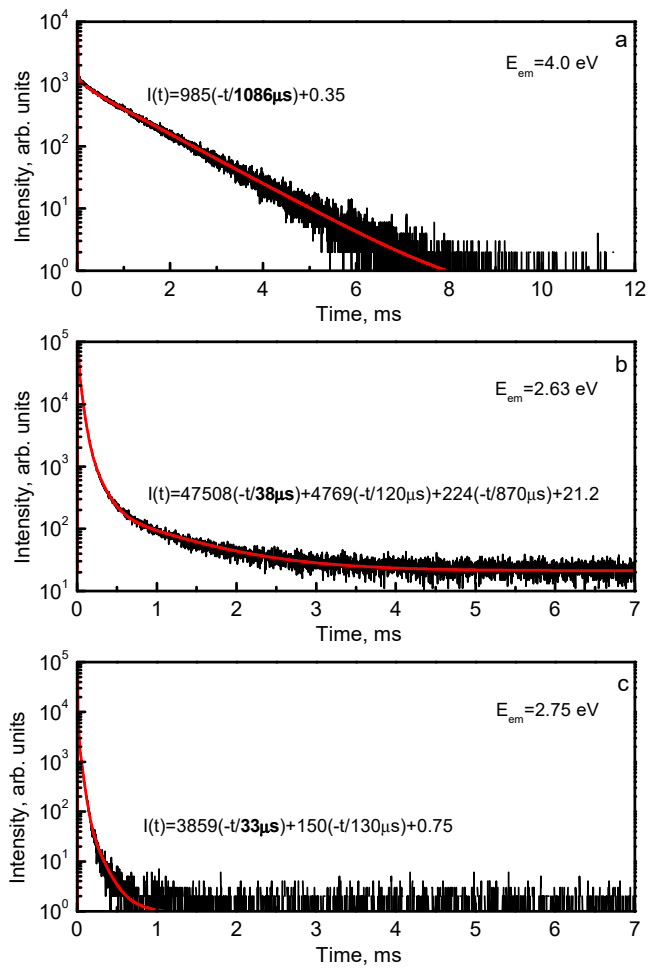

Figure 4. Decay curves of the (a) $4.0 \mathrm{eV}$, (b) $2.63 \mathrm{eV}$ and (c) $2.75 \mathrm{eV}$ emissions of $\mathrm{Y}_{3} \mathrm{Al}_{5} \mathrm{O}_{12}: \mathrm{Bi}$ at $4.2 \mathrm{~K}$. 


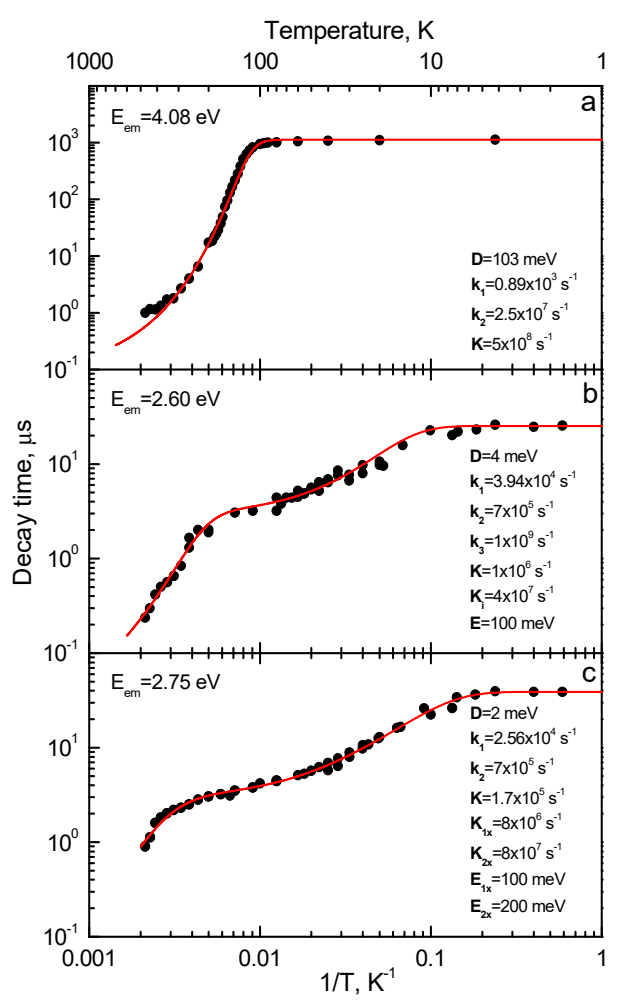

Figure 5. Temperature dependences of decay times measured for (a) the UV emission, (b) the $2.6 \mathrm{eV}$ emission and (c) the $2.75 \mathrm{eV}$ emission of $\mathrm{Lu}_{3} \mathrm{Al}_{5} \mathrm{O}_{12}$ : $\mathrm{Bi}$. The circles are experimental data. Solid lines are the best fits of the two or three excited-state level models (Figure 6 and Figure 10) to the experimental data (for details see the text). The parameters of the fits are reported in the figures. (a) $\mathrm{E}_{\mathrm{exc}}=4.6 \mathrm{eV}$, $\mathrm{E}_{\mathrm{em}}=4.1 \mathrm{eV} ;(\mathbf{b}) \mathrm{E}_{\mathrm{exc}}=4.7 \mathrm{eV}, \mathrm{E}_{\mathrm{em}}=2.4 \mathrm{eV} ;(\mathbf{c}) \mathrm{E}_{\mathrm{exc}}=5.3 \mathrm{eV}, \mathrm{E}_{\mathrm{em}}=3.2 \mathrm{eV}$. See also [16-18]. Presented with the publisher's permission.

\subsection{Dynamics of the Triplet Excited State of $B i^{3+}$ Centers}

Thermally stimulated transitions between the metastable and emitting minima of the triplet RES and between the excited and ground state of the luminescence centers responsible for the UV emission reveal themselves in the temperature dependences of the luminescence spectra and decay kinetics. The excited states dynamics of the luminescence center responsible for the UV emission are described within the phenomenological model sketched in Figure 6.

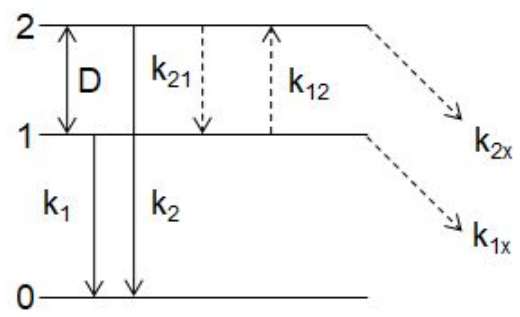

Figure 6. Energy level diagram used for the description of the excited states dynamics of the $\mathrm{Bi}^{3+}$-related luminescence centers responsible for the UV emission. For details, see the text.

The time evolution of the populations $N_{1}, N_{2}$ of the excited levels 1 and 2, respectively, can be described by the following rate equations:

$$
\begin{aligned}
& \frac{\mathrm{d} N_{1}}{\mathrm{~d} t}=-k_{1} N_{1}-k_{12} N_{1}-k_{21} N_{2}-k_{1 x} N_{1} \\
& \frac{\mathrm{d} N_{2}}{\mathrm{~d} t}=-k_{2} N_{2}-k_{21} N_{2}-k_{12} N_{1}-k_{2 x} N_{2}
\end{aligned}
$$


where $k_{1}, k_{2}, k_{12}, k_{21}$, and $k_{1(2) x}$ are radiative transition rates from levels 1,2 , non-radiative rates of phonon assisted transitions between the radiative level 2 and metastable level 1 and the quenching channel from the level 1(2), respectively. Non-radiative transitions between levels 1,2 can be written as:

$$
\begin{gathered}
k_{21}=K(n+1), k_{12}=K n \\
n=1 /\left[\exp \left(D / k_{B} T\right)-1\right]
\end{gathered}
$$

where $K, n, D$ are the zero-temperature transition rate between the levels 1 and 2, the Bose-Einstein factor, and energy spacing between the levels, respectively. Non-radiative quenching channel is considered in the usual barrier form:

$$
k_{1(2) x}=K_{1(2) x}\left(-\frac{E_{1(2) x}}{k_{B} T}\right)
$$

with $K_{1(2) x}$ being a frequency factor and $E_{1(2) x}$ the height of the barrier.

Application of the two-excited-level models on the temperature evolution of the UV luminescence intensity and decay times allowed determination of characteristic parameters of the corresponding triplet RES, e.g., the energy separation $(D)$ between the emitting and metastable levels of the triplet RES, the rates of the radiative $\left(k_{1}, k_{2}\right)$ and nonradiative $(K)$ transitions from these levels, and activation energy $E_{1(2) x}$ for the luminescence thermal quenching (for more details, see Refs. $[9,13,16-18,20-22,70,71]$ ). Some parameters of the triplet RES corresponding to the UV emission of $\mathrm{Bi}^{3+}$-doped compounds are shown in Table 1.

As evident from Table 1, the triplet RES responsible for the UV emission is characterized by very large $\left(\sim 10^{2} \mathrm{meV}\right)$ energy distance $\mathrm{D}$ between the metastable and emitting levels of the triplet RES which can be explained by extremely large spin-orbit interaction energy characteristic for a free $\mathrm{Bi}^{3+}$ ion $(\xi=2.102 \mathrm{eV} \mathrm{[4]).} \mathrm{Therefore,} \mathrm{the} \mathrm{higher-energy} \mathrm{(UV)} \mathrm{emission} \mathrm{of} \mathrm{all} \mathrm{the} \mathrm{investigated} \mathrm{materials} \mathrm{can}$ surely be ascribed to the electronic transitions from the triplet RES of $\mathrm{Bi}^{3+}$ corresponding to the ${ }^{3} \mathrm{P}_{1,0} \rightarrow$ ${ }^{1} \mathrm{~S}_{0}$ transitions of a free $\mathrm{Bi}^{3+}$ ion.

In some $\mathrm{Bi}^{3+}$-doped compounds, a fast (ns) component is observed at low temperatures in the UV luminescence decay. This component is associated with transitions from the emitting level of the triplet RES related to the ${ }^{3} \mathrm{P}_{1}$ level of a free $\mathrm{Bi}^{3+}$ ion. The electronic transitions between the ground state $\left({ }^{1} \mathrm{~S}_{0}\right)$ and the ${ }^{3} \mathrm{P}_{1}$-related excited state are partly allowed due to mixing of the triplet ${ }^{3} \mathrm{P}_{1}$ state with the singlet ${ }^{1} \mathrm{P}_{1}$ state by the spin-orbit interaction. Due to a strong spin-orbit interaction, the probability of the radiative decay of the emitting level $\left(k_{2}\right)$ is relatively large (see Table 1 ). The radiative transitions from the metastable ${ }^{3} \mathrm{P}_{0}$-related state can occur due to mixing of the ${ }^{3} \mathrm{P}_{1}$ - and ${ }^{3} \mathrm{P}_{0}$-related states by the vibronic interaction with the non-totally symmetric vibrations or by the hyperfine interaction (see, e.g., [132] and references therein). The only stable Bi isotope ${ }^{209} \mathrm{Bi}$ has a nuclear spin of $\mathrm{I}=9 / 2$. Therefore, in $\mathrm{Bi}^{3+}$-doped compounds with a weak vibronic interaction, such as alkali-earth oxides, sulfides, fluorides (see, e.g., [84,86,88-92] and references therein), $\mathrm{ScBO}_{3}: \mathrm{Bi}$ [78], $\mathrm{LuBO}_{3}: \mathrm{Bi}[78]$, $\mathrm{Cs}_{2} \mathrm{NaYBr}_{6}: \mathrm{Bi}$ [97], $\mathrm{Cs}_{2} \mathrm{NaLaCl}_{6}: \mathrm{Bi}$ [97], $\mathrm{Cs}_{2} \mathrm{NaYCl}_{6}: \mathrm{Bi}$ [98], $\mathrm{NaScO}_{2}: \mathrm{Bi}$, and $\mathrm{YAl}_{3} \mathrm{~B}_{4} \mathrm{O}_{12}: \mathrm{Bi}$ (see also [68] and references therein), where the Stokes shift is extremely small (see Table 1) and even a vibronic structure of the emission and excitation spectra is observed at low temperatures, mainly the hyperfine interaction can be expected to be responsible for the radiative decay of the metastable ${ }^{3} \mathrm{P}_{0}$-related level. The influence of the hyperfine interaction on the probability of the radiative ${ }^{3} \mathrm{P}_{0} \rightarrow{ }^{1} \mathrm{~S}_{0}$ transitions in $\mathrm{Bi}^{3+}$-doped alkali-earth oxides was investigated in [133].

\subsection{Relaxed Excited States Models}

Hitherto, two models have been proposed to describe RES of the $\mathrm{ns}^{2}$-ion-doped ionic crystals with strongly different electron-phonon and spin-orbit interactions. The systems with a strong spin-orbit interaction and a very weak electron-phonon interaction can be described within the RES model, proposed by Seitz [134], which considers the spin-orbit interaction in RES being dominant. In this 
model, the excited states of the luminescence center originate from the ${ }^{3} \mathrm{P}_{0},{ }^{3} \mathrm{P}_{1},{ }^{3} \mathrm{P}_{2}$, and ${ }^{1} \mathrm{P}_{1}$ levels of a free $\mathrm{ns}^{2}$ ion, which are split in the crystal field of the corresponding symmetry. For the degenerate energy levels, the Jahn-Teller effect is taken into account as a perturbation. The totally symmetric ${ }^{3} \mathrm{P}_{0}$ state is not degenerate, therefore it cannot be Jahn-Teller active. The configuration coordinates $(q)$ of the ${ }^{3} \mathrm{P}_{0}$ and ${ }^{1} \mathrm{~S}_{0}$ minima in this model should coincide.

The analysis of results obtained in a huge number of works (see, e.g., review papers [131,132,135]) have convincingly confirmed the suggestion of Seitz that the absorption processes in $\mathrm{ns}^{2}$-ion-doped compounds can be described in the approximation of a weak crystal field. This means that the spin-orbit interaction must be considered to be dominant in the unrelaxed excited state of the luminescence center. However, this model cannot adequately describe the luminescence characteristics and the relaxed excited state structure of the systems with a strong electron-phonon interaction.

For the systems of this type, a new RES model was proposed by Hizhnyakov [136], and the RES theory was developed in $[135,137]$. In this theory, the interaction of impurity optical electrons with non-totally symmetric vibrations is considered to be dominant in the relaxed excited state, while the spin-orbit, hyperfine, and other interactions are taken as small perturbations. As a result, the Jahn-Teller minima of different symmetries can be formed on the adiabatic potential energy surface of the singlet $\left({ }^{1} \mathrm{P}\right)$ and triplet $\left({ }^{3} \mathrm{P}\right)$ excited states. Due to the spin-orbit interaction, each Jahn-Teller minimum of the triplet RES is split into the upper emitting level and the lower metastable level, corresponding to the ${ }^{3} \mathrm{P}_{1}$ and ${ }^{3} \mathrm{P}_{0}$ levels of a free $\mathrm{Bi}^{3+}$ ion, respectively (Figure 7 , solid lines). The applicability of this model was confirmed by the systematic experimental study of luminescence characteristics of $\mathrm{ns}^{2}$-ion-doped alkali halide crystals by the methods of time-resolved polarization spectroscopy in a wide temperature range, down to $0.4 \mathrm{~K}$ (see, e.g., [132,138]). It was also shown that in the $\mathrm{Tl}^{+}, \mathrm{Pb}^{2+}$, $\mathrm{Bi}^{3+}$ centers with a strong spin-orbit interaction, each metastable minimum of the triplet RES may not lie exactly under the corresponding emitting minimum, like in the $\mathrm{Ga}^{+}, \mathrm{In}^{+}, \mathrm{Ge}^{2+}, \mathrm{Sn}^{2+}$ centers with a weak spin-orbit interaction. Instead, it can be shifted towards smaller coordinate $q$ values with respect to the emitting minimum (Figure 7). Due to that, the energy barriers for the thermally stimulated transitions between the metastable minima of various orientations can be much smaller than those between various emitting minima (see, e.g., $[85,132,139]$ and references therein).

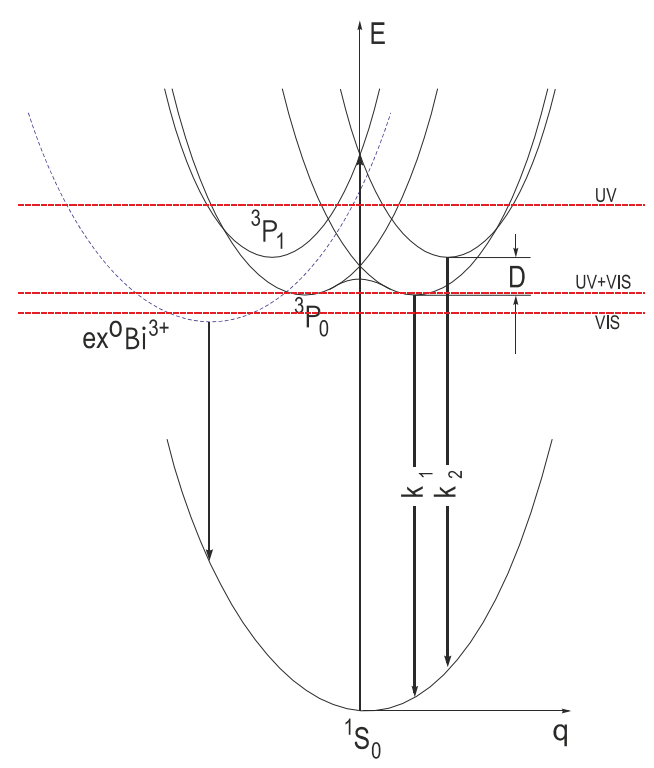

Figure 7. Schematic configuration coordinate diagram of the $\mathrm{Bi}^{3+}$-related energy levels. The electronic transitions between the ground state, corresponding to the ${ }^{1} \mathrm{~S}_{0}$ level, and the excited states, corresponding to the ${ }^{3} \mathrm{P}_{1}$ and ${ }^{3} \mathrm{P}_{0}$ levels of a free $\mathrm{Bi}^{3+}$ ion and the triplet $\mathrm{Bi}^{3+}$-related localized exciton state $\left(\mathrm{ex}^{0} \mathrm{Bi}^{3+}\right)$, are indicated by arrows. The straight red dotted lines indicate the position of the bottom of $\mathrm{CB}$ in the case where only the UV emission (UV), only the VIS emission (VIS), and both the UV and VIS emissions (UV+VIS) can appear in the luminescence spectrum of a $\mathrm{Bi}^{3+}$-doped compound. 
Thus, in the ns $^{2}$-ion-doped compounds characterized by a strong electron-phonon interaction, different models have to be used for the description of the structure and properties of the unrelaxed and relaxed excited states of a luminescence center.

Since a free $\mathrm{Bi}^{3+}$ ion is characterized by the largest spin-orbit interaction energy $(\xi)$ among all $\mathrm{ns}^{2}$ ions, different models should also be used for the description of the triplet RES responsible for the UV luminescence of $\mathrm{Bi}^{3+}$ centers in the compounds with an extremely small electron-phonon interaction (e.g., in alkaline-earth oxides, sulfates, fluorides) with respect to the materials with a relatively strong electron-phonon interaction (large FWHM and S), such as alkali halides, oxyorthosilicates, etc. For the description of the latter type systems, the model $[135,137]$ should be considered. However, usually only the model [134] is used in the literature for the description of the UV luminescence of all $\mathrm{Bi}^{3+}$-doped materials.

To investigate the applicability of the model $[135,137]$ to the centers with extremely strong spin-orbit interaction, the luminescence characteristics of two $\mathrm{Bi}^{3+}$-doped crystals with strongly different electron-phonon interaction ( $\mathrm{KCl}: \mathrm{Bi}$ and $\mathrm{CaO}: \mathrm{Bi})$ were compared in [85]. As evident from Figure 8, the characteristics of $\mathrm{KCl}: \mathrm{Bi}$ and $\mathrm{CaO}: \mathrm{Bi}$ are different. In the emission spectrum of $\mathrm{KCl}: \mathrm{Bi}$ at $4.2 \mathrm{~K}$, the broad (FWHM $=0.4 \mathrm{eV}$ ) complex band located around $2.5 \mathrm{eV}$ is observed (Figure $8 \mathrm{a}$, curve 1) (see also [140]). The lowest-energy excitation band of this emission is located around $3.8 \mathrm{eV}$ (curve 2), thus, $\mathrm{S} \approx 1.3 \mathrm{eV}$.

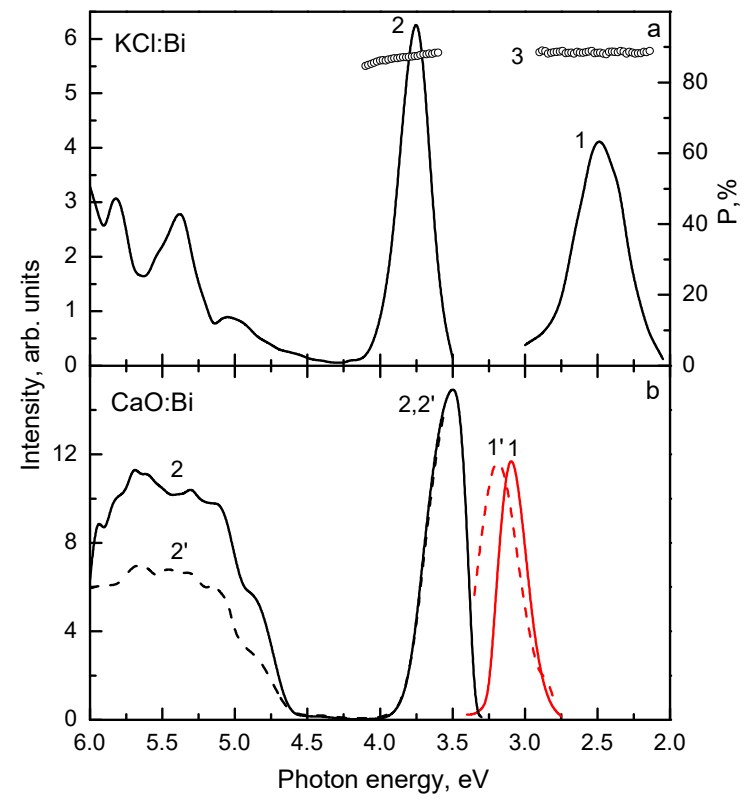

Figure 8. Emission (curves 1,1'), excitation (curves 2,2'), and polarization (curve 3) spectra of (a) KCl:Bi and (b) $\mathrm{CaO}: \mathrm{Bi}$ at $4.2 \mathrm{~K}$. In (a), $\mathrm{E}_{\mathrm{exc}}=3.7 \mathrm{eV}$ (curves 1,3) and $\mathrm{E}_{\mathrm{em}}=2.6 \mathrm{eV}$ (curves 2,3). In (b), $\mathrm{E}_{\mathrm{exc}}=3.5 \mathrm{eV}$, slow component (curve 1), $\mathrm{E}_{\mathrm{exc}}=3.6 \mathrm{eV}$, fast component (curve 1'), $\mathrm{E}_{\mathrm{em}}=3.1 \mathrm{eV}$ (curve 2), and $\mathrm{E}_{\mathrm{em}}=$ $3.3 \mathrm{eV}$ (curve 2'). Based on the data reported in [85]. Presented with the publisher's permission.

In the emission spectrum of $\mathrm{CaO}: \mathrm{Bi}$ at $4.2 \mathrm{~K}$, the narrow $(\mathrm{FWHM}=0.14 \mathrm{eV})$ strong $3.1 \mathrm{eV}$ and weak $3.3 \mathrm{eV}$ bands are observed (Figure $8 \mathrm{~b}$, curves $1,1^{\prime}$ ). Their excitation spectra coincide (curves $\left.2,2^{\prime}\right)$. The lowest-energy excitation band is located at $3.5 \mathrm{eV}$, i.e., $\mathrm{S}=0.4 \mathrm{eV}$. The intensity of the $3.1 \mathrm{eV}$ emission remains constant up to $100 \mathrm{~K}$ and then decreases. The reduction of the $3.1 \mathrm{eV}$ emission is accompanied with the $3.3 \mathrm{eV}$ emission enhancement. The intensity redistribution between the $3.1 \mathrm{eV}$ and $3.3 \mathrm{eV}$ emissions around $140 \mathrm{~K}$ points to the thermally stimulated transitions between the corresponding levels.

Two fast (17 ns and $27 \mathrm{~ns}$ ) and two slow (1.38 ms and $2.8 \mathrm{~ms})$ components were observed at $4.2 \mathrm{~K}$ in the $\mathrm{KCl}$ :Bi emission decay (Figure 9a). Their excitation spectra practically coincide. The emission spectra of two fast decay components are located at $2.54 \mathrm{eV}$ and $2.46 \mathrm{eV}$, respectively, and the emission 
spectra of two slow decay components, at $2.84 \mathrm{eV}$ and $2.68 \mathrm{eV}$, respectively. The decay times of the slow components are constant up to about $60 \mathrm{~K}$ and then decrease exponentially. The $\mathrm{D}$ value is estimated to be of the order of $10^{2} \mathrm{meV}$.

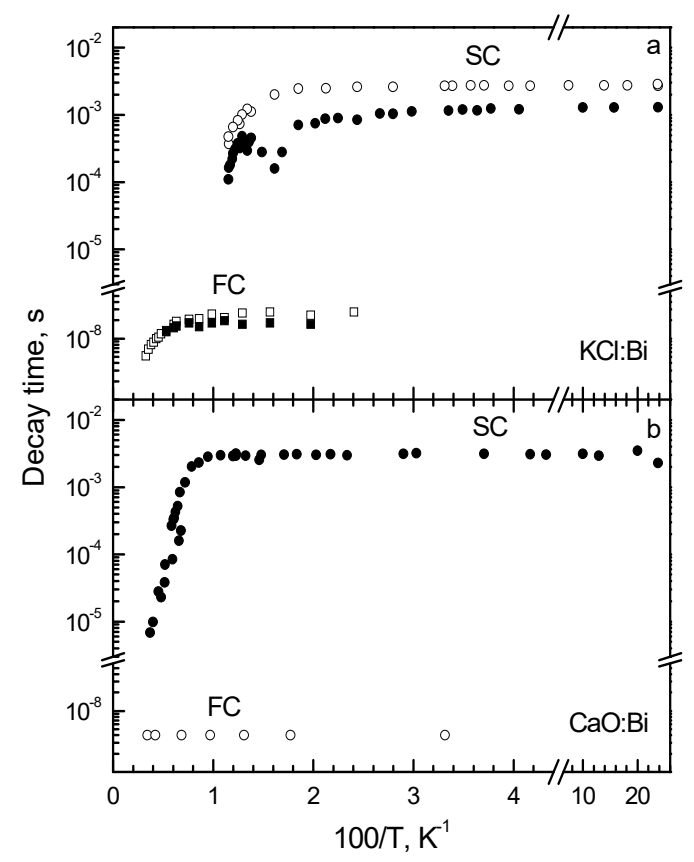

Figure 9. Temperature dependences of the decay times of the slow (SC) and fast (FC) decay components of the triplet luminescence of (a) $\mathrm{KCl}: \mathrm{Bi}$ and (b) $\mathrm{CaO}: \mathrm{Bi}$. In (a), $\mathrm{E}_{\mathrm{exc}}=3.7 \mathrm{eV}, \mathrm{E}_{\mathrm{em}}=2.68 \mathrm{eV}$ (empty circles) and $2.84 \mathrm{eV}$ (solid circles), $\mathrm{E}_{\mathrm{em}}=2.46 \mathrm{eV}$ (empty squares) and $2.54 \mathrm{eV}$ (solid squares). In (b), $\mathrm{E}_{\mathrm{exc}}=3.6 \mathrm{eV}, \mathrm{E}_{\mathrm{em}}=3.1 \mathrm{eV}$ (solid circles) and $\mathrm{E}_{\mathrm{em}}=3.3 \mathrm{eV}$ (empty circles). Based on the data reported in [85]. Presented with the publisher's permission.

At $4.2 \mathrm{~K}$, only the slow component $(3.25 \mathrm{~ms})$ is observed in the decay kinetics of the $3.1 \mathrm{eV}$ emission of $\mathrm{CaO}: \mathrm{Bi}$ and only the fast component $(4 \mathrm{~ns})$, in the decay kinetics of the $3.3 \mathrm{eV}$ emission (Figure $9 \mathrm{~b}$ ). These components arise from RES, related to ${ }^{3} \mathrm{P}_{0}$ and ${ }^{3} \mathrm{P}_{1}$ excited levels of a free $\mathrm{Bi}^{3+}$ ion. Decay time of the slow component decreases exponentially at $\mathrm{T}>100 \mathrm{~K}$ due to the thermally stimulated ${ }^{3} \mathrm{P}_{0} \rightarrow{ }^{3} \mathrm{P}_{1}$ transitions with the activation energy of about $152 \mathrm{meV}$.

Results obtained in [85] confirmed the conclusion [84] that the Seitz model [134], considering the spin-orbit interaction in the triplet RES being dominant, should be used for the description of the luminescence characteristics of $\mathrm{CaO}: \mathrm{Bi}$. These data also indicate that in each Jahn-Teller minimum of the triplet RES of $\mathrm{KCl}: \mathrm{Bi}$, the metastable minimum is located under emitting minimum (Figure 7). The radiative transitions from these minima result in appearance of the slow and fast decay component, respectively. The fast component is strongly polarized in the $<100>$ direction [96]. The shift of the slow component emission spectra to higher energies with respect to those of the fast components, as well as a very small polarization degree of the slow decay component are caused by the shift of the metastable minima towards a smaller configuration coordinate $q$ values with respect to the emitting minimum as well as the decrease of the energy barriers between the metastable minima of different orientation as compared with the emitting minima (see Figure 7). Analysis of these data allows to conclude that the theoretical model $[135,137]$ is still valid in the case of $\mathrm{KCl}: \mathrm{Bi}$, despite the strong spin-orbit interaction.

Comparison of the Stokes shifts and FWHM of emission bands as well as the values of RES parameters presented in Table 1 indicate that the $\mathrm{Bi}^{3+}$ center in aluminum garnets and oxyorthosilicates can be considered as an intermediate case between $\mathrm{Bi}^{3+}$-doped $\mathrm{CaO}$ and $\mathrm{KCl}$. These data also allow to conclude that the electron-phonon interaction in oxyorthosilicates and $\mathrm{Y}_{4} \mathrm{Al}_{2} \mathrm{O}_{9}$ : $\mathrm{Bi}$ is noticeably stronger than that in garnets. Indeed, the larger probability $\left(\mathrm{k}_{1}\right)$ of the radiative decay of the triplet RES metastable minima points to a stronger electron-phonon interaction in these compounds. In addition, 
a smaller value of the spin-orbit splitting energy (D) of the triplet RES of $\mathrm{Bi}^{3+}$ center in oxyorthosilicates and $\mathrm{Y}_{4} \mathrm{Al}_{2} \mathrm{O}_{9}$ as compared with aluminum garnets is caused by stronger suppression of the spin-orbit interaction by the electron-phonon interaction (see $[135,137])$. Thus, the structure and properties of the triplet RES of these materials and the characteristics of their luminescence might be described in terms of the theory $[135,137]$ which considers a strong Jahn-Teller effect to be a dominant interaction in the triplet RES.

\section{Visible Luminescence of $\mathrm{Bi}^{3+}$-Doped Compounds}

\subsection{Characteristics of the Visible Luminescence}

Characteristics of the lower-energy luminescence (the VIS emission) in various $\mathrm{Bi}^{3+}$-doped materials are similar and presented in Table 2. Let us demonstrate them at an example of the $\mathrm{Lu}_{3} \mathrm{Al}_{5} \mathrm{O}_{12}: \mathrm{Bi}$ and $\mathrm{Y}_{3} \mathrm{Al}_{5} \mathrm{O}_{12}$ :Bi single crystalline films investigated in [16-18].

In $\mathrm{Lu}_{3} \mathrm{Al}_{5} \mathrm{O}_{12}: \mathrm{Bi}$, two broad VIS emission bands with large Stokes shifts are located at $2.6 \mathrm{eV}$ and $2.75 \mathrm{eV}$ (Figure 1a). In $\mathrm{Y}_{3} \mathrm{Al}_{5} \mathrm{O}_{12}: \mathrm{Bi}$, analogous bands are observed at $2.63 \mathrm{eV}$ and $2.75 \mathrm{eV}$ (Figure $1 \mathrm{~b}$ ). Comparison of the UV and VIS emission spectra shows that FWHM and S values of the VIS emission are several times larger as compared with those of the UV emission. The lowest-energy excitation band of the VIS emission is always slightly shifted to lower-energies with respect to that of the UV emission (Figure 2b,c) (compare also Tables 1 and 2). The VIS emission is much more effectively excited in the higher-energy absorption bands as compared with the UV emission. As the temperature increases, the intensity redistribution takes place between the UV emission and the lower-energy VIS emission of $\mathrm{Lu}_{3} \mathrm{Al}_{5} \mathrm{O}_{12}: \mathrm{Bi}$ and $\mathrm{Y}_{3} \mathrm{Al}_{5} \mathrm{O}_{12}: \mathrm{Bi}$ (see, e.g., Figure $3 \mathrm{c}$ ).

The decay curves of the VIS emissions in $\mathrm{Y}_{3} \mathrm{Al}_{5} \mathrm{O}_{12}$ : $\mathrm{Bi}$ measured at $4.2 \mathrm{~K}$ are shown in Figure $4 \mathrm{~b}, \mathrm{c}$. At $4.2 \mathrm{~K}$, the components with the decay times $\tau_{\mathrm{SC}} \approx 33$ and $38 \mu$ s dominate in the decay kinetics of the $2.63 \mathrm{eV}$ and $2.75 \mathrm{eV}$ emissions, respectively. At $\mathrm{T}<6 \mathrm{~K}$, the decay times remain constant (Figure $5 \mathrm{~b}, \mathrm{c}$ ) which means that the radiative transitions take place from the metastable levels. As the temperature increases, the decay times shorten exponentially due to thermally stimulated transitions between the metastable and emitting levels and reach a constant value at the temperatures (around $100 \mathrm{~K}$ ), where the system achieves thermal equilibrium. Such temperature dependences are characteristic for the radiative transitions from the triplet RES of a luminescence center (see also $[7,9,78,83,93])$. At higher temperatures, the decay time decreases due to the luminescence thermal quenching. Analogous $\tau_{\mathrm{SC}}(\mathrm{T})$ dependences were obtained, e.g., for the triplet emission of $\mathrm{Ga}^{+}$- and $\mathrm{In}^{+}$- doped alkali halides (see, e.g., [132]) due to a small spin-orbit interaction energy characteristic for free $\mathrm{Ga}^{+}$and $\mathrm{In}^{+}$ions $\left(\xi \approx 0.2-0.3 \mathrm{eV}\right.$, see, e.g., [4]). Indeed, $\mathrm{D}=0.33-0.67 \mathrm{meV}$ was obtained in [132] for $\mathrm{Ga}^{+}$centers and $\mathrm{D}=2.15-3.04 \mathrm{meV}$, for $\operatorname{In}^{+}$centers.

In $\mathrm{Lu}_{3} \mathrm{Al}_{5} \mathrm{O}_{12}: \mathrm{Bi}$, as well as in some other $\mathrm{Bi}^{3+}$-doped materials (e.g., $\mathrm{Lu}_{2} \mathrm{SiO}_{5}: \mathrm{Bi}, \mathrm{Gd}_{3} \mathrm{Ga}_{5} \mathrm{O}_{12}: \mathrm{Bi}$ ), the participation of the singlet exciton state in the VIS luminescence decay kinetics is also evident. This is caused by the fact that in case of excitons, the singlet state is located close to the triplet state (Figure 10b). The probability $\left(\mathrm{k}_{3}\right)$ of its radiative decay is found to be $10^{8}-5 \times 10^{9} \mathrm{~s}^{-1}$ and the energy distance between the singlet and triplet states $\mathrm{E}=75-150 \mathrm{meV}$ (see $[9,16,21,74])$. 
a)

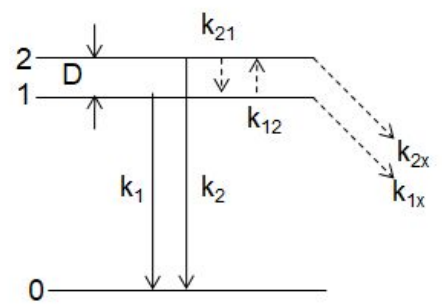

b)

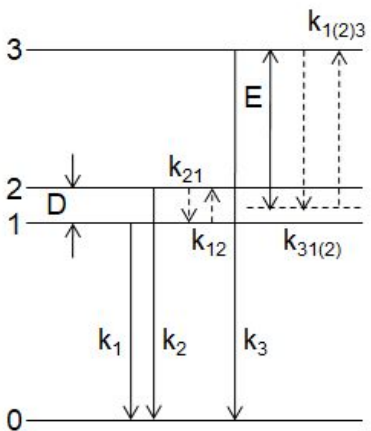

Figure 10. Energy level diagrams used for the description of the excited states dynamics of the $\mathrm{Bi}^{3+}$-related luminescence centers responsible for the VIS emissions. In (a) two-excited-level diagram, in (b) three-excited-level diagram. For details, see the text.

\subsection{Dynamics of the $B i^{3+}$-Related Exciton-Like States}

Thermally stimulated transitions between the metastable and emitting minima of the triplet RES, triplet and singlet excited states, and excited and ground states of the luminescence center responsible for the VIS emission reveal themselves in the temperature dependences of the VIS emission spectra and decay kinetics. The phenomenological models are proposed to describe the excited-state dynamics of these centers. Application of the two- or three-excited-level models on the temperature evolution of the VIS luminescence decay times allows determination of characteristic parameters of the corresponding RES (the energy separations between the excited states and the rates of the radiative and non-radiative transitions from these states). The excited states dynamics of the luminescence center responsible for the VIS emission is described within the phenomenological model sketched in Figure 10.

In case of the two-excited-level model (Figure 10a), the time evolution of the populations $N_{1}$, $\mathrm{N}_{2}$ of the excited levels 1 and 2, respectively, can be described by the rate equations given by Equation (1) with consideration of Equations (2) and (3). In case of the three-excited-level model (Figure 10b), the time evolution of the populations $N_{1}, N_{2}, N_{3}$ of the excited levels 1,2 and 3, respectively, can be described by the following rate equations:

$$
\begin{aligned}
& \frac{\mathrm{d} N_{1}}{\mathrm{~d} t}=-k_{1} N_{1}-k_{12} N_{1}-k_{13} N_{1}+k_{21} N_{2}+k_{31} N_{3} \\
& \frac{\mathrm{d} N_{2}}{\mathrm{~d} t}=-k_{2} N_{2}-k_{21} N_{2}-k_{23} N_{2}+k_{12} N_{1}+k_{32} N_{3} \\
& \frac{\mathrm{d} N_{3}}{\mathrm{~d} t}=-k_{3} N_{3}-k_{31} N_{3}-k_{32} N_{3}+k_{13} N_{1}+k_{23} N_{2}
\end{aligned}
$$

where analogous parameters have the same meaning as in (1). In addition, $k_{3}$ is the radiative transition rate from the singlet level 3 and $k_{3(2) 1}, k_{1(2) 3}$, are non-radiative rates of transitions between the levels $3(2)$ and 1 :

$$
\begin{gathered}
k_{31}=K^{\prime}\left(n^{\prime}+1\right), k_{13}=K^{\prime} n^{\prime}, \\
n^{\prime}=1 /\left[\exp \left(E / k_{B} T\right)-1\right] .
\end{gathered}
$$

$E$ is the energy distance between the triplet and singlet levels. Since $D<<E$ we consider

$$
k_{31}=k_{32}, k_{13}=k_{23} \text {. }
$$

The values of some parameters are presented in Table 2. A strong difference between the structure and parameters of RES responsible for the UV and VIS emissions clearly indicates their different origin.

As evident from Table 2, the VIS emission is characterized not only by the large Stokes shift and FWHM. In all the works $[7,9,16-18,21,69,72-78,83,93,95]$ where the low-temperature luminescence decay kinetics was investigated, also a very small $(\sim 1 \mathrm{meV})$ energy distance $D$ between the two lowest excited levels was reported. 


\subsection{On the Origin of the Excited States Responsible for the VIS Luminescence}

In most of the studies, a possible origin of the unrelaxed excited states, responsible for the lowest-energy excitation band of the VIS emission, was mainly considered for various $\mathrm{Bi}^{3+}$-doped compounds (see, e.g., [7,64]). For example, the lowest energy excitation band of the VIS emission of $\mathrm{YNbO}_{4}$ : $\mathrm{Bi}$ was ascribed to the $\mathrm{Bi}^{3+}\left(6 \mathrm{~s}^{2}\right) \rightarrow \mathrm{Nb}^{5+}\left(\mathrm{d}^{0}\right)$ MMCT (see also [141]). It should be noted that the consideration of absorption and emission bands of some $\mathrm{Bi}^{3+}$-doped complex oxides as an electron transfer between $\mathrm{Bi}^{3+}$ and host lattice transition metal ions was proposed about 50 years ago [1] (see also $[6,141,142])$.

In [65], an empirical model, proposed earlier for $\mathrm{Pr}^{3+}$ - and $\mathrm{Tb}^{3+}$-doped $\mathrm{d}^{0}$ closed-shell transition metal compounds, was applied to predict the energy position of the MMCT bands in various $\mathrm{Bi}^{3+}$-doped closed-shell $\mathrm{d}^{0}$ transition metal $\left(\mathrm{M}^{\mathrm{n}+}\right)$ complex oxides. The dependence of the energy positions of the $\mathrm{Bi}^{3+}$-related absorption bands $\mathrm{E}_{\mathrm{abs}}$ on the ratio between the optical electronegativities $\mathrm{X}_{\mathrm{opt}}\left(\mathrm{M}^{\mathrm{n}+}\right)$ of the $\mathrm{d}^{0}$ metal cations and the shortest $\mathrm{Bi}^{3+}-\mathrm{M}^{\mathrm{n}+}$ interatomic distances was found to be linear. It was described by the following empirical equation:

$$
\mathrm{E}_{\mathrm{abs}}\left(\mathrm{Bi}^{3+}, \mathrm{cm}^{-1}\right)=46,000-27,000\left\{\mathrm{X}_{\mathrm{opt}}\left(\mathrm{M}^{\mathrm{n}+}\right) / \mathrm{d}\left(\mathrm{Bi}^{3+}-\mathrm{M}^{\mathrm{n}+}\right)\right\} .
$$

It was concluded that any $\mathrm{Bi}^{3+}$-related absorption band satisfying this equation is of the MMCT origin.

This model was developed further in [7] where the structural characteristics of the host lattice, anion relaxation resulting from $\mathrm{Bi}^{3+}$ doping, and electronegativities and coordination numbers of the $\mathrm{Bi}^{3+}$ and $\mathrm{M}^{\mathrm{n}+}$ ions in the compounds were taken into account. For the metals with the coordination number $\mathrm{CN}^{\prime}\left(\mathrm{M}^{\mathrm{n}+}\right)=4$, the Equation (1) was modified to:

$$
\operatorname{MMCT}\left(\mathrm{Bi}^{3+}, \mathrm{cm}^{-1}\right)=70,000-52,000\left\{\mathrm{X}_{4}\left(\mathrm{M}^{\mathrm{n}+}\right) / \mathrm{d}_{\mathrm{corr}}\right\},
$$

where $\mathrm{d}_{\text {corr }}$ is the shortest distance between $\mathrm{Bi}^{3+}$ and $\mathrm{M}^{\mathrm{n}+}$ ions corrected to account for the effect of anion relaxation due to Bi doping.

For the metals with the coordination numbers $\mathrm{CN}^{\prime}\left(\mathrm{M}^{\mathrm{n}+}\right)>4$, the following equation was proposed:

$$
\operatorname{MMCT}\left(\mathrm{Bi}^{3+}, \mathrm{cm}^{-1}\right)=55,000-45,500\left\{\mathrm{X}_{\mathrm{CN}^{\prime}>4}\left(\mathrm{M}^{\mathrm{n}+}\right) / \mathrm{d}_{\mathrm{corr}}\right\} \text {. }
$$

In $[7,64,65]$, the energies of the ${ }^{1} \mathrm{~S}_{0} \rightarrow{ }^{3} \mathrm{P}_{1}$ transitions of a $\mathrm{Bi}^{3+}$ ion and the $\mathrm{Bi}^{3+} \rightarrow \mathrm{M}^{\mathrm{n}+} \mathrm{MMCT}$ transitions were calculated for many $\mathrm{Bi}^{3+}$-doped compounds. In a few cases, e.g., in $\mathrm{YVO}_{4}: \mathrm{Bi}$, these energies were obtained to be very close ( $3.779 \mathrm{eV}$ and $3.778 \mathrm{eV}$, respectively [65]). As both these energies are close to the energy of the lowest-energy excitation band of the VIS emission in $\mathrm{YVO}_{4}: \mathrm{Bi}$ $(3.78 \mathrm{eV})$, in principle, both the ${ }^{1} \mathrm{~S}_{0} \rightarrow{ }^{3} \mathrm{P}_{1}$ transitions of a $\mathrm{Bi}^{3+}$ ion and the $\mathrm{Bi}^{3+} \rightarrow \mathrm{V}^{5+}$ MMCT transitions could be considered as responsible for the lowest-energy $\mathrm{Bi}^{3+}$-related excitation band in $\mathrm{YVO}_{4}: \mathrm{Bi}$. In [1,3], this band was ascribed to MMCT and in [76], to the ${ }^{1} \mathrm{~S}_{0} \rightarrow{ }^{3} \mathrm{P}_{1}$ transitions. However, in most of the considered materials, the position of the lowest-energy excitation band of the VIS emission and the MMCT energy (see, e.g., $[10,65]$ ) are significantly different. For example, in $\mathrm{Lu}_{3} \mathrm{Al}_{5} \mathrm{O}_{12}: \mathrm{Bi}$, the MMCT energy is $5.95 \mathrm{eV}$ [10] while the lowest excitation band of the $2.6 \mathrm{eV}$ emission is located at $4.6 \mathrm{eV}$. The same is true for $\mathrm{Y}_{3} \mathrm{Al}_{5} \mathrm{O}_{12}: \mathrm{Bi}$. In $\mathrm{YPO}_{4}: \mathrm{Bi}$, the MMCT energy (7.3 eV [10]) is also much higher as compared with the position $(\approx 5.5 \mathrm{eV}$, Table 2$)$ of the lowest excitation band.

In $\mathrm{Bi}^{3+}$-doped compounds, the UV emission is concluded to arise from the radiative decay of the triplet RES of a single $\mathrm{Bi}^{3+}$ ion, and the lowest-energy excitation band of this emission corresponds to the ${ }^{1} \mathrm{~S}_{0} \rightarrow{ }^{3} \mathrm{P}_{1}$ transitions of $\mathrm{Bi}^{3+}$. According to $[7,64]$, the MMCT occurs from the ground ${ }^{1} \mathrm{~S}_{0}$ state of a $\mathrm{Bi}^{3+}$ ion to the bottom of the conduction band (CB) formed by the energy levels of $\mathrm{d}^{0}$ or $\mathrm{d}^{10}$ host lattice ions, and the energy of the MMCT is defined as the energy difference between the ${ }^{1} \mathrm{~S}_{0}$ and MMCT states (Figure 11). Therefore, in general, the lowest-energy excitation bands of the UV and VIS emissions should not coincide as these bands arise due to processes of different origin. However, in all 
the $\mathrm{Bi}^{3+}$-doped compounds, where both the UV and VIS emissions are present, their lowest-energy excitation bands are close (see, e.g., Figure $2 b, c$ and compare the $E_{\text {exc }}$ values in Tables 1 and 2). In some cases, they practically coincide (see, e.g., [24,120]), and the intensity redistribution is observed between the UV and VIS emissions (see, e.g., $[9,17,18,93,114,115,120]$ and Figure 3c). For example, the lowest excitation bands of the UV and VIS emissions completely coincide in $\mathrm{La}_{2} \mathrm{Zr}_{2} \mathrm{O}_{7}$ : $\mathrm{Bi}$ [120]. This indicates that the VIS emission of $\mathrm{La}_{2} \mathrm{Zr}_{2} \mathrm{O}_{7}: \mathrm{Bi}$, ascribed in [120] to the impurity trapped exciton, is excited in the ${ }^{1} \mathrm{~S}_{0} \rightarrow{ }^{3} \mathrm{P}_{1}$ absorption band of $\mathrm{Bi}^{3+}(4.32 \mathrm{eV})[7,64,65]$ even at $4.2 \mathrm{~K}$, despite the fact that the lowest calculated MMCT energy in this material is $4.88 \mathrm{eV}$ [65] or $5.06 \mathrm{eV}$ [10]. In our opinion, the intensity redistribution between the UV and VIS emissions observed in this work can be caused by the thermally stimulated release of an electron from the ${ }^{3} \mathrm{P}$ level of $\mathrm{Bi}^{3+}$ into $\mathrm{CB}$. From the $\mathrm{I}(\mathrm{T})$ dependence in the $\mathrm{T}<50 \mathrm{~K}$ temperature range, the activation energy of this process can be estimated as $\approx 2 \mathrm{meV}$. This value can correspond to the energy distance between the triplet RES of $\mathrm{Bi}^{3+}$ and $\mathrm{CB}$. The reverse intensity redistribution observed in [120] at higher temperature can be caused by thermally stimulated transitions from the localized exciton state to the ${ }^{3} \mathrm{P}_{1}$ state of $\mathrm{Bi}^{3+}$ over the energy barrier of about $27 \mathrm{meV}$.

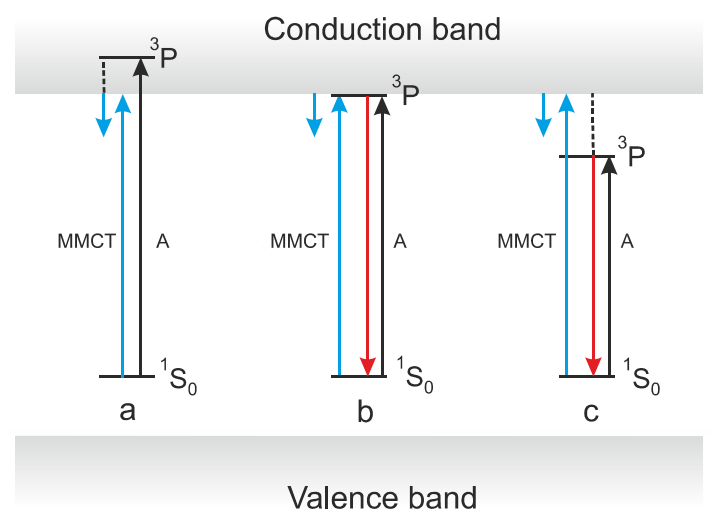

Figure 11. Schematic presentation of energy levels in $\mathrm{Bi}^{3+}$-doped compounds proposed in [7].

According to [7], the UV emission appears when the ${ }^{3} \mathrm{P}_{1}$ level of $\mathrm{Bi}^{3+}$ is located below CB. In this case, the energy of the MMCT should always be higher as compared with the energy of the ${ }^{1} \mathrm{~S}_{0}$ $\rightarrow{ }^{3} \mathrm{P}_{1}$ transition (Figure 11). However, in most of the investigated cases, the excitation band of the VIS emission is slightly shifted to lower energies as compared to that of the UV emission (see, e.g., $[14,15,19,24,64,78,93-96,104,109,110,119,121,140,141]$ and Figure $2 b, c)$.

Thus, the data considered above allow us to suggest that the electron transitions, corresponding to the ${ }^{1} \mathrm{~S}_{0} \rightarrow{ }^{3} \mathrm{P}_{1}$ transition of a free $\mathrm{Bi}^{3+}$ ion, are most probably responsible for the lowest excitation band of both the UV and VIS emissions. The MMCT transitions as well as the ${ }^{1} \mathrm{~S}_{0} \rightarrow{ }^{3} \mathrm{P}_{2}$ and ${ }^{1} \mathrm{~S}_{0}$ $\rightarrow{ }^{1} \mathrm{P}_{1}$ transitions of a $\mathrm{Bi}^{3+}$ ion, resulting in the electron release into $\mathrm{CB}$, can be responsible for the higher-energy excitation bands of the VIS luminescence.

\subsection{On the Origin of the Visible Luminescence}

The VIS emission was identified in the literature as the emission corresponding to the ${ }^{3} \mathrm{P}_{1,0} \rightarrow{ }^{1} \mathrm{~S}_{0}$ transitions of a free $\mathrm{Bi}^{3+}$ ion $[3,26,28-30,36,39,40,42,43,124,127,130,143-153]$, D-state emission $[63,114,115,120,128,154]$, charge transfer emission $[1,10,65,114,115,154]$, impurity-trapped or impurity-bound exciton emission [12,69,83,120,122,123,128,154-156], MMCT emission [6,7,63-65,120, $128,130,141,156,157]$, and emission of $\mathrm{Bi}^{3+}$ pairs and clusters $[1,10,14,15,19,24,58,64,78,95,97,99,102,104$, $109,110,112,113,119-121,128,154,158,159]$ (see also review papers [7,10,11]). However, in most of these papers, the structure and parameters of RES, responsible for the VIS emission, were not determined, and conclusions about the origin of this emission were not confirmed by experimental data.

Detailed investigations of the VIS emission by the time-resolved spectroscopy methods in a wide temperature range (down to $0.4 \mathrm{~K}$ ) and determination of the RES parameters carried out 
in $[7,9,13,16-18,21,72-78,83,93,95,99,156]$ allow us to make a justified conclusion on the exciton-like origin of the emission in the considered $\mathrm{Bi}^{3+}$-doped compounds. The VIS emission was interpreted as the luminescence of an exciton localized around a $\mathrm{Bi}^{3+}$-related center. Indeed, since a free $\mathrm{Bi}^{3+}$ ion has the largest spin-orbit interaction energy among all the other $\mathrm{ns}^{2}$ ions $(\xi=2.102 \mathrm{eV}[4])$, a very small energy distance $(\mathrm{D}=0.34-5.7 \mathrm{meV}$, see Table 2$)$ between the metastable and emitting levels of the triplet RES responsible for the VIS emission can only be explained by the exciton-like origin of this emission. In addition to the small spin-orbit interaction energy, a strong exciton-phonon interaction is also characteristic for excitons which explains the large Stokes shift and FWHM of the VIS emission.

The structure and parameters of the triplet RES should be similar for all exciton-like emissions in the same host material. This was clearly demonstrated on the example of caesium iodides in $[160,161]$ where similar RES parameters were obtained for the self-trapped excitons and for the excitons localized around various intrinsic and impurity defects. Therefore, in Table 3, available data on the exciton-like luminescence in some undoped materials are collected to compare them with corresponding characteristics of the $\mathrm{Bi}^{3+}$-related VIS emission.

Table 3. Emission peak positions $\left(\mathrm{E}_{\mathrm{em}}\right)$, full widths at half maxima (FWHM), the Stokes shifts (S), positions of the lowest-energy excitation band $\left(\mathrm{E}_{\mathrm{exc}}\right)$, and decay times $\left(\tau_{\mathrm{SC}}\right)\left(\right.$ at $0.4 \mathrm{~K}$ for $\mathrm{PbWO}_{4}$ and $4.2 \mathrm{~K}$ for the other materials) of the triplet exciton-like emissions of the undoped compounds. The spin-orbit splitting energy (D) and the probabilities of the radiative decay of the metastable $\left(\mathrm{k}_{1}\right)$ and emitting $\left(\mathrm{k}_{2}\right)$ levels of the triplet RES.

\begin{tabular}{|c|c|c|c|c|c|c|c|c|c|}
\hline Compound & $\begin{array}{c}\mathrm{E}_{\mathrm{em}} \\
\mathrm{eV}\end{array}$ & $\begin{array}{c}\text { FWHM, } \\
\text { eV }\end{array}$ & $\begin{array}{l}\mathrm{S} \\
\mathrm{eV}\end{array}$ & $\begin{array}{c}E_{\text {exc }} \\
\text { eV }\end{array}$ & $\begin{array}{c}\tau_{\mathrm{SC}} \\
\mu \mathrm{S}\end{array}$ & $\begin{array}{c}\mathrm{D}, \\
\mathrm{meV}\end{array}$ & $\begin{array}{c}\mathbf{k}_{1} \\
\times 10^{3} \\
\mathbf{s}^{-1}\end{array}$ & $\begin{array}{c}k_{2} \\
\times 10^{5} \\
s^{-1}\end{array}$ & Refs. \\
\hline \multirow[t]{2}{*}{ YNbO4 } & 3.06 & - & 1.71 & 4.77 & $\approx 400$ & 0.74 & - & - & [162] \\
\hline & 2.89 & 0.62 & 2.07 & 4.96 & 180 & 0.63 & - & - & {$[77]$} \\
\hline $\mathrm{LuNbO}_{4}$ & 3.13 & 0.64 & 1.52 & 4.65 & $\approx 250$ & - & - & - & {$[162,163]$} \\
\hline \multirow[t]{2}{*}{$\mathrm{GdNbO}_{4}$} & 2.82 & - & 2.00 & 4.82 & - & - & - & - & [164] \\
\hline & 2.95 & - & 1.93 & 4.88 & - & - & - & - & [165] \\
\hline \multirow[t]{2}{*}{$\mathrm{YVO}_{4}$} & 2.99 & 0.66 & 1.04 & 4.03 & - & - & - & - & [141] \\
\hline & 2.72 & 0.67 & 1.22 & 3.94 & 550 & 0.124 & - & - & [166] \\
\hline $\mathrm{LuVO}_{4}$ & 2.82 & - & 1.26 & 4.08 & - & - & - & - & [28] \\
\hline $\mathrm{GdVO}_{4}$ & 2.77 & - & 1.22 & 3.99 & - & - & - & - & [3] \\
\hline \multirow[t]{5}{*}{$\mathrm{Lu}_{3} \mathrm{Al}_{5} \mathrm{O}_{12}$} & 5.00 & - & 2.30 & 7.30 & - & - & - & - & [167] \\
\hline & 4.95 & - & 2.45 & 7.40 & - & - & - & - & [167] \\
\hline & 4.36 & - & 2.70 & 7.06 & - & - & - & - & [167] \\
\hline & 4.90 & 0.80 & 2.30 & 7.20 & 282 & - & - & - & {$[168,169]$} \\
\hline & 3.65 & 0.80 & 3.46 & 7.11 & 207 & - & - & - & {$[168,169]$} \\
\hline \multirow[t]{5}{*}{$\mathrm{Y}_{3} \mathrm{Al}_{5} \mathrm{O}_{12}$} & 4.74 & - & 2.43 & 7.17 & - & - & - & - & [167] \\
\hline & 4.22 & - & 2.66 & 6.88 & - & - & - & - & {$[167,170]$} \\
\hline & 4.80 & 0.80 & 2.10 & 6.90 & - & - & - & - & [169] \\
\hline & 3.95 & 1.23 & 2.85 & 6.80 & - & - & - & - & [169] \\
\hline & 4.95 & 0.70 & 1.95 & 6.90 & - & - & - & - & [170] \\
\hline $\mathrm{Y}_{3} \mathrm{Ga}_{5} \mathrm{O}_{12}$ & 4.10 & 0.70 & 2.60 & 6.70 & - & - & - & - & [171] \\
\hline $\mathrm{Gd}_{3} \mathrm{Ga}_{5} \mathrm{O}_{12}$ & 3.44 & 0.68 & 1.52 & 4.96 & - & - & - & - & [172] \\
\hline \multirow[t]{5}{*}{$\mathrm{YAlO}_{3}$} & 5.60 & - & 2.23 & 7.83 & - & - & - & - & [173] \\
\hline & 5.63 & - & 2.27 & 7.90 & - & - & - & - & [173] \\
\hline & 4.12 & - & 3.01 & 7.13 & - & - & - & - & [173] \\
\hline & 5.68 & - & 2.21 & 7.89 & - & - & - & - & [174-176] \\
\hline & 5.28 & - & 2.61 & 7.89 & - & - & - & - & [175] \\
\hline
\end{tabular}


Table 3. Cont.

\begin{tabular}{|c|c|c|c|c|c|c|c|c|c|}
\hline Compound & $\begin{array}{c}E_{\text {em }}, \\
\text { eV }\end{array}$ & $\begin{array}{c}\text { FWHM, } \\
\text { eV }\end{array}$ & $\begin{array}{c}\mathrm{S} \\
\mathrm{eV}\end{array}$ & $\begin{array}{l}\text { Eexc }_{\text {ex }} \\
\text { eV }\end{array}$ & $\begin{array}{c}\tau_{\mathrm{SC}} \\
\mu \mathrm{S}\end{array}$ & $\begin{array}{c}\text { D, } \\
\text { meV }\end{array}$ & $\begin{array}{c}\mathbf{k}_{1} \\
\times 10^{3} \\
\mathbf{s}^{-1}\end{array}$ & $\begin{array}{c}\mathrm{k}_{2} \\
\times 10^{5} \\
\mathrm{~s}^{-1}\end{array}$ & Refs. \\
\hline \multirow[t]{4}{*}{$\mathrm{LuAlO}_{3}$} & 6.13 & - & 2.12 & 8.25 & - & - & - & - & [177] \\
\hline & 5.90 & - & 2.22 & 8.12 & - & - & - & - & [177] \\
\hline & 4.49 & - & 3.45 & 7.94 & - & - & - & - & [177] \\
\hline & 4.22 & - & 3.37 & 7.59 & - & - & - & - & [177] \\
\hline \multirow[t]{2}{*}{$\mathrm{LuYAlO}_{3}$} & 6.13 & - & 2.26 & 8.39 & - & - & - & - & [176] \\
\hline & 5.55 & - & 2.38 & 7.93 & - & - & - & - & [176] \\
\hline \multirow[t]{4}{*}{$\mathrm{PbWO}_{4}$} & 2.76 & 0.62 & 1.41 & 4.17 & 30 & 0.45 & 39 & 3.7 & [178] \\
\hline & 2.36 & 0.52 & 1.59 & 3.95 & 250 & 0.30 & 4.05 & 1 & {$[179,180]$} \\
\hline & 2.38 & 0.51 & 1.52 & 3.90 & 210 & 0.33 & 4.72 & 1.2 & {$[179,180]$} \\
\hline & 2.40 & 0.52 & 1.50 & 3.90 & 240 & 0.35 & 4.10 & 0.83 & {$[179,180]$} \\
\hline $\mathrm{CaWO}_{4}$ & 2.88 & 0.60 & 2.32 & 5.20 & 360 & - & - & - & {$[122,123]$} \\
\hline $\mathrm{Ca}_{2} \mathrm{MgWO}_{6}$ & 2.88 & - & 1.29 & 4.17 & - & - & - & - & [130] \\
\hline \multirow{2}{*}{$\mathrm{Lu}_{2} \mathrm{SiO}_{5}$} & 4.80 & - & 1.80 & 6.60 & - & - & - & - & [181-183] \\
\hline & 3.80 & - & 2.90 & 6.70 & - & - & - & - & {$[181,182]$} \\
\hline \multirow[t]{2}{*}{$\mathrm{Y}_{2} \mathrm{SiO}_{5}$} & 3.60 & - & 3.10 & 6.70 & - & - & - & - & [183] \\
\hline & 3.20 & - & 3.50 & 6.70 & - & - & - & - & [183] \\
\hline $\mathrm{LaPO}_{4}$ & 4.80 & - & 3.50 & 8.30 & - & - & - & & [184] \\
\hline $\mathrm{LuPO}_{4}$ & 4.30 & - & 4.40 & 8.70 & - & - & - & - & {$[185,186]$} \\
\hline $\mathrm{LaB}_{3} \mathrm{O}_{6}$ & 3.60 & 0.90 & 4.10 & 7.70 & - & - & - & - & [187] \\
\hline $\mathrm{LuBO}_{3}$ & 3.40 & - & 4.40 & 7.80 & - & - & - & - & [186] \\
\hline $\mathrm{LiLaP}_{4} \mathrm{O}_{12}$ & 2.80 & 0.70 & 2.43 & 5.20 & 800 & - & - & - & [72] \\
\hline $\mathrm{Sr}_{3} \mathrm{Ga}_{4} \mathrm{O}_{9}$ & 3.26 & - & 1.70 & 4.96 & - & - & - & - & [58] \\
\hline
\end{tabular}

Unfortunately, for most of these materials, the RES parameters were not determined since for that task investigations of the luminescence decay kinetics at temperatures well below $4.2 \mathrm{~K}$ are needed. For example, in $\mathrm{PbWO}_{4}$ the slow component decay time ( $\left.\tau_{\mathrm{SC}}\right)$ reaches its maximum value only at $\mathrm{T}<0.6 \mathrm{~K}[178-180]$.

Comparison of the data presented in Table 3 with those in Table 2 demonstrates that the exciton-like emissions in an undoped material and the lower-energy (VIS) emission of the same host material, $\mathrm{Bi}^{3+}$-doped have very close values of $\mathrm{D}, \mathrm{FWHM}$, and $\mathrm{S}$. This is an additional confirmation of the exciton-like origin of the broad lower-energy emission bands in these compounds (see also $[69,83]$ ).

A drastic difference in the $\mathrm{D}$ values (up to two orders of magnitude), appearing in the decay kinetics of the luminescence arising from the triplet RES of an impurity ion with respect to that arising from the triplet state of an exciton localized around the impurity ion, was also clearly demonstrated for $\mathrm{Tl}^{+}-[188,189]$ and $\mathrm{Pb}^{2+}$-doped [190-192] caesium halides. In these compounds both types of the impurity-related emission bands mentioned above were observed in a single system. The Stokes shifts and FWHM related to the two types of the emission bands were found to be considerably different as well.

Let us consider possible mechanisms of the processes resulting in the appearance of the exciton-like luminescence in $\mathrm{Bi}^{3+}$-doped compounds.

\subsection{On Possible Mechanisms of Processes Responsible for the VIS Luminescence}

We suggest that the VIS emission appears under excitation of a $\mathrm{Bi}^{3+}$ ion with the energy $\left(\mathrm{h} v_{\mathrm{exc}}\right)$ which allows an electron delocalization from the excited state of $\mathrm{Bi}^{3+}$ into $\mathrm{CB}$ and its subsequent immediate recombination with the hole remained at the $\mathrm{Bi}^{3+}$ ion (the $\mathrm{Bi}^{4+}$ hole center). For that, 
the lowest-energy relaxed excited state of $\mathrm{Bi}^{3+}$ (responsible for the UV emission) should be located inside $\mathrm{CB}$ (see Figure 7). As a result of the electron-hole recombination around the $\mathrm{Bi}^{3+}$ ion, a localized exciton $\left(\mathrm{ex}^{0} \mathrm{Bi}^{3+}\right)$ is created. The radiative decay of the lowest-energy triplet localized exciton state results in the appearance of the $\mathrm{Bi}^{3+}$-related exciton-like emission $\left(\mathrm{h} v_{\mathrm{em}}\right)$ in case the corresponding RES is located below the bottom of CB:

$$
\mathrm{Bi}^{3+}+\mathrm{h} v_{\mathrm{exc}} \rightarrow \mathrm{e}^{-}(\mathrm{CB}) \ldots \mathrm{Bi}^{4+} \rightarrow\left(\mathrm{e}^{-}+\mathrm{e}^{+}\right) \mathrm{Bi}^{3+} \rightarrow \mathrm{ex}^{0} \mathrm{Bi}^{3+} \rightarrow \mathrm{Bi}^{3+}+\mathrm{h} v_{\mathrm{em}}
$$

In the considered case, only the VIS emission can appear. In case the relaxed excited states of both the $\mathrm{Bi}^{3+}$ ion and the localized exciton $\mathrm{ex}^{0} \mathrm{Bi}^{3+}$ are located below or close to the bottom of $\mathrm{CB}$, both the UV and VIS emissions can appear. The UV/VIS emission intensity ratio depends not only on the RES position with respect to the bottom of $\mathrm{CB}$ but also on the rate of vibronic relaxation in the $\mathrm{Bi}^{3+}$ excited state and the probability of an electron delocalization from this state. No VIS emission can appear in case the lowest-energy $\mathrm{Bi}^{3+}$-related level (corresponding to the ${ }^{3} \mathrm{P}_{1}$ level of a free $\mathrm{Bi}^{3+}$ ion) is located well below the bottom of $\mathrm{CB}$.

Similar mechanism of the appearance of the VIS emission was proposed in [155] (see also [120]), where this emission was ascribed to the impurity-bound exciton recombination. It was suggested that the emitting level of $\mathrm{InBO}_{3}$ : $\mathrm{Bi}$ is situated either close to or inside $\mathrm{CB}$ of the host lattice, so that after excitation the luminescence center can get ionized. According to [155], this results in formation of an impurity-trapped exciton, with the hole located at the luminescence center and the electron located in its neighborhood.

It should be noted that the above-mentioned $\mathrm{Bi}^{3+}$-related center can be not only a single $\mathrm{Bi}^{3+}$ ion, but also a dimer $\left\{\mathrm{Bi}^{3+}-\mathrm{Bi}^{3+}\right\}$ or a $\mathrm{Bi}^{3+}$ ion located close to a crystal lattice defect $d\left(\left\{\mathrm{Bi}^{3+}-d\right\}\right.$ center). In this case, the localized excitons of the type of $\mathrm{ex}^{0}\left\{\mathrm{Bi}^{3+}-\mathrm{Bi}^{3+}\right\}$ and $\mathrm{ex}^{0}\left\{\mathrm{Bi}^{3+}-d\right\}$ can also be created and their radiative decay can be accompanied by the VIS emission. This means that several overlapping emission bands of exciton-like origin can appear in $\mathrm{Bi}^{3+}$-doped compounds resulting in a complex structure of the VIS emission band.

The luminescence of the localized exciton of the type of $\mathrm{ex}^{0}\left\{\mathrm{Bi}^{3+}-d\right\}$ can appear with the highest probability in case the $\mathrm{Bi}^{3+}$ ion substitutes for a divalent or monovalent host lattice ion where the excess charge of $\mathrm{Bi}^{3+}$ should be compensated by some defect $(d)$. Probably, this is the case of $\mathrm{Sr}_{3} \mathrm{Ga}_{4} \mathrm{O}_{9}$ :Bi [58], where two emission bands could arise not only from single $\mathrm{Bi}^{3+}$ ions, substituting for $\mathrm{Sr}^{2+}$ ions in different lattice sites, but also from the localized excitons of the type of $\mathrm{ex}^{0} \mathrm{Bi}^{3+}$ and $\mathrm{ex}^{0}\left\{\mathrm{Bi}^{3+}-d\right\}$. In the materials of this type, an electron transfer from the valence band to the $\mathrm{Bi}^{3+}$ ion, resulting in the formation of a stable $\mathrm{Bi}^{2+}$ center, is also possible. In more detail, this process was considered for $\mathrm{PbWO}_{4}$ :Bi in Ref. [73] (see Appendix A). In this case, besides the radiative electron-hole recombination, resulting in the appearance of the $\mathrm{Bi}^{3+}$-related exciton-like luminescence, the electron $\mathrm{Bi}^{2+}$ centers and the self-trapped holes can also be optically created. These centers were indeed detected in EPR [73,193].

\section{On the Dependence of the UV/VIS Emission Intensity Ratio on the Band-Gap and Band-Edge Energy}

According to Figure 7, the UV/VIS emission intensity ratio should strongly depend on the position of the lowest-energy RES of $\mathrm{Bi}^{3+}$ with respect to the $\mathrm{CB}$ edge. Therefore, it could also depend on the band gap energy $E_{g}$ of the host material and increase with increasing $E_{g}$ [154]. The best materials to investigate these dependences could be multicomponent garnets where both the $\mathrm{CB}$ edge energy and $\mathrm{E}_{\mathrm{g}}$ can be changed by variation of their composition (see, e.g., [194-199]). Let us consider some examples.

The UV/VIS emission intensity ratio was found to be much larger in $\mathrm{Y}_{3} \mathrm{Al}_{5} \mathrm{O}_{12}: \mathrm{Bi}$ $\left(\mathrm{E}_{\mathrm{g}} \approx 7.7 \mathrm{eV}[10,154]\right)$ as compared to $\mathrm{Lu}_{3} \mathrm{Al}_{5} \mathrm{O}_{12}: \mathrm{Bi}\left(\mathrm{E}_{\mathrm{g}} \approx 7.9 \mathrm{eV}[10,154]\right)$ (compare Figure 1a and $\left.\mathrm{b}\right)$. This could mean that the triplet RES of $\mathrm{Bi}^{3+}$ is located closer to the bottom of $\mathrm{CB}$ in $\mathrm{Lu}_{3} \mathrm{Al}_{5} \mathrm{O}_{12}$ as compared to $\mathrm{Y}_{3} \mathrm{Al}_{5} \mathrm{O}_{12}$, despite the larger band gap in $\mathrm{Lu}_{3} \mathrm{Al}_{5} \mathrm{O}_{12}$.

In Ref. [200], the effect of $\mathrm{Ga}^{3+}$ doping on the photoluminescence properties of $\mathrm{Y}_{3} \mathrm{Al}_{5-\mathrm{x}} \mathrm{Ga}_{\mathrm{x}} \mathrm{O}_{12}$ :Bi was studied. It was shown that the incorporation of the $\mathrm{Ga}^{3+}$ ions results in a strong reduction of 
the band gap edge (by $1 \mathrm{eV}$ from $\mathrm{Y}_{3} \mathrm{Al}_{5} \mathrm{O}_{12}$ : $\mathrm{Bi}$ to $\mathrm{Y}_{3} \mathrm{Ga}_{5} \mathrm{O}_{12}$ : $\mathrm{Bi}$ ). In [195-199], it was shown that the increasing $\mathrm{Ga}$ content also results in a drastic decrease of the $\mathrm{CB}$ bottom energy in different $\mathrm{Ce}^{3+}$-doped multicomponent garnets. The presence of two- $\mathrm{UV}$ and VIS - emission bands in $\mathrm{Y}_{3} \mathrm{Al}_{5} \mathrm{O}_{12}$ : Bi with the close lowest-energy excitation bands indicates that the triplet RES of $\mathrm{Bi}^{3+}$ should be located close to the bottom of $\mathrm{CB}$ of $\mathrm{Y}_{3} \mathrm{Al}_{5} \mathrm{O}_{12}$ [7]. In this case, the reduction of $\mathrm{E}_{\mathrm{g}}$ and the $\mathrm{CB}$ bottom energy with the increasing Ga content should result in the disappearance of the $\mathrm{UV}$ emission in $\mathrm{Y}_{3} \mathrm{Ga}_{5} \mathrm{O}_{12}: \mathrm{Bi}$. Indeed, no UV emission was observed in [12]. However, according to [13,14,16,17], both in $\mathrm{Y}_{3} \mathrm{Al}_{5} \mathrm{O}_{12}: \mathrm{Bi}$ $\left(\mathrm{E}_{\mathrm{g}} \approx 7.7 \mathrm{eV}[10,154]\right)$ and in $\mathrm{Y}_{3} \mathrm{Ga}_{5} \mathrm{O}_{12}: \mathrm{Bi}\left(\mathrm{E}_{\mathrm{g}} \approx 6.6 \mathrm{eV}\right.$ [10]), the UV emission is much stronger than the VIS emission (compare Figure 12a and b). In [110], the UV/VIS emission intensity ratio is about 2. The reason of such strong difference in the experimental data [12], [13,14], and [110] is not clear.

In $\mathrm{Ce}^{3+}$-doped multicomponent garnets [196], the influence of $\mathrm{Gd}$ on the $\mathrm{E}_{\mathrm{g}}$ value and the position of the lowest-energy $5 \mathrm{~d}_{1}$ excitation band of $\mathrm{Ce}^{3+}$ with respect to $\mathrm{CB}$ was found to be much weaker [194] and dependent on the Ga and Gd content [196,199]. In general, the $5 d_{1}-C B$ energy distance slightly increases with the increasing $\mathrm{Gd}$ content. In case the same dependence is valid for the $\mathrm{Bi}^{3+}$-doped gallates, the luminescence spectra of $\mathrm{Y}_{3} \mathrm{Ga}_{5} \mathrm{O}_{12}$ : $\mathrm{Bi}$ and $\mathrm{Gd}_{3} \mathrm{Ga}_{5} \mathrm{O}_{12}$ : $\mathrm{Bi}$ should be similar (like in [12]). However, according to $[13,14,74,75,110]$, in $\mathrm{Bi}^{3+}$-doped $(\mathrm{Gd}, \mathrm{Y})_{3} \mathrm{Ga}_{5} \mathrm{O}_{12}$ multicomponent garnets, the UV/VIS emission intensity ratio decreases drastically with the increasing Gd content (compare Figure $12 \mathrm{~b}$ and c). The absence of the UV emission in $\mathrm{Gd}_{3} \mathrm{Ga}_{5} \mathrm{O}_{12}: \mathrm{Bi}[12,74,75]$ and the strongly dominating UV emission in $\mathrm{Y}_{3} \mathrm{Ga}_{5} \mathrm{O}_{12}: \mathrm{Bi}[13,14]$ could indicate that the RES of $\mathrm{Bi}^{3+}$ is located inside $\mathrm{CB}$ in $\mathrm{Gd}_{3} \mathrm{Ga}_{5} \mathrm{O}_{12}$ : $\mathrm{Bi}$ and well below the bottom of $\mathrm{CB}$, in $\mathrm{Y}_{3} \mathrm{Ga}_{5} \mathrm{O}_{12}: \mathrm{Bi}$. However, the $\mathrm{E}_{\mathrm{g}}$ values $(\approx 6.6 \mathrm{eV}$ and $\approx 6.4 \mathrm{eV}[10])$ in $\mathrm{Y}_{3} \mathrm{Ga}_{5} \mathrm{O}_{12}: \mathrm{Bi}$ and $\mathrm{Gd}_{3} \mathrm{Ga}_{5} \mathrm{O}_{12}:$ Bi are close.

The data reported above indicate that the UV/VIS emission intensity ratio is not determined only by the band gap energy. Most probably, it depends much more on the probability ratio of the vibronic relaxation in the triplet excited state of $\mathrm{Bi}^{3+}$ center and the $\mathrm{Bi}^{3+}$ ionization followed by the formation of the exciton-like state. In some Gd-based compounds, the UV emission of $\mathrm{Bi}^{3+}$ centers can be absent due to an effective $\mathrm{Bi}^{3+}-\mathrm{Gd}^{3+}$ energy transfer. In addition, in case the VIS emission arises from $\mathrm{ex}^{0}\left\{\mathrm{Bi}^{3+}\right.$ $\left.-\mathrm{Bi}^{3+}\right\}$ or $\mathrm{ex}^{0}\left\{\mathrm{Bi}^{3+}-d\right\}$, its intensity should also depend on the $\mathrm{Bi}^{3+}$ content and on the concentration of defects $(d)$ in the investigated sample.

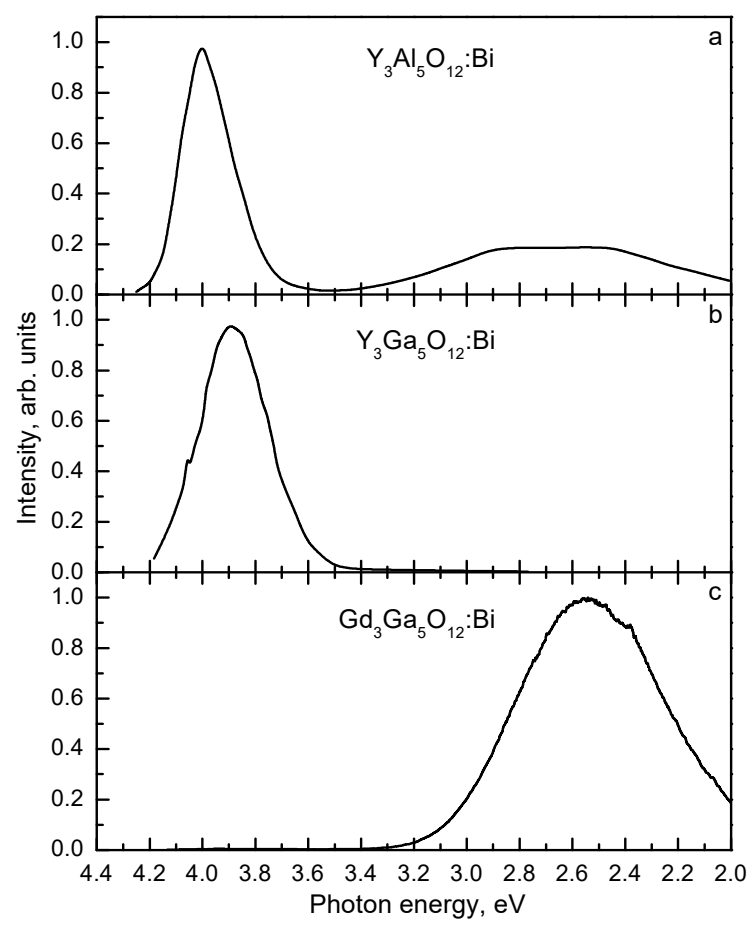

Figure 12. Emission spectra of (a) $\mathrm{Y}_{3} \mathrm{Al}_{5} \mathrm{O}_{12}$ : $\mathrm{Bi}$ [17], (b) $\mathrm{Y}_{3} \mathrm{Ga}_{5} \mathrm{O}_{12}: \mathrm{Bi}$ [13], and (c) $\mathrm{Gd}_{3} \mathrm{Ga}_{5} \mathrm{O}_{12}: \mathrm{Bi}$ [74]. $\mathrm{T}=80 \mathrm{~K}$. Based on the data reported in $[13,17,74]$, presented with the publisher permission. 


\section{On the Luminescence Ascribed in Literature to $\left\{\mathrm{Bi}^{3+}-\mathrm{Bi}^{3+}\right\}$ Dimers and $\mathrm{Bi}^{3+}$ Clusters}

In many papers (see, e.g., [1,10,14,15,19,24,58,64,78,95,97,99,102,104,109,110,112,113,119-121,128, $154,158,159,201,202])$, the lower-energy emission bands of $\mathrm{Bi}^{3+}$-doped compounds were ascribed to the $\left\{\mathrm{Bi}^{3+}-\mathrm{Bi}^{3+}\right\}$ pairs or the clusters of $\mathrm{Bi}^{3+}$ ions. The characteristics of this luminescence are presented in Table 4.

Table 4. Emission peak positions ( $\left.E_{e m}\right)$, full widths at half maxima (FWHM), the Stokes shifts (S), positions of the lowest-energy excitation band $\left(E_{\text {exc }}\right)$, and decay times $\left(\tau_{S C}\right)$ of the slow decay component at LHeT obtained for the luminescence ascribed in literature to dimer $\left\{\mathrm{Bi}^{3+}-\mathrm{Bi}^{3+}\right\}$ centers. The spin-orbit splitting energy (D) and the probabilities of the radiative decay of the metastable $\left(\mathrm{k}_{1}\right)$ and emitting $\left(\mathrm{k}_{2}\right)$ levels of the triplet RES.

\begin{tabular}{|c|c|c|c|c|c|c|c|c|c|}
\hline Compound & $\begin{array}{c}E_{\text {em }} \\
\text { eV }\end{array}$ & $\begin{array}{l}\text { FWHM, } \\
\text { eV }\end{array}$ & $\begin{array}{l}\text { S, } \\
\text { eV }\end{array}$ & $\begin{array}{l}\text { Eexc, } \\
\text { eV }\end{array}$ & $\begin{array}{l}\tau_{\mathrm{SC}} \\
\mathrm{ms}\end{array}$ & $\begin{array}{c}\text { D, } \\
\text { meV }\end{array}$ & $\begin{array}{c}\mathbf{k}_{1} \\
\times 10^{3} \\
\mathbf{s}^{-1}\end{array}$ & $\begin{array}{c}\mathbf{k}_{2} \\
\times 10^{4} \\
\mathrm{~s}^{-1}\end{array}$ & Refs. \\
\hline $\mathrm{Y}_{3} \mathrm{Al}_{5} \mathrm{O}_{12}: \mathrm{Bi}$ & 2.88 & 0.81 & 1.44 & 4.32 & 0.023 & - & - & - & {$[15]$} \\
\hline $\mathrm{Y}_{3} \mathrm{Al}_{5} \mathrm{O}_{12}: \mathrm{Bi}$ & 2.64 & $\approx 1.1$ & 1.88 & 4.52 & - & - & - & - & [19] \\
\hline $\mathrm{Lu}_{3} \mathrm{Al}_{5} \mathrm{O}_{12}: \mathrm{Bi}$ & 2.66 & 0.84 & 1.92 & 4.58 & - & - & - & - & [19] \\
\hline $\mathrm{Y}_{3} \mathrm{Ga}_{5} \mathrm{O}_{12}: \mathrm{Bi}$ & 2.54 & 0.73 & 1.72 & 4.26 & - & - & - & - & [110] \\
\hline $\mathrm{Y}_{3} \mathrm{Ga}_{5} \mathrm{O}_{12}: \mathrm{Bi}$ & 2.64 & - & 1.50 & 4.29 & - & - & - & - & [14] \\
\hline $\mathrm{Gd}_{3} \mathrm{Ga}_{5} \mathrm{O}_{12}: \mathrm{Bi}$ & 2.61 & - & 1.49 & 4.10 & - & - & - & - & {$[14]$} \\
\hline $\mathrm{Lu}_{2} \mathrm{SiO}_{5}: \mathrm{Bi}$ & 2.75 & - & 0.80 & 3.55 & - & - & - & - & [202] \\
\hline $\mathrm{LaBO}_{3}: \mathrm{Bi}$ & 2.69 & 0.54 & 1.84 & 4.53 & 0.11 & 5.7 & 9.2 & 30 & {$[78,95]$} \\
\hline $\mathrm{LaB}_{3} \mathrm{O}_{6}: \mathrm{Bi}$ & 3.17 & 0.77 & 1.60 & 4.77 & - & - & - & - & [104] \\
\hline $\mathrm{La}_{2} \mathrm{O}_{3}: \mathrm{Bi}$ & 2.18 & - & 1.47 & 3.65 & - & - & - & - & [112] \\
\hline YOCl:Bi & 3.00 & 0.66 & 1.87 & 4.87 & 0.11 & 4.9 & 9.2 & 75 & [99] \\
\hline GdOCl:Bi & 2.79 & 0.77 & 2.03 & 4.82 & 0.007 & - & - & - & [99] \\
\hline $\mathrm{YPO}_{4}: \mathrm{Bi}$ & $3.72-3.82$ & 0.95 & $\approx 1.75$ & $5.46-5.56$ & - & - & - & - & {$[1,24,113,128]$} \\
\hline $\mathrm{LuPO}_{4}: \mathrm{Bi}$ & 3.72 & 0.95 & 1.79 & 5.51 & - & - & - & - & {$[24]$} \\
\hline $\mathrm{Sr}_{3} \mathrm{Ga}_{4} \mathrm{O}_{9}: \mathrm{Bi}$ & 2.34 & $\approx 0.40$ & 1.49 & 3.83 & - & - & - & - & [58] \\
\hline $\mathrm{Sr}_{3} \mathrm{Ga}_{4} \mathrm{O}_{9}: \mathrm{Bi}$ & 1.82 & 0.60 & 1.93 & 3.75 & - & - & - & - & [58] \\
\hline $\mathrm{GdAlO}_{3}: 1 \% \mathrm{Bi}$ & 2.58 & 0.82 & 1.69 & 4.27 & - & - & - & - & [109] \\
\hline $\mathrm{GdAlO}_{3}: 5 \% \mathrm{Bi}$ & 2.50 & 0.90 & 1.69 & 4.19 & - & - & - & - & [109] \\
\hline $\mathrm{LiLaP}_{4} \mathrm{O}_{12}: \mathrm{Bi}$ & 2.78 & 0.63 & 2.17 & 4.95 & - & - & - & - & [102] \\
\hline $\mathrm{La}_{2} \mathrm{Zr}_{2} \mathrm{O}_{7}: \mathrm{Bi}$ & 2.41 & $\approx 0.95$ & 1.86 & 4.27 & - & - & - & - & [159] \\
\hline $\mathrm{Y}_{2} \mathrm{Sn}_{2} \mathrm{O}_{7}: \mathrm{Bi}$ & 2.41 & 0.67 & 1.74 & 4.35 & - & - & - & - & [119] \\
\hline$(\mathrm{Y}, \mathrm{Gd})_{2} \mathrm{O}_{2} \mathrm{SO}_{4}: \mathrm{Bi}$ & 2.69 & 0.87 & 1.85 & 4.54 & - & - & - & - & [121] \\
\hline $\mathrm{Li}_{6}(\mathrm{Y}, \mathrm{Gd})\left(\mathrm{BO}_{3}\right)_{3}: \mathrm{Bi}$ & 2.30 & - & 2.05 & 4.35 & - & - & - & - & [121] \\
\hline $\mathrm{Cs}_{2} \mathrm{NaYBr}_{6}: \mathrm{Bi}$ & 2.66 & 0.23 & 0.61 & 3.36 & - & - & - & - & [97] \\
\hline $\mathrm{Cs}_{2} \mathrm{NaLaCl}_{6}: \mathrm{Bi}$ & 3.28 & 0.43 & 0.48 & 3.90 & - & - & - & - & [97] \\
\hline
\end{tabular}

The most comprehensive investigation of dimer impurity centers was performed in $\mathrm{ns}^{2}$-ion-doped alkali halides (see, e.g., [203-207] and references therein). Most of the studies were devoted to the dimer $\mathrm{Tl}^{+}$centers. $\mathrm{As} \mathrm{Tl}^{+}$and $\mathrm{Bi}^{3+}$ ions have the same electronic configuration, the characteristics of the $\left\{\mathrm{Bi}^{3+}-\mathrm{Bi}^{3+}\right\}$ dimers in different compounds are expected to be similar to those of the $\mathrm{Tl}^{+}$dimers in alkali halides. Let us consider the latter centers in more detail. 


\subsection{Ultraviolet Luminescence}

The dimer impurity centers in alkali halides were found to appear only in highly doped crystals, and their concentration was usually much smaller as compared with the concentration of single impurity centers. The absorption coefficient in the single center absorption band shows a linear dependence on the impurity content. In the dimer-related absorption bands, the absorption coefficient quadratically increases with the increasing impurity concentration. However, for the luminescence intensity, the same concentration dependence can be obtained only under excitation in the absorption spectrum region, where the optical density (OD) does not exceed 0.2 , since only at $\mathrm{OD}<0.2$, a linear dependence holds between the number of the absorbed and radiated quanta (see, e.g., [204] and references therein). Therefore, at $\mathrm{OD}<0.2$, the linear concentration dependence should be observed for the luminescence intensity of single impurity centers and quadratic, for the impurity dimers. At higher optical density (e.g., $\mathrm{OD} \approx 0.5-1.0$ ), the luminescence intensity dependence on the impurity concentration becomes sublinear for single impurity centers and superlinear for dimers. When OD $>2$, the luminescence intensity becomes practically independent of the impurity concentration or even decreases due to the reabsorption, concentration quenching, or energy transfer processes.

The Stokes shift an FWHM of the dimer-related emission bands in alkali halides were found to be close or even smaller as compared with emission bands of the corresponding single centers [204]. The low-temperature luminescence decay kinetics was also found to be similar in the single and dimer $\mathrm{Tl}^{+}$centers [206].

Two types of dimer $\mathrm{Tl}^{+}$centers were detected in alkali halides, the centers of the $\mathrm{D}_{2 \mathrm{~h}}$ symmetry and the centers of the $\mathrm{D}_{4 \mathrm{~h}}$ symmetry (see, e.g., [203-207]). In some systems, the centers of both types coexist (see, e.g., [205]). In the case of the $\mathrm{D}_{2 \mathrm{~h}}$-type centers, two close $\mathrm{Tl}^{+}$ions can strongly perturb each other and can be considered as a quasimolecule $\left(\mathrm{Tl}^{+}\right)_{2}$ consisting of two $\mathrm{Tl}^{+}$ions. The electron states of the quasimolecule can be considered as molecular orbitals constructed from the electron states of the two $\mathrm{Tl}^{+}$ions. In the case of the $\mathrm{D}_{4 \mathrm{~h}}$-type centers, two $\mathrm{Tl}^{+}$ions are separated by an anion (see, e.g., [206]). Such a $\left\{\mathrm{Tl}^{+}\right.$- anion $\left.-\mathrm{Tl}^{+}\right\}$dimer center can be considered as a single $\mathrm{Tl}^{+}$ion perturbed by the field of the second $\mathrm{Tl}^{+}$ion. The absorption and emission bands of the dimer centers of both types arise from electronic transitions between the energy levels of these centers (for more details, see $[203,204,207]$ and references therein).

According to $[7,65,77,158]$, the $\mathrm{Bi}^{3+}$ - $\mathrm{Bi}^{3+}$ distances in the investigated materials are about $3-4 \AA$. Therefore, the same considerations could also be applied in case of dimer $\mathrm{Bi}^{3+}$ centers in more complicated materials. The analysis of literature data allows to suggest that the UV luminescence of such $\left\{\mathrm{Bi}^{3+}-\mathrm{Bi}^{3+}\right\}$ dimer centers was also observed in complex oxides, namely, in $\mathrm{Y}_{3} \mathrm{Al}_{5} \mathrm{O}_{12}: \mathrm{Bi}$ [201] and $\mathrm{Lu}_{2} \mathrm{SiO}_{5}: \mathrm{Bi}[9,21]$.

In [201], the spectra of $\mathrm{Y}_{3} \mathrm{Al}_{5} \mathrm{O}_{12}$ : $\mathrm{Bi}$ with two different $\mathrm{Bi}^{3+}$ concentrations (0.13 and 0.27 at.\%) were compared at room temperature (RT). Under excitation in the region of the lowest-energy $(4.54 \mathrm{eV})$ absorption band of $\mathrm{Bi}^{3+}$, the presence of two types of $\mathrm{Bi}^{3+}$-related centers was revealed from the dependence of the UV emission band position on the excitation energy. The higher energy $(4.045 \mathrm{eV})$ emission band was ascribed to single $\mathrm{Bi}^{3+}$ centers. The $3.995 \mathrm{eV}$ emission band, slightly shifted to lower energies with respect to the former, was ascribed to $\mathrm{Bi}^{3+}$ pairs since it can be better distinguished with the increasing $\mathrm{Bi}^{3+}$ concentration. The decay kinetics is not too different for these UV emissions. It is slower for the $3.995 \mathrm{eV}$ emission as compared to the $4.045 \mathrm{eV}$ emission. The energy transfer between the single and dimer centers was suggested due to the overlap of the emission band of the single $\mathrm{Bi}^{3+}$ centers with the absorption band of dimers. However, no dependence of the UV emission band position on the $\mathrm{Bi}^{3+}$ content (varying from 0.07 to 0.18 at.\%) was noticed in $\mathrm{Lu}_{3} \mathrm{Al}_{5} \mathrm{O}_{12}$ : $\mathrm{Bi}$ [19].

In [21], two UV emission bands located at $3.45 \mathrm{eV}$ and $3.30 \mathrm{eV}$ and having similar characteristics (Table 5) were observed in $\mathrm{Lu}_{2} \mathrm{SiO}_{5}: \mathrm{Bi}$ with a large $\mathrm{Bi}$ content (2.24 at.\%). The steady-state emission spectrum of $\mathrm{Lu}_{2} \mathrm{SiO}_{5}: \mathrm{Bi}$ is presented in Figure 13a, however, the presence of two emission bands becomes evident in the time-resolved emission spectra shown in Figure 13b. Comparison of the shapes of their excitation spectra (Figure 14) indicates that the center with the $3.30 \mathrm{eV}$ emission competes 
with the dominating $3.45 \mathrm{eV}$ emission center in the excitation light absorption process. The excitation spectrum of the $3.30 \mathrm{eV}$ emission is shifted to lower energies with respect to that of the $3.45 \mathrm{eV}$ emission and distorted due to a strong absorption arising from the main $\mathrm{Bi}^{3+}$ centers. Such behavior is characteristic for the dimer centers of the $\mathrm{D}_{4 \mathrm{~h}}$ symmetry in alkali halides (see, e.g., [204-206]). The decay kinetics of both these emissions is alike (Figure 15). From the temperature dependence of the decay times, the parameters of the corresponding RES were calculated and found to be similar (see Table 5).

Table 5. Characteristics of two UV emission bands of $\mathrm{Lu}_{2} \mathrm{SiO}_{5}: 2.24$ at.\% Bi at $4.2 \mathrm{~K}$.

\begin{tabular}{ccccccccc}
\hline $\begin{array}{c}\mathbf{E}_{\mathbf{e m}}, \\
\mathbf{e V}\end{array}$ & $\begin{array}{c}\text { FWHM, } \\
\mathbf{e V}\end{array}$ & $\begin{array}{c}\mathbf{S}, \\
\mathbf{e V}\end{array}$ & $\begin{array}{c}\mathrm{E}_{\mathbf{e x c},} \\
\mathbf{e V}\end{array}$ & $\begin{array}{c}\boldsymbol{\tau}_{\mathrm{SC}}, \\
\mathbf{\mu s}\end{array}$ & $\begin{array}{c}\mathbf{D}, \\
\mathbf{m e V}\end{array}$ & $\begin{array}{c}\mathbf{k}_{\mathbf{1}} \\
\times \mathbf{1 0}^{\mathbf{3}}, \mathbf{s}^{\mathbf{- 1}}\end{array}$ & $\begin{array}{c}\mathbf{k}_{\mathbf{2}} \\
\times \mathbf{1 0}^{\mathbf{8}}, \mathbf{s}^{\mathbf{- 1}}\end{array}$ & $\begin{array}{c}\mathbf{K} \\
\times \mathbf{1 0}^{\mathbf{8}}, \mathbf{s}^{\mathbf{- 1}}\end{array}$ \\
\hline 3.45 & 0.28 & 0.75 & 4.20 & 292 & 65 & 3.51 & 1.0 & 1.0 \\
\hline 3.30 & 0.40 & 0.80 & 4.10 & 298 & 55 & 3.36 & 0.6 & 0.5 \\
\hline
\end{tabular}

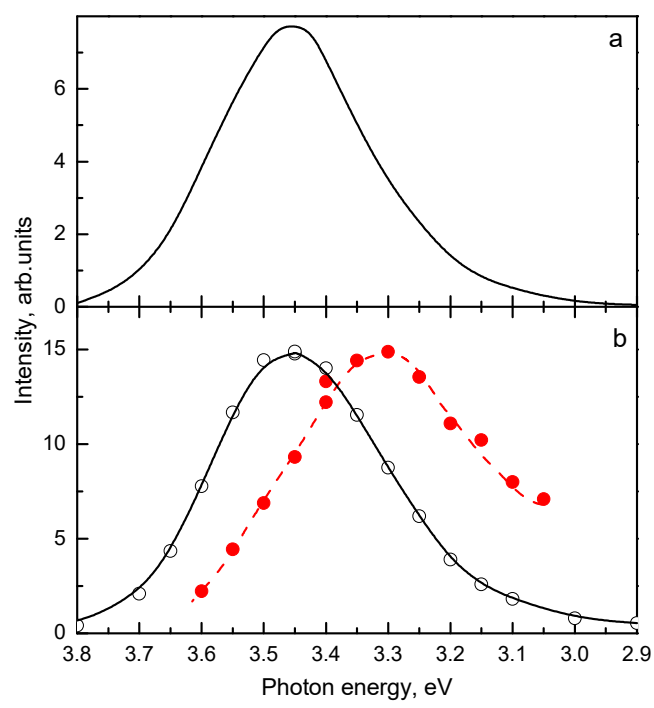

Figure 13. (a) The steady-state UV emission spectrum of $\mathrm{Lu}_{2} \mathrm{SiO}_{5}: \mathrm{Bi}$ measured in [21] under $\mathrm{E}_{\text {exc }}=$ $4.15 \mathrm{eV}$ and $(\mathrm{b})$ time-resolved $(\mathrm{t}=300 \mu \mathrm{s})$ emission spectra measured under $\mathrm{E}_{\text {exc }}=4.15 \mathrm{eV}$ (empty circles) and $\mathrm{E}_{\mathrm{exc}}=3.8 \mathrm{eV}$ (solid circles). $\mathrm{T}=4.2 \mathrm{~K}$. Based on the data reported in [21], presented with the publisher permission.

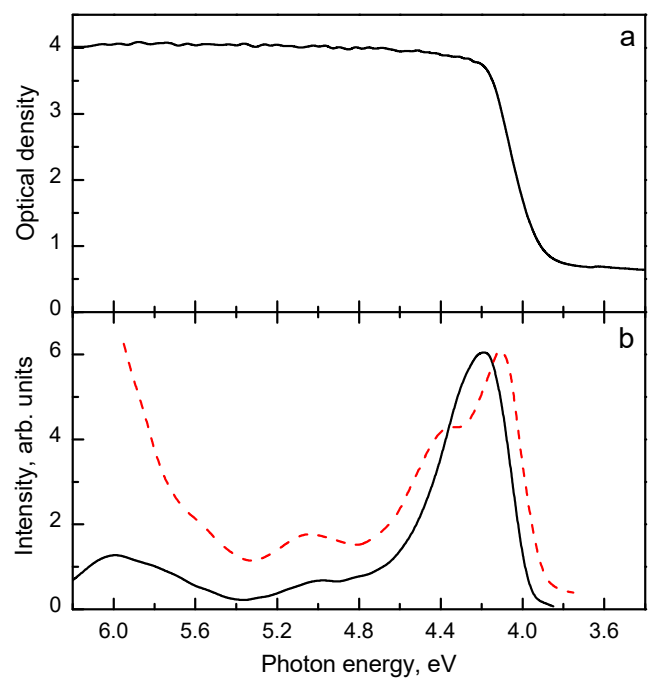

Figure 14. (a) Absorption spectrum of $\mathrm{Lu}_{2} \mathrm{SiO}_{5}: \mathrm{Bi}$ at $295 \mathrm{~K}$. (b) Normalized excitation spectra measured at $4.2 \mathrm{~K}$ for $\mathrm{E}_{\mathrm{em}}=3.5 \mathrm{eV}$ (solid line) and $\mathrm{E}_{\mathrm{em}}=3.15 \mathrm{eV}$ (dashed line). Based on the data reported in [21], presented with the publisher permission. 


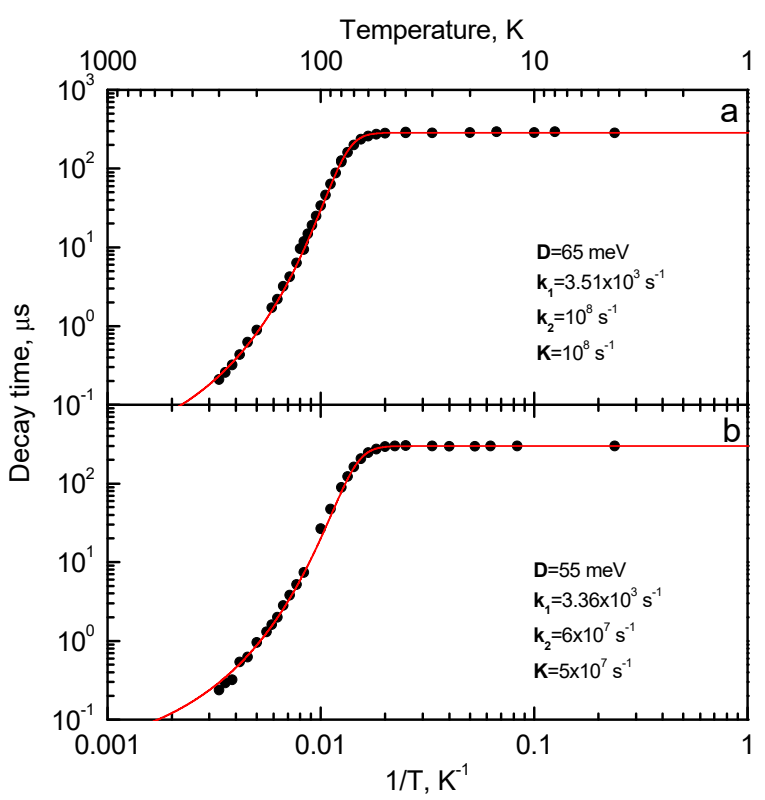

Figure 15. Temperature dependences of the decay times of the (a) $3.5 \mathrm{eV}$ and (b) $3.3 \mathrm{eV}$ emissions of $\mathrm{Lu}_{2} \mathrm{SiO}_{5}: \mathrm{Bi}$ measured under $\mathrm{E}_{\mathrm{exc}}=4.15 \mathrm{eV}$ and $\mathrm{E}_{\mathrm{exc}}=3.9 \mathrm{eV}$, respectively. Solid lines are the best fits to experimental data of the two excited-state level models shown in Figure 6 (for details, see the text). The parameters of the fit are reported in the figures. Based on the data reported in [21], presented with the publisher's permission.

The obtained data indicate that both the strong $3.45 \mathrm{eV}$ emission and weak $3.30 \mathrm{eV}$ emission arise from the triplet RES of $\mathrm{Bi}^{3+}$-related centers. It is not excluded that the $3.30 \mathrm{eV}$ emission of $\mathrm{Lu}_{2} \mathrm{SiO}_{5}: \mathrm{Bi}$ arises from dimer $\left\{\mathrm{Bi}^{3+}-\mathrm{Bi}^{3+}\right\}$ centers. It should be noted that in [21], the $3.30 \mathrm{eV}$ emission was ascribed to the $\mathrm{Bi}^{3+}$ ions located in the Lu2 lattice sites (Bi2 centers). If so, the Bi2 centers should exist in $\mathrm{Y}_{2} \mathrm{SiO}_{5}$ :Bi as well. However, no related emission was observed in [20] in the $\mathrm{Y}_{2} \mathrm{SiO}_{5}$ :Bi sample with much smaller $\mathrm{Bi}^{3+}$ content $(0.04$ at. $\% \mathrm{Bi}$ ). This fact could confirm our suggestion on the dimer origin of the $3.30 \mathrm{eV}$ emission in $\mathrm{Lu}_{2} \mathrm{SiO}_{5}: \mathrm{Bi}$. Unfortunately, the concentration dependences of the luminescence intensity were not studied in $[20,21]$ due to the absence of samples with various $\mathrm{Bi}^{3+}$ content.

The search for the UV emission of $\left\{\mathrm{Bi}^{3+}-\mathrm{Bi}^{3+}\right\}$ dimers should be carried out by the comparison of the emission spectra and decay kinetics under excitation in different regions of the lowest-energy (A) absorption band, as well as by the detailed study of the concentration dependence of the UV emission intensity.

\subsection{Visible Luminescence}

As mentioned above, in many works devoted to the investigation of the luminescence characteristics of the $\mathrm{Bi}^{3+}$-doped compounds, the lower-energy broad emission bands, usually located in the visible spectral range and having the characteristics (see Table 4) which are strongly different from the characteristics of the UV emission of the single $\mathrm{Bi}^{3+}$ centers (Table 1), were ascribed to the $\left\{\mathrm{Bi}^{3+}-\mathrm{Bi}^{3+}\right\}$ dimers or $\mathrm{Bi}^{3+}$ clusters (see, e.g., [158] and references therein). This conclusion was often based only on the spectra measured at room temperature, without precise measurements of the $\mathrm{Bi}^{3+}$ concentration dependence of the luminescence intensity. A strong difference in the luminescence characteristics (in particular, the values of $\mathrm{S}, \mathrm{FWHM}$, and $\mathrm{D})$ of the single $\mathrm{Bi}^{3+}$ centers and the centers ascribed to $\left\{\mathrm{Bi}^{3+}\right.$ $\left.\mathrm{Bi}^{3+}\right\}$ dimers was not explained. For example, in $[58,97,99,104,110,112,121]$, the lower-energy emission of $\mathrm{Y}_{3} \mathrm{Ga}_{5} \mathrm{O}_{12}: \mathrm{Bi}[110],(\mathrm{Y}, \mathrm{Gd})_{2} \mathrm{O}_{2} \mathrm{SO}_{4}: \mathrm{Bi}$ and $\mathrm{Li}_{6}(\mathrm{Y}, \mathrm{Gd})\left(\mathrm{BO}_{3}\right)_{3}: \mathrm{Bi}$ [121], $\mathrm{LaB}_{3} \mathrm{O}_{6}: \mathrm{Bi}$ [104], $\mathrm{La}_{2} \mathrm{O}_{3}: \mathrm{Bi}$ [112], $\mathrm{Cs}_{2} \mathrm{NaYBr}_{6}: \mathrm{Bi}$ and $\mathrm{Cs}_{2} \mathrm{NaLaCl}_{6}: \mathrm{Bi}$ [97], YOCl:Bi and $\mathrm{GdOCl}: \mathrm{Bi}$ [99], $\mathrm{Sr}_{3} \mathrm{Ga}_{4} \mathrm{O}_{9}: \mathrm{Bi}$ [58] was attributed to $\mathrm{Bi}^{3+}$ pairs or clusters based solely on their large FWHM and S.

In $[14,15,19,24,58,78,95,102,109,113,119,202]$, the lower-energy emission band of $\mathrm{Y}_{3} \mathrm{Ga}_{5} \mathrm{O}_{12}: \mathrm{Bi}$ and $\mathrm{Gd}_{3} \mathrm{Ga}_{5} \mathrm{O}_{12}: \mathrm{Bi}[14], \mathrm{Y}_{2} \mathrm{Sn}_{2} \mathrm{O}_{7}: \mathrm{Bi}$ [119], $\mathrm{LaBO}_{3}: \mathrm{Bi}[78,95], \mathrm{Y}_{3} \mathrm{Al}_{5} \mathrm{O}_{12}: \mathrm{Bi}$ and $\mathrm{LuAl}_{5} \mathrm{O}_{12}: \mathrm{Bi}[15,19]$, 
$\mathrm{YPO}_{4}: \mathrm{Bi}$ [24,113], $\mathrm{LuPO}_{4}: \mathrm{Bi}$ [24], $\mathrm{GdAlO}_{3}: \mathrm{Bi}$ [109], $\mathrm{LiLaP}_{4} \mathrm{O}_{12}: \mathrm{Bi}$ [102], and $\mathrm{Lu}_{2} \mathrm{SiO}_{5}: \mathrm{Bi}$ [202] was attributed to $\mathrm{Bi}^{3+}$ pairs or clusters due to an increase of the VIS/UV emission intensity ratio with the increasing $\mathrm{Bi}^{3+}$ content. However, this effect cannot be used for the confirmation of the dimer-related origin of the VIS emission.

Indeed, the number of single $\mathrm{Bi}^{3+}$ centers responsible for the UV emission has to increase linearly with the increasing $\mathrm{Bi}^{3+}$ concentration. However, the emission spectra are usually measured under excitation in the absorption band maximum where OD is too large. In this case, the emission intensity can be practically independent of the impurity concentration due to the saturation effect (see, e.g., $[14,19,119])$. In many works even the decrease of the UV emission intensity of single $\mathrm{Bi}^{3+}$ centers with the increasing $\mathrm{Bi}^{3+}$ content was observed (see, e.g., $\left.[15,24,113]\right)$. This effect can be caused by various processes, such as increasing reabsorption or concentration quenching of the UV emission (in case of the small Stokes shift where the emission and absorption bands of single $\mathrm{Bi}^{3+}$ centers are overlapped), energy transfer to some other centers (e.g., to $\mathrm{Gd}^{3+}$ ions in $\mathrm{Gd}$-containing materials $[15,75,76,78,104,111,208]$ or to other $\mathrm{Bi}^{3+}$ - related centers, see, e.g., $\left.[97,104,201]\right)$. For example, the absence of the $\mathrm{Bi}^{3+}$ emission in $\mathrm{GdP}_{3} \mathrm{O}_{9}: \mathrm{Bi}[111]$ and $\mathrm{GdB}_{3} \mathrm{O}_{6}: \mathrm{Bi}[104,208]$ was explained just by an effective $\mathrm{Bi}^{3+} \rightarrow \mathrm{Gd}^{3+}$ energy transfer as the $\mathrm{Bi}^{3+}$ emission band overlaps the $\mathrm{Gd}^{3+}{ }^{8} \mathrm{~S} \rightarrow{ }^{6} \mathrm{P}$ absorption lines. In $\mathrm{LaB}_{3} \mathrm{O}_{6}: \mathrm{Bi}$, the $\mathrm{Bi}^{3+}$ emission is very weak due to the energy transfer between the centers responsible for the UV and VIS emissions [104]. The concentration quenching of the UV emission was reported, e.g., in [111] for $\mathrm{ScP}_{3} \mathrm{O}_{9}: \mathrm{Bi}$ and in [78] for $\mathrm{LnBO}_{3}: \mathrm{Bi}(\mathrm{Ln}=\mathrm{Sc}, \mathrm{Lu})$. It takes place in case the $\mathrm{Bi}^{3+}$ concentration exceeds the critical value needed for energy migration among the $\mathrm{Bi}^{3+}$ ions, due to that, the excitation energy can be transferred to quenching centers.

Unlike for the UV emission, for the VIS emission, the probability of its reabsorption, concentration quenching, and energy transfer is negligible due to its large Stokes shift and the absence of absorption bands in visible spectral region. Therefore, the VIS emission intensity always increases with the increasing $\mathrm{Bi}^{3+}$ content, which could explain the increasing VIS/UV ratio. However, the sublinear dependence of the emission intensity on the $\mathrm{Bi}^{3+}$ concentration is usually reported (see, e.g., $[15,24,58$, $113,119])$. For example, as the $\mathrm{Bi}^{3+}$ content in $\mathrm{YPO}_{4}$ :Bi increases 40 times, the lower-energy $(3.81 \mathrm{eV})$ emission intensity increases only about 4 times [113]. In our opinion, such concentration dependence does not allow to conclude that the $3.81 \mathrm{eV}$ emission arises from the $\left\{\mathrm{Bi}^{3+}-\mathrm{Bi}^{3+}\right\}$ pairs.

The lower-energy broad emission bands of $\mathrm{Bi}^{3+}$-doped compounds were considered as arising from $\mathrm{Bi}^{3+}$ pairs also in $[10,103,113,154,158,159]$. A new mechanism for the $\left\{\mathrm{Bi}^{3+}-\mathrm{Bi}^{3+}\right\}$ emission was proposed in [103] and further investigated in [10,154,159]. It was suggested that in a pair of neighboring $\mathrm{Bi}^{3+}$ ions, an electron transfer from the excited state of one $\mathrm{Bi}^{3+}$ ion to a neighboring $\mathrm{Bi}^{3+}$ ion is possible. The electronic transitions within $\mathrm{Bi}^{3+}$ pairs were associated to an intervalence charge transfer (IVCT) of the type $\mathrm{Bi}^{3+}\left(6 \mathrm{~s}^{2}\right), \mathrm{Bi}^{3+}\left(6 \mathrm{~s}^{2}\right) \rightarrow \mathrm{Bi}^{4+}\left(6 \mathrm{~s}^{1}\right) \mathrm{Bi}^{2+}\left(6 \mathrm{~s}^{2} \mathrm{p}^{1}\right)$. The IVCT is only possible when the ground state of $\mathrm{Bi}^{2+}$ is located below the first excited state of $\mathrm{Bi}^{3+}$. In [103] was shown that this is the case of $\mathrm{Li}_{2} \mathrm{BaP}_{2} \mathrm{O}_{7}: \mathrm{Bi}$. In [159], the vacuum referred binding energies of the electron in the ground state of $\mathrm{Bi}^{2+}$ and in the lowest-energy excited state of $\mathrm{Bi}^{3+}$ were compared for 15 compounds. It was found that the ground level of $\mathrm{Bi}^{2+}$ is always located below the ${ }^{3} \mathrm{P}_{1}$ level of $\mathrm{Bi}^{3+}$. This means that the excitation of one $\mathrm{Bi}^{3+}$ ion in the $\left\{\mathrm{Bi}^{3+}-\mathrm{Bi}^{3+}\right\}$ pair can always result in the electron transfer toward another $\mathrm{Bi}^{3+}$ ion of the pair and formation of the $\left\{\mathrm{Bi}^{4+}-\mathrm{Bi}^{2+}\right\}$ pair. The electron back transfer in the $\left\{\mathrm{Bi}^{4+}-\mathrm{Bi}^{2+}\right\}$ pair was suggested to result in the appearance of the initial $\left\{\mathrm{Bi}^{3+}-\mathrm{Bi}^{3+}\right\}$ pair in the ground state. It was concluded that this process can be radiative resulting in the broad emission band in the visible region, which is the case, e.g., of $\mathrm{LaBO}_{3}$ [78], $\mathrm{La}_{2} \mathrm{O}_{3}$ [112], and $\mathrm{YOCl}$ [99]. In $\mathrm{Li}_{2} \mathrm{BaP}_{2} \mathrm{O}_{7}: \mathrm{Bi}$, this process was assumed to be nonradiative and, as a result, the emission ascribed to dimers was absent [103]. Since also no emission of single $\mathrm{Bi}^{3+}$ centers was observed in this compound even at the lowest temperatures, it was concluded in $[103,159]$ that IVCT between two neighboring $\mathrm{Bi}^{3+}$ ions can be responsible for the quenching of the triplet luminescence of single $\mathrm{Bi}^{3+}$ centers as well.

However, the absence of the UV luminescence of single $\mathrm{Bi}^{3+}$ centers in $\mathrm{Li}_{2} \mathrm{BaP}_{2} \mathrm{O}_{7}$ : $\mathrm{Bi}$ (as well as in many other $\mathrm{Bi}^{3+}$-doped compounds, see, e.g., $\left.[12,58,72-77,99,102,104,109]\right)$ is most probably caused by 
the location of the lowest-energy relaxed excited level of $\mathrm{Bi}^{3+}$ inside CB. The same can also be true for the VIS emission ascribed in literature to $\mathrm{Bi}^{3+}$ dimers as well as for any other emission. In our opinion, the luminescence quenching in $\mathrm{Bi}^{3+}$-doped compounds considered in $[103,159]$ can be caused by the location of the corresponding relaxed excited states inside the conduction band.

It should also be noted that in the $\mathrm{Bi}^{3+}-\mathrm{Bi}^{3+}$ IVCT model, the perturbation of energy levels of one $\mathrm{Bi}^{3+}$ ion by another closely located $\mathrm{Bi}^{3+}$ ion as well as the possibility of the molecular bond formation between the two close $\mathrm{Bi}^{3+}$ ions were not taken into account. Under the lowest-energy excitation, the ${ }^{1} \mathrm{~S}_{0} \rightarrow{ }^{3} \mathrm{P}_{1}$ transitions of the single $\mathrm{Bi}^{3+}$ ion were considered despite the presence of a closely located second $\mathrm{Bi}^{3+}$ ion. However, as the perturbation of a $\mathrm{Bi}^{3+}$ ion by another $\mathrm{Bi}^{3+}$ ion in the $\left\{\mathrm{Bi}^{3+}-\mathrm{Bi}^{3+}\right\}$ pair was considered to be negligible, it is not clear why the electron recombination with almost unperturbed $\mathrm{Bi}^{4+}$ ion results in the broad VIS emission with a large Stokes shift, but not in the slightly perturbed $\mathrm{UV}$ emission of a single $\mathrm{Bi}^{3+}$ center. As the considered IVCT process takes place in the dimer $\left\{\mathrm{Bi}^{3+}\right.$ $\left.\mathrm{Bi}^{3+}\right\}$ center, it is also not clear how it can explain the quenching of the UV emission of another, single $\mathrm{Bi}^{3+}$ center. In some works, the energy distances $\mathrm{D}$ between the emitting and metastable levels of the triplet RES were determined for the centers responsible for both the UV and VIS emissions of the same compound. From comparison of the data in Tables 1 and 4 it is evident that the values of D differ by up to two orders of magnitude. However, it was not explained how the formation of the $\left\{\mathrm{Bi}^{3+}-\mathrm{Bi}^{3+}\right\}$ pair can result in such strong reduction of the spin-orbit splitting energy of the triplet RES of $\mathrm{Bi}^{3+}$ (e.g., from $55 \mathrm{meV}$ to $5.7 \mathrm{meV}$ in $\mathrm{LaBO}_{3}: \mathrm{Bi}$, see [78]).

In [158], an empirical equation was proposed to estimate of the $\mathrm{Bi}^{3+}-\mathrm{Bi}^{3+}$ IVCT energy, similar to that proposed in [7] for the calculation of the MMCT energy. However, for most of the $\mathrm{Bi}^{3+}$-doped compounds considered in [158], the experimental position of the lowest-energy excitation band of the VIS emission ascribed in the literature to $\left\{\mathrm{Bi}^{3+}-\mathrm{Bi}^{3+}\right\}$ centers (see Eexc values in Table 4) markedly differs from the calculated IVCT energy. Only in $\mathrm{LaZr}_{2} \mathrm{O}_{7}$ :Bi (where, however, the VIS emission was ascribed to the impurity trapped exciton [120]), these energies were found to be close $(4.27 \mathrm{eV}[120,159]$ and $4.22 \mathrm{eV}$ [158], respectively).

Thus, in our opinion, the presence of the luminescent $\left\{\mathrm{Bi}^{3+}-\mathrm{Bi}^{3+}\right\}$ pairs or clusters in $\mathrm{Bi}^{3+}$-doped compounds is not confirmed by experimental data. The data of $[21,201]$ allow only to suggest that the lower-energy UV emission bands reported in these papers could arise from the $\left\{\mathrm{Bi}^{3+}-\mathrm{Bi}^{3+}\right\}$ dimers. The broad visible $\mathrm{Bi}^{3+}$-related emission bands with the large Stokes shifts presented in Tables 2 and 4 are all of an exciton-like origin. These bands can arise from the excitons localized around different $\mathrm{Bi}^{3+}$-related centers, including also the $\left\{\mathrm{Bi}^{3+}-\mathrm{Bi}^{3+}\right\}$ dimers, i.e., from $\mathrm{ex}^{0} \mathrm{Bi}^{3+}, \mathrm{ex}^{0}\left\{\mathrm{Bi}^{3+}-\mathrm{Bi}^{3+}\right\}$, $\operatorname{ex}^{0}\left\{\mathrm{Bi}^{3+}-d\right)$.

In our opinion, in case the IVCT between two close $\mathrm{Bi}^{3+}$ ions can really take place, the electron-hole recombination in the optically created $\left\{\mathrm{Bi}^{4+}-\mathrm{Bi}^{2+}\right\}$ pair could result in the formation of an exciton localized around the $\left\{\mathrm{Bi}^{3+}-\mathrm{Bi}^{3+}\right\}$ pair. The radiative decay of $\mathrm{ex}^{0}\left\{\mathrm{Bi}^{3+}-\mathrm{Bi}^{3+}\right\}$ should result in the appearance of the broad emission band with the large Stokes shift characteristic for an exciton-like emission.

The luminescence origin of $\mathrm{Bi}^{3+}$-doped compounds can be confirmed only by the study of the luminescence decay kinetics in a wide temperature range which allows to determine the parameters of the corresponding RES. Only the dependence of the number of luminescence centers on the concentration of $\mathrm{Bi}^{3+}$ in the crystal can indicate, whether the single $\mathrm{Bi}^{3+}$ ions or the $\left\{\mathrm{Bi}^{3+}-\mathrm{Bi}^{3+}\right\}$ pairs are responsible for the investigated emission. As an example, in Figures 16 and 17, the dependences of the luminescence intensity on the $\mathrm{Bi}^{3+}$ concentration inside the investigated samples are presented for the exciton-like VIS emission of $\mathrm{Gd}_{3} \mathrm{Ga}_{5} \mathrm{O}_{12}$ : $\mathrm{Bi}[74,75]$ and the $\mathrm{Bi}^{3+}$-doped vanadates [76] and niobates [77]. These dependences were measured under excitation in the absorption band region where the optical density is surely small $(\mathrm{OD}<0.5)$ (see Figure 16a). The superlinear dependence of the emission intensity on the $\mathrm{Bi}^{3+}$ content was found only for the VIS emission of the $\mathrm{Bi}^{3+}$-doped niobates [77] (Figure 17b). This allowed us to ascribe this band to the exciton localized around a dimer $\left\{\mathrm{Bi}^{3+}-\mathrm{Bi}^{3+}\right\}$ center: ex $\left\{\mathrm{Bi}^{3+}-\mathrm{Bi}^{3+}\right\}$. In other cases, the dependence was linear or sublinear (Figures $16 \mathrm{~b}$ 
and 17a). This indicates that the lower-energy exciton-like emission is connected with a single $\mathrm{Bi}^{3+}$ ion associated with a lattice defect $\left(\mathrm{ex}^{0}\left\{\mathrm{Bi}^{3+}-d\right\}\right)$.
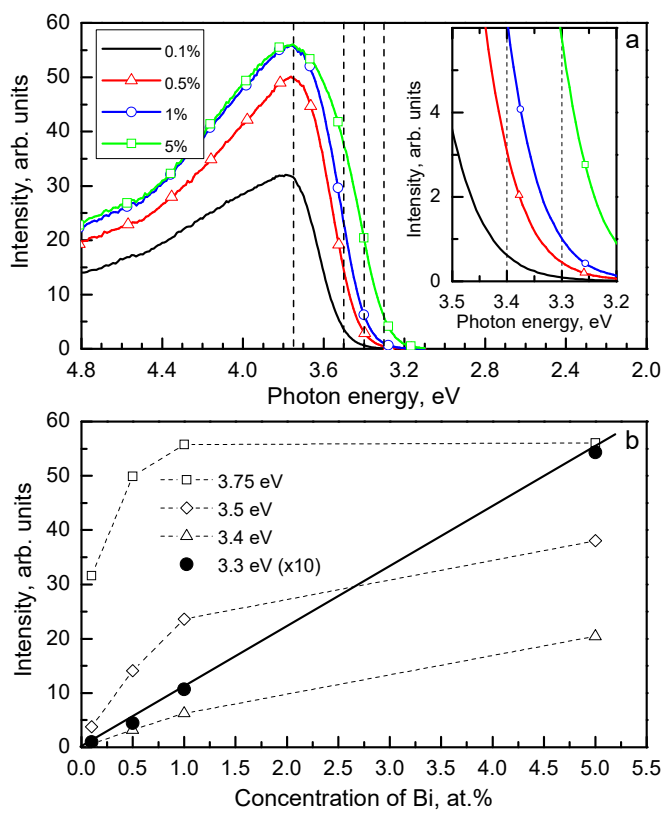

Figure 16. (a) The excitation band of the $\mathrm{Bi}^{3+}$-related $2.19 \mathrm{eV}$ emission measured at the same conditions at $295 \mathrm{~K}$ for the $\mathrm{YVO}_{4}$ :Bi powders with different $\mathrm{Bi}^{3+}$ contents (shown in the legend). (b) The dependences of the $2.19 \mathrm{eV}$ emission intensity, taken from Figure 16a for some selected excitation energies, on the $\mathrm{Bi}^{3+}$ content. See also [76]. Presented with the publisher's permission.

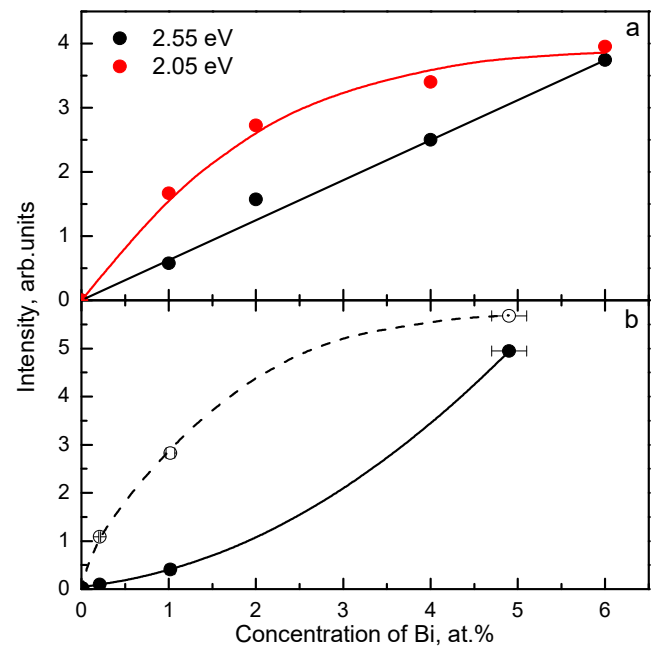

Figure 17. Dependences of the maximum luminescence intensity on the Bi content inside the powder measured at $80 \mathrm{~K}$ (a) for the $2.55 \mathrm{eV}$ and $2.05 \mathrm{eV}$ emission bands of $\mathrm{Gd}_{3} \mathrm{Ga}_{5} \mathrm{O}_{12}$ : $\mathrm{Bi}$ under excitation $E_{\text {exc }}$ $=4.08 \mathrm{eV}$ and $E_{\text {exc }}=3.4 \mathrm{eV}$, respectively and $(\mathbf{b})$ for the $2.41 \mathrm{eV}$ emission of $\mathrm{YNbO}_{4}: \mathrm{Bi}$ under excitation $E_{\text {exc }}=3.6 \mathrm{eV}$ (solid line) and for the $2.53 \mathrm{eV}$ emission of $\mathrm{YNbO}_{4}$ :Bi under excitation in the absorption band maximum $\left(\mathrm{E}_{\mathrm{exc}}=4.09 \mathrm{eV}\right.$, dashed line). Based on the data reported in [75-77]. Presented with the publisher's permission.

It should be noted that the sublinear dependence of luminescence intensity on the impurity concentration, reaching the saturation (for example, similar to that presented in Figure 16b, empty squares), usually obtained under excitation in the absorption band maximum, is often interpreted as the luminescence concentration quenching. For example, the $\mathrm{Bi}^{3+}$-related emission intensity was found to increase with the increasing Bi content only up to $\approx 0.5$ at. $\%$ in $\mathrm{GdNbO}_{4}: \mathrm{Bi}[125,157]$ and up 
to 0.5 at.\% [153], 1 at.\% [101], or 1.5-2 at.\% [125,150] in $\mathrm{YNbO}_{4}:$ Bi. At higher Bi content, it reaches the maximum and then decreases. However, such dependence could appear due to too large optical density in the chosen excitation region. As evident from Figures $16 \mathrm{~b}$ and $17 \mathrm{a}, \mathrm{b}$, no concentration quenching is observed in the considered $\mathrm{Bi}^{3+}$-doped compounds at least up to 6 at. $\%$ of $\mathrm{Bi}^{3+}$.

In many cases, the lowest excitation band of the VIS emission is shifted to lower energies with respect to the lowest excitation band of the UV emission of a $\mathrm{Bi}^{3+}$ center (see, e.g., [14,15,19,24,64,78,93$96,104,109,110,112,119,121,140,141]$ and compare $E_{\text {exc }}$ values in Table 1, Table 2, and Table 4). It is not excluded that in this case the lower-energy part of the excitation band arises from $\left\{\mathrm{Bi}^{3+}-\mathrm{Bi}^{3+}\right\}$ dimers. Under excitation in this $\left\{\mathrm{Bi}^{3+}-\mathrm{Bi}^{3+}\right\}$-related band, the VIS emission of $\mathrm{ex}^{0}\left\{\mathrm{Bi}^{3+}-\mathrm{Bi}^{3+}\right\}$ can appear which is overlapped with the ex ${ }^{0} \mathrm{Bi}^{3+}$ emission. Indeed, in many cases, the VIS emission band is found to be complex (see, e.g., $[9,16-18,21,74,75,77,95,102,128])$. This means that it can consist of emission bands of the excitons localized around different $\mathrm{Bi}^{3+}$-related centers.

The mechanism of the appearance of the visible $\left\{\mathrm{Bi}^{3+}-\mathrm{Bi}^{3+}\right\}$-related exciton-like emission could be the following. Like in the case of a single $\mathrm{Bi}^{3+}$ center (see equation (11)), the lowest-energy RES of a $\left\{\mathrm{Bi}^{3+}-\mathrm{Bi}^{3+}\right\}$ dimer can be located inside $\mathrm{CB}$. Under excitation in the lowest-energy absorption band of the $\left\{\mathrm{Bi}^{3+}-\mathrm{Bi}^{3+}\right\}$ center, the electron from the $\left\{\mathrm{Bi}^{3+}-\mathrm{Bi}^{3+}\right\}$ center can be optically released into $\mathrm{CB}$ and then recombine with the hole remained at the dimer center. The electron-hole recombination results in the formation of $\mathrm{ex}^{0}\left\{\mathrm{Bi}^{3+}-\mathrm{Bi}^{3+}\right\}$ whose radiative decay results in the appearance of the $\left\{\mathrm{Bi}^{3+}\right.$ $\left.\mathrm{Bi}^{3+}\right\}$-related exciton-like emission:

$$
\left\{\mathrm{Bi}^{3+}-\mathrm{Bi}^{3+}\right\}+\mathrm{h} v_{\mathrm{exc}} \rightarrow \mathrm{e}^{-} \mathrm{CB} \ldots\left\{\mathrm{Bi}^{4+}-\mathrm{Bi}^{3+}\right\} \rightarrow \mathrm{ex}^{0}\left\{\mathrm{Bi}^{3+}-\mathrm{Bi}^{3+}\right\} \rightarrow\left\{\mathrm{Bi}^{3+}-\mathrm{Bi}^{3+}\right\}+\mathrm{h} v_{\mathrm{em}}
$$

\section{The $\mathrm{Bi}^{2+}, \mathrm{Bi}^{+}$and $\mathrm{Bi}^{0}$ Emission Centers}

The richness of the $\mathrm{Bi}^{3+}$-based luminescence in various hosts is further enlarged by bismuth emitting centers with the valence lower than $3^{+}$, the research of which started systematically in the 1990s. In 1994, the red emission of Bi-doped $\mathrm{SrB}_{4} \mathrm{O}_{7}$ was explained by Blasse et al. [105] as due to the divalent $\mathrm{Bi}^{2+}$ based on the similarity of luminescence characteristics with isoelectronic $\mathrm{Pb}^{+}$[209] and $\mathrm{Tl}^{0}[210,211]$ centers. In the same year, $\mathrm{Bi}^{2+}$ luminescence was briefly reported in alkali earth sulfates [212], followed by reports dealing with $\mathrm{Bi}^{2+}$ in crystalline hosts of $\mathrm{Me}^{2+} \mathrm{BPO}_{5}(\mathrm{Me}=\mathrm{Ca}$, $\mathrm{Sr}, \mathrm{Ba}$ ) [213], $\mathrm{BaB}_{8} \mathrm{O}_{13}$ [214], $\mathrm{BaSO}_{4}$ [215], $\mathrm{Sr}_{2} \mathrm{P}_{2} \mathrm{O}_{7}$ [216], $\mathrm{Ba}_{2} \mathrm{P}_{2} \mathrm{O}_{7}$ [106], $\mathrm{MeF}_{2}$ ( $\mathrm{Me}=\mathrm{Ca}, \mathrm{Sr}$ ) [217], and $\mathrm{CaAl}_{12} \mathrm{O}_{19}$ [218].

Electron configuration $\left(6 \mathrm{~s}^{2} 6 \mathrm{p}\right)$ of $\mathrm{Bi}^{2+}$ is split by spin-orbit coupling and crystal field into the ${ }^{2} \mathrm{P}_{1 / 2}$ ground state and ${ }^{2} \mathrm{P}_{3 / 2}(1)$ and ${ }^{2} \mathrm{P}_{3 / 2}(2)$ excited states [105]. It gives rise to the emission transition ${ }^{2} \mathrm{P}_{3 / 2}(1) \rightarrow{ }^{2} \mathrm{P}_{1 / 2}$ and two excitation maxima arising from ${ }^{2} \mathrm{P}_{1 / 2} \rightarrow{ }^{2} \mathrm{P}_{3 / 2}(1),{ }^{2} \mathrm{P}_{3 / 2}(2)$ ones, see Figure 18. The third excitation maximum in Figure 18 at shorter wavelength below $300 \mathrm{~nm}$ was ascribed to ${ }^{2} \mathrm{P}_{1 / 2} \rightarrow{ }^{2} \mathrm{~S}_{1 / 2}\left(6 \mathrm{~s}^{2} 7 \mathrm{~s}\right)$ allowed transition $[105,213]$. However, later on, based on theoretical calculations determining the intensity of transitions resulting from the admixture of parity-allowed $6 s \rightarrow 6 p$ and $6 p$ $\rightarrow 6 \mathrm{~d}$ transitions [219], the $300 \mathrm{~nm}$ excitation maximum was attributed rather to a mixed state of $6 \mathrm{~s} 6 \mathrm{p}^{2}$, $6 s^{2} 6 d$, and $6 s^{2} 6 p$ configurations. 


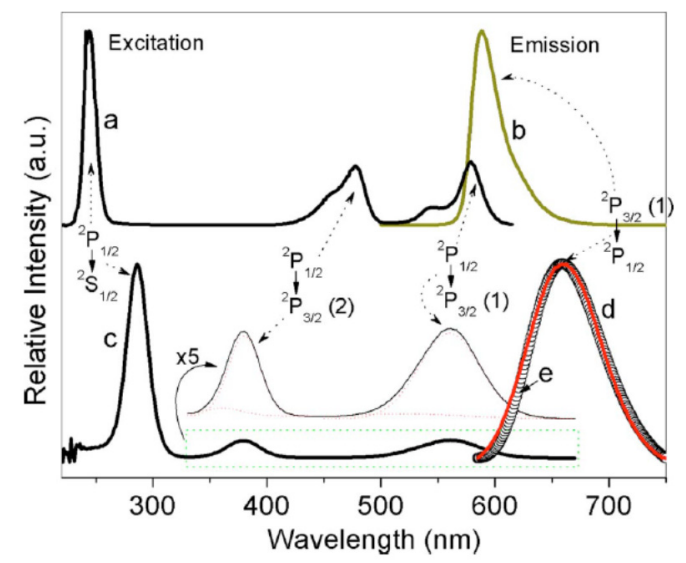

Figure 18. Excitation and emission spectra of $\mathrm{SrB}_{4} \mathrm{O}_{7}: 0.5 \% \mathrm{Bi}(\mathbf{a})$ em $=630 \mathrm{~nm} ;(\mathbf{b})$ ex $=245 \mathrm{~nm}$ and $\mathrm{SrB}_{6} \mathrm{O}_{10}: 0.5 \% \mathrm{Bi}(\mathbf{c})$ em $=690 \mathrm{~nm} ;(\mathbf{d})$ ex $=380 \mathrm{~nm}$. Reprinted from [220] with permission.

Vibrational structure at the high energy side of $\mathrm{Bi}^{2+}$ emission in $\mathrm{SrB}_{4} \mathrm{O}_{7}$ at $4.2 \mathrm{~K}$ observed already in [105] was subjected to theoretical calculations and ascribed to two totally symmetric off-center vibrations of $\mathrm{Bi}^{2+}$ [221]. The emission transition is parity forbidden (p-p), but this selection rule is relaxed by admixture of emitting level with higher lying ${ }^{2} \mathrm{~S}_{1 / 2}$ term and observed decay times are about $10 \mu \mathrm{s}$ in $\mathrm{SrB}_{4} \mathrm{O}_{7}$ host [105]. In [103] the energy levels of $\mathrm{Bi}^{2+}$ were situated within the band gap of $\mathrm{Li}_{2} \mathrm{BaP}_{2} \mathrm{O}_{7}$ and it turns out that the emitting ${ }^{2} \mathrm{P}_{3 / 2}(1)$ state is about $1 \mathrm{eV}$ below the bottom of $\mathrm{CB}$ providing sufficiently high energy barrier against the thermal ionization quenching. Furthermore, high thermal stability of $\mathrm{Bi}^{2+}$ emission in $\mathrm{SrB}_{4} \mathrm{O}_{7}$ (reported in 20-300 K) [222] and $\mathrm{Sr}_{2} \mathrm{P}_{2} \mathrm{O}_{7}$ (reported up to $500 \mathrm{~K}$ ) [223] also points to very limited thermal quenching to the ground state within the temperature range studied.

Given the dominant p-character of the ground and lowest excited levels which are included in the radiative deexcitation of $\mathrm{Bi}^{2+}$, such a center becomes sensitive to the surrounding crystal field defined by the chemical composition and structure of the host. Currently available studies show the spread in the $\mathrm{Bi}^{2+}$ emission peak positions from about $550 \mathrm{~nm}$ in $\mathrm{CaF}_{2}$ [218] to about $716 \mathrm{~nm}$ in $\mathrm{Ba}_{2} \mathrm{P}_{2} \mathrm{O}_{7}$ [106] . In case of stable solid solutions, expected in $(\mathrm{Ca}, \mathrm{Sr}) \mathrm{F}_{2}$ [218], $(\mathrm{Ca}, \mathrm{Sr}) \mathrm{BPO}_{5}$ [213], or $(\mathrm{Ca}, \mathrm{Sr}) \mathrm{SO}_{4}$ [224] the peak position and FWHM could even be finely tuned. In case when $\mathrm{Bi}^{2+}$ shows the emission peak within $580-630 \mathrm{~nm}$ and its thermal stability is sufficient, application of such a phosphor for white LED sources was considered, e.g., in [220,222]. Occurrence of a broad excitation ${ }^{2} \mathrm{P}_{1 / 2} \rightarrow{ }^{2} \mathrm{P}_{3 / 2}(2)$ band within 380-480 nm enables to use the blue or near UV LEDs as excitation sources. Nevertheless, due to partially forbidden character of this transition, its oscillator strength might be too low for practical application. It has been partially improved e.g., by admixing Ca into $\mathrm{SrB}_{4} \mathrm{O}_{7}$ host [222].

The discovery of a new broad ((FWHM $150 \mathrm{~nm}$ ) emission peak at $1150 \mathrm{~nm}$ with the decay time of $650 \mu$ s in the Bi-doped $\mathrm{SiO}_{2}$ glass in 1999 [225] provided a new hot topic widely explored by many laboratories. Since amorphous hosts are out of the scope of this review, the reader is directed to a nice review on this subject published by Sun et al. in 2014 [8]. The charge state of bismuth and composition of related emission center in amorphous matrices were a subject of debate for a decade, briefly reviewed in [106]. In that work, the $\mathrm{Bi}^{0}$ center in $\mathrm{Ba}_{2} \mathrm{P}_{2} \mathrm{O}_{7}$ crystalline powder host was ascribed to a broad emission band in the near infrared region peaking at $1100 \mathrm{~nm}$, having the FWHM of $140 \mathrm{~nm}$, and decay time above $600 \mu \mathrm{s}$, see Figure 19. 


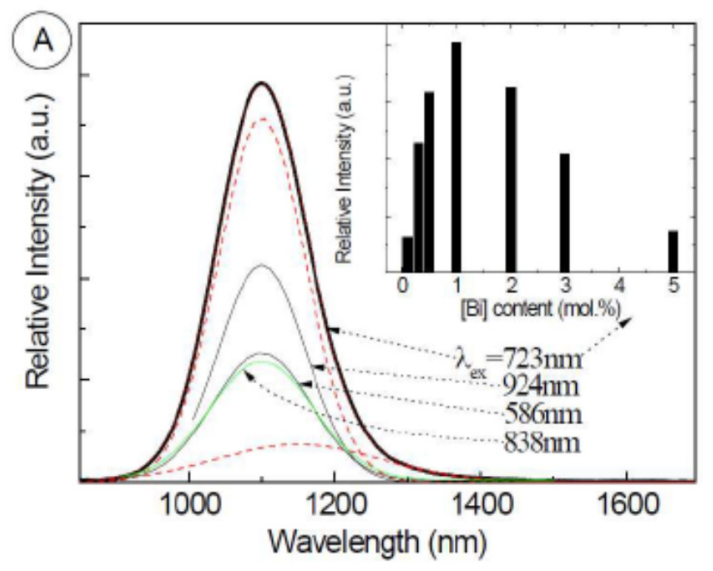

Figure 19. Near infrared emission spectra of $\mathrm{Ba}_{2} \mathrm{P}_{2} \mathrm{O}_{7}: \mathrm{Bi}$ excited at $586 \mathrm{~nm}, 723 \mathrm{~nm}$ (dotted lines: Gaussian peak fits), $838 \mathrm{~nm}$, and $924 \mathrm{~nm}$, respectively, and dependence of NIR emission intensity on nominal bismuth concentration (inset). Reprinted from [106] with permission.

This emission center can be formed and removed reversibly by annealing the sample at $1100{ }^{\circ} \mathrm{C}$ in the $\mathrm{CO}$ atmosphere or air, respectively. Its counter-appearance with the $\mathrm{Bi}^{2+}$ center in such annealing cycles proves bismuth with a valence lower than $2^{+}$to be a responsible center. Based on analyses of the literature data and available lattice sites it has been attributed to radiative transition between to ${ }^{2} \mathrm{D}_{3 / 2}$ $\rightarrow{ }^{4} \mathrm{~S}_{3 / 2}$ levels of $\mathrm{Bi}^{0}$. In continuation of the search for such near infrared luminescence bismuth-based centers the sintered ceramic of $\mathrm{Ba}_{2} \mathrm{~B}_{5} \mathrm{O}_{9} \mathrm{Cl}$ : Bi was prepared and treated under air or $95 \% \mathrm{~N}_{2} / 5 \% \mathrm{H}_{2}$ atmospheres at $850^{\circ} \mathrm{C}$ [107]. It follows from the set of excitation and emission spectra collected that there are at least two emission centers in the bismuth doped compound, which correspond to the emissions at $1030 \mathrm{~nm}$ and $1061 \mathrm{~nm}$. Two different emission centers are due to the substitution of bismuth for $\mathrm{Ba}$ in two different sites, $\mathrm{Ba}(2)$ and $\mathrm{Ba}(1)$ in the $\mathrm{Ba}_{2} \mathrm{~B}_{5} \mathrm{O}_{9} \mathrm{Cl}$ structure. The presence of two centers is also reflected in the decay curves of the emissions at $1030 \mathrm{~nm}$ and $1061 \mathrm{~nm}$ with the decay times of $30.2 \mu$ s and $35.9 \mu$ s, respectively, as illustrated in Figure 20.

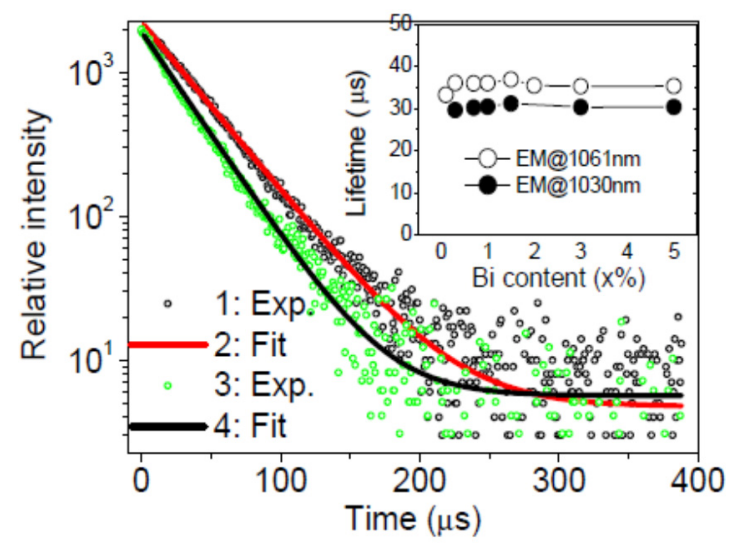

Figure 20. Decay and fit (with simple exponential decay equation) curves of $\mathrm{Ba}_{2(1-x)} \mathrm{B}_{5} \mathrm{O}_{9} \mathrm{Cl}: 2 \mathrm{x} \% \mathrm{Bi}$ $(x=0.7)$ : (1) and (2) for the case of the emission at $1061 \mathrm{~nm}$ upon $478 \mathrm{~nm}$ excitation, and (3) and (4) for the emission at $1030 \mathrm{~nm}$ upon the excitation of $298 \mathrm{~nm}$. Inset shows the dependence of lifetime on the bismuth content $\mathrm{x} \%$. Reprinted from [107] with permission.

When treating $\mathrm{Ba}_{2} \mathrm{~B}_{5} \mathrm{O}_{9} \mathrm{Cl}: \mathrm{Bi}$ alternatively in air and $\mathrm{N}_{2} / \mathrm{H}_{2}$ atmosphere, the above described near infrared $(1030+1061 \mathrm{~nm})$ and red $650 \mathrm{~nm}$ emission centers, the latter being $\mathrm{Bi}^{2+}$, can be removed and restored reversibly. With prolongation of treatment in $\mathrm{N}_{2} / \mathrm{H}_{2}$ the near infrared emission increases monotonically at the expense of that of $650 \mathrm{~nm}$. With the same reasoning it proves bismuth with the valence lower than $2^{+}$to be a center responsible for the infrared emission. By analysis of its excitation 
spectra peak positions it turns out that they cannot be ascribed to $\mathrm{Bi}^{+}$[226]. Therefore, the most probable assignment becomes again $\mathrm{Bi}^{0}$ despite the decay time more than one order of magnitude shorter in the near infrared emission of $\mathrm{Ba}_{2} \mathrm{~B}_{5} \mathrm{O}_{9} \mathrm{Cl}: \mathrm{Bi}$ compared to the above described $\mathrm{Ba}_{2} \mathrm{P}_{2} \mathrm{O}_{7}: \mathrm{Bi}$. Shorter decay time is explained by the enhanced electron-phonon interaction which promotes admixing of ${ }^{4} \mathrm{~S}_{3 / 2}$ with higher ${ }^{4} \mathrm{P},{ }^{2} \mathrm{P}$, or ${ }^{2} \mathrm{D}$ energy states. Consequently, it decreases the forbidden character of radiative transition ${ }^{2} \mathrm{D}_{3 / 2} \rightarrow{ }^{4} \mathrm{~S}_{3 / 2}$ of $\mathrm{Bi}^{0}$ center.

Interestingly, the emission picture in $\mathrm{Ba}_{2} \mathrm{~B}_{5} \mathrm{O}_{9} \mathrm{Cl}$ : $\mathrm{Bi}$ becomes even richer, if the changes in emission pattern are monitored more systematically during the annealing cycle [227]. As the annealing time increases from $0.5 \mathrm{~h}$ to $2.5 \mathrm{~h}$, the $\mathrm{Bi}^{0}$ luminescence at $1055 \mathrm{~nm}$ gradually becomes more intense at the expense of the $\mathrm{Bi}^{2+} 660 \mathrm{~nm}$ emission and it reaches the maximum at the dwell time of $2.5 \mathrm{~h}$. This reflects the change of bismuth valence state from +2 to 0 in the in situ reduction. At intermediate annealing times, besides already established excitation and emission peaks of $\mathrm{Bi}^{2+}$ and $\mathrm{Bi}^{0}$ centers, there are additional broad luminescence signals within 600 to $850 \mathrm{~nm}$ upon $330 \mathrm{~nm}$ excitation with maxima at $660 \mathrm{~nm}$ and $790 \mathrm{~nm}$, Figure 21. The decay time of these emissions is much longer, of about $1.15 \mathrm{ms,}$ i.e., strikingly different from those related to $\mathrm{Bi}^{2+}$ and $\mathrm{Bi}^{0}$ centers. Similar slow decay was also found for a new band at about $970 \mathrm{~nm}$ arising in the same intermediate phase of annealing cycle. All in all, the valence conversion most probably happens starting from $\mathrm{Bi}^{2+}$ via $\mathrm{Bi}^{+}$to $\mathrm{Bi}^{0}$ in $\mathrm{Ba}_{2} \mathrm{~B}_{5} \mathrm{O}_{9} \mathrm{Cl}$ : $\mathrm{Bi}$ by the in situ reduction process. The intermediate species shows extraordinarily broad luminescence from 600 to $1200 \mathrm{~nm}$ with the lifetime longer than $1 \mathrm{~ms}$, due to the cascade transitions from ${ }^{3} \mathrm{P}_{2}$ and ${ }^{3} \mathrm{P}_{1}$ to ${ }^{3} \mathrm{P}_{0}$, and their emission characteristics are rather different from those of the $\mathrm{Bi}^{0}$ and $\mathrm{Bi}^{2+}$ centers in the $\mathrm{Ba}_{2} \mathrm{~B}_{5} \mathrm{O}_{9} \mathrm{Cl}$ host.
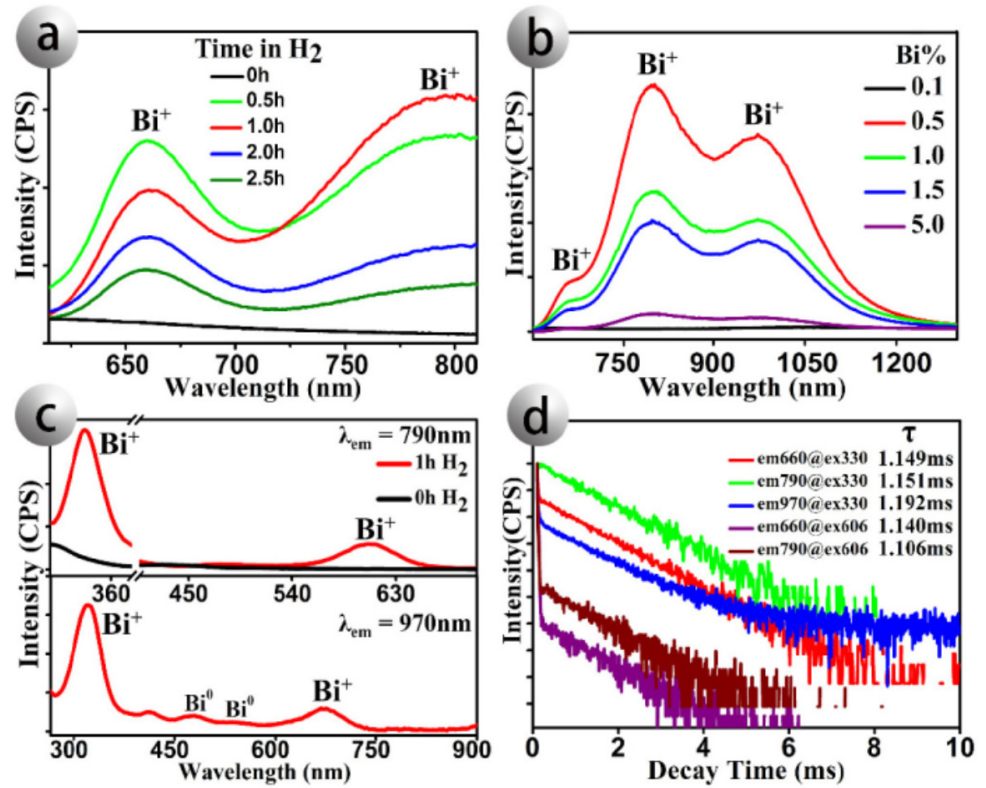

Figure 21. (a) Emission spectra $\left(\lambda_{\mathrm{ex}}=330 \mathrm{~nm}\right)$ of $\mathrm{Ba}_{1.99} \mathrm{~B}_{5} \mathrm{O}_{9} \mathrm{Cl}: 1 \% \mathrm{Bi}$ treated in $\mathrm{N}_{2} / \mathrm{H}_{2}$ for different time; (b) emission spectra $\left(\lambda_{e x}=330 \mathrm{~nm}\right)$ of $\mathrm{Ba}_{2(1-\mathrm{x} \%)} \mathrm{B}_{5} \mathrm{O}_{9} \mathrm{Cl}: 2 \mathrm{x} \% \mathrm{Bi}(\mathrm{x}=0.1,0.5,1.0,1.5,5.0)$ treated in $\mathrm{N}_{2} / \mathrm{H}_{2}$ for $1 \mathrm{~h}$ detected by visible and NIR photomultipliers; the spectra were rescaled and combined; (c) excitation spectra $\left(\lambda_{\mathrm{em}}=790 \mathrm{~nm}, \lambda_{\mathrm{em}}=970 \mathrm{~nm}\right)$ of $\mathrm{Ba}_{1.99} \mathrm{~B}_{5} \mathrm{O}_{9} \mathrm{Cl}: 1 \%$ Bi treated in $\mathrm{N}_{2} / \mathrm{H}_{2}$ for $1 \mathrm{~h}$ and 0h; (d) decay curves of $\mathrm{Ba}_{1.99} \mathrm{~B}_{5} \mathrm{O}_{9} \mathrm{Cl}: 1 \%$ Bi treated in $\mathrm{H}_{2} / \mathrm{N}_{2}$ for $1 \mathrm{~h}$. Reprinted from [227] with permission.

\section{Conclusions}

In $\mathrm{Bi}^{3+}$-doped compounds, the $\mathrm{Bi}^{3+}$-related luminescence of at least three types can be observed:

1. The UV emission band of single $\mathrm{Bi}^{3+}$ centers with the relatively small FWHM and $\mathrm{S}$ and the ms-decay time at $4.2 \mathrm{~K}$. As the temperature increases, the decay time remains constant up to $40-100 \mathrm{~K}$ owing to a large $\left(\sim 10^{2} \mathrm{meV}\right)$ energy distance $\mathrm{D}$ between the emitting and metastable levels of the 
lowest-energy triplet RES of $\mathrm{Bi}^{3+}$ corresponding to the excited ${ }^{3} \mathrm{P}_{1}$ and ${ }^{3} \mathrm{P}_{0}$ levels of a free $\mathrm{Bi}^{3+}$ ion. Similar characteristics should also be observed for a $\mathrm{Bi}^{3+}$ ion perturbed by a crystal lattice defect $\left(\mathrm{a}\left\{\mathrm{Bi}^{3+}\right.\right.$ $-d\}$ center). The concentration dependence of the UV emission intensity should be linear.

2. The UV emission of dimer $\left\{\mathrm{Bi}^{3+}-\mathrm{Bi}^{3+}\right\}$ centers with the emission and excitation spectra slightly shifted to lower energies with respect to the spectral bands of the single $\mathrm{Bi}^{3+}$ centers, showing the superlinear dependence of the intensity on the $\mathrm{Bi}^{3+}$ concentration.

3. The lower-energy (usually VIS) emission bands of an exciton-like origin with the large FWHM and Stokes shift and with the temperature dependence of the decay time characteristic for the triplet RES with a very small $(\sim 1 \mathrm{meV})$ energy distance $\mathrm{D}$ between the emitting and metastable levels. These bands arise from the excitons localized around different $\mathrm{Bi}^{3+}$-related defects: $\mathrm{ex}^{0} \mathrm{Bi}^{3+}, \mathrm{ex}^{0}\left\{\mathrm{Bi}^{3+}\right.$ $d\}$, and $\mathrm{ex}^{0}\left\{\mathrm{Bi}^{3+}-\mathrm{Bi}^{3+}\right\}$. In the latter case, the VIS emission intensity shows the superlinear dependence on the $\mathrm{Bi}^{3+}$ concentration.

The appearance of the exciton-like emission under excitation in the lowest-energy $\mathrm{Bi}^{3+}$-related absorption band can be explained in the following way:

Under this excitation, the electron transition takes place from the ground state of the $\mathrm{Bi}^{3+}$, $\left\{\mathrm{Bi}^{3+}-d\right\}$ or $\left\{\mathrm{Bi}^{3+}-\mathrm{Bi}^{3+}\right\}$ center into the triplet excited state of this center located inside $\mathrm{CB}$. As a result, the electron in $\mathrm{CB}$ and the hole remained at the $\mathrm{Bi}^{3+},\left\{\mathrm{Bi}^{3+}-d\right\}$, or $\left\{\mathrm{Bi}^{3+}-\mathrm{Bi}^{3+}\right\}$ center are optically created. An immediate electron-hole recombination results in the formation of an exciton localized around the $\mathrm{Bi}^{3+},\left\{\mathrm{Bi}^{3+}-d\right\}$, or $\left\{\mathrm{Bi}^{3+}-\mathrm{Bi}^{3+}\right\}$ centers. The radiative decay of these localized excitons results in the appearance of the exciton-like emission bands related to the $\mathrm{Bi}^{3+},\left\{\mathrm{Bi}^{3+}-d\right\}$, or $\left\{\mathrm{Bi}^{3+}-\right.$ $\left.\mathrm{Bi}^{3+}\right\}$ centers, respectively. The exciton-like origin of these emission bands is evident from the structure and parameters of the corresponding relaxed excited state (especially, from a very small values of the spin-orbit splitting energy D of the triplet RES) as well as from the large Stokes shift and FWHM of the emission band characteristic just for the luminescence of an exciton-like origin.

Luminescence spectra of some $\mathrm{Bi}^{3+}$-doped compounds contain the overlapping emission bands of excitons localized around different $\mathrm{Bi}^{3+}$-related centers. This explains the dependence of the intensity and position of the complex VIS emission band on the concentration of $\mathrm{Bi}^{3+}$ ions and crystal structure defects $(d)$ in the investigated material.

The luminescence quenching observed in some $\mathrm{Bi}^{3+}$-doped compounds can be caused by the location of the corresponding relaxed excited states inside the conduction band.

From the comparison of the FWHM and S values of the UV emission bands and the parameters of the triplet RES of $\mathrm{Bi}^{3+}$ centers (Table 1), we conclude that the electron-phonon interaction of $\mathrm{Bi}^{3+}$ with its nearest surroundings noticeably increases in the following sequence of oxides: $\mathrm{CaO}: \mathrm{Bi} \rightarrow$ $\mathrm{Y}_{3} \mathrm{Al}_{5} \mathrm{O}_{12}: \mathrm{Bi} \rightarrow \mathrm{YAlO}_{3}: \mathrm{Bi} \rightarrow \mathrm{Y}_{2} \mathrm{SiO}_{5}: \mathrm{Bi} \rightarrow \mathrm{Y}_{4} \mathrm{Al}_{2} \mathrm{O}_{9}: \mathrm{Bi} \rightarrow \mathrm{La}_{2} \mathrm{SO}_{6}: \mathrm{Bi}$. In the same sequence of oxides, the spin-orbit splitting energy (D) decreases due to suppression of the spin-orbit interaction by the increasing electron-phonon interaction.

The analysis of the experimental data on luminescence characteristics of $\mathrm{Bi}^{3+}$-doped materials reported above allows to conclude that for the correct interpretation of an emission band origin, the following investigations have to be carried out:

1. The measurement of temperature dependence of the investigated luminescence decay time in a wide temperature range (down to $4.2 \mathrm{~K}$ and lower temperatures) and the determination of the RES parameters, especially the $\mathrm{D}$ value. These measurements allow to separate the triplet emission of single $\left(\mathrm{Bi}^{3+},\left\{\mathrm{Bi}^{3+}-d\right\}\right)$, and dimer $\left(\left\{\mathrm{Bi}^{3+}-\mathrm{Bi}^{3+}\right\}\right)$ centers from the triplet $\mathrm{Bi}^{3+}$-related luminescence of an exciton-like origin.

2. The measurement of the dependence of the investigated luminescence intensity on the concentration of $\mathrm{Bi}^{3+}$ under excitation in the absorption spectrum region where the optical density does not exceed 0.5. Only at these conditions, the luminescence intensity is proportional to the absorption intensity and, consequently, to the number of the corresponding luminescence centers. In case of absence of the re-absorption, concentration quenching and energy transfer from $\mathrm{Bi}^{3+}$ ions, the number of single $\mathrm{Bi}^{3+}$ centers should increase linearly with the increasing concentration of $\mathrm{Bi}^{3+}$ ions, while the 
superlinear (quadratic) concentration dependence is characteristic for the number of dimer $\mathrm{Bi}^{3+}$ related centers (both the $\left\{\mathrm{Bi}^{3+}-\mathrm{Bi}^{3+}\right\}$ centers and the $\mathrm{ex}^{0}\left\{\mathrm{Bi}^{3+}-\mathrm{Bi}^{3+}\right\}$ ). These measurements allow to separate the single $\mathrm{Bi}^{3+}$ - and the dimer $\left\{\mathrm{Bi}^{3+}-\mathrm{Bi}^{3+}\right\}$-related luminescence centers.

Regarding the bismuth centers with the valence lower than $3^{+}$, the $\mathrm{Bi}^{2+}$ emission in the red spectral region was convincingly evidenced in a number of crystalline hosts. Pronounced treatment of some oxide or oxyhalide hosts with large divalent site in reduction atmosphere can decrease further the charge state of bismuth to zero and such a $\mathrm{Bi}^{0}$ center provides a broad infrared emission around 1000-1200 nm. As an intermediate state during the reduction atmosphere-air annealing cycles also the $\mathrm{Bi}^{+}$center was proposed in $\mathrm{Ba}_{2} \mathrm{~B}_{5} \mathrm{O}_{9} \mathrm{Cl}$ host to explain emission bands at $660 \mathrm{~nm}, 790 \mathrm{~nm}$ and $970 \mathrm{~nm}$, but these assignments still need further verification in another host(s).

Besides the above-mentioned detailed investigations of $\mathrm{Bi}^{3+}$-doped compounds in a wide temperature range by the methods of the steady-state and time-resolved luminescence spectroscopy, the application of other investigation methods (e.g., electron paramagnetic resonance, nuclear magnetic resonance, thermally stimulated luminescence, etc.) could also be very useful for clarification of the geometrical structure of the $\mathrm{Bi}^{3+}$-related centers and determination of their excited states location with respect to the conduction band. In this respect, it is worth mentioning the recently published positioning of $\mathrm{Bi}^{3+}$ and $\mathrm{Bi}^{2+}$ ground states in $\mathrm{YPO}_{4}$ [228]. Further progress in the experimental research of these materials could surely be complemented by theoretical models of the $\mathrm{Bi}^{3+}$-related excited states, including into consideration the energy levels of $\mathrm{Bi}^{3+}$ ions and the host states and allowing to determine the energy level structure of $\mathrm{Bi}^{3+}$-related luminescence centers. These studies as well as the electronic band structure calculations could allow to predict the luminescence characteristics of new $\mathrm{Bi}^{3+}$-doped compounds suitable for different applications.

This is also valid for Bi ions of lower valence states. The knowledge of the valence state of bismuth ions as well as the host influence on the valence state and structure of Bi-related centers and on the luminescence origin in various Bi-activated materials is needed to understand the physical processes taking place in these materials. This could help to create novel materials for practical applications. In more detail, possible future directions for the search, fabrication, research, and development of Bi-activated photonic materials suitable for different applications are considered in the review paper [8].

Author Contributions: All the authors (A.K., E.M., M.N., S.Z., and Y.Z.) participated in the acquisition, analysis, and interpretation of the experimental data on luminescence of $\mathrm{Bi}^{3+}$-doped compounds, discussion and improvement of the manuscript and approved the submitted version. Y.Z. collected and analyzed the data presented in Section 1. The manuscript was written by M.N. (Section 1, Section 6, Section 7), S.Z. (Section 1, Section 2, Section 3, Section 4, Section 5, Section 7, and Appendix A), and E.M. (Sections 2.2 and 3.2). E.M. elaborated phenomenological models for description of excited-state dynamics and calculated the parameters of the excited states of $\mathrm{Bi}^{3+}$-related luminescence centers. The figures for Section 2, Section 3, Section 4, Section 5 were prepared by A.K. All authors have read and agreed to the published version of the manuscript.

Funding: This research was funded by the European Regional Development Fund in Estonia (Center of Excellence TK141, project No. 2014-2020.4.01.15-0011), Estonian Research Council grant (PUT PRG 619), Ministry of Education, Youth and Sports of Czech Republic (projects LO1409 and CZ.02.1.01/0.0/0.0/16_013/0001406), Polish National Science Centre (project no. 2018/31/B/ST8/00774).

Acknowledgments: The work was supported by the ERDF funding in Estonia granted to the Center of Excellence TK141 "Advanced materials and high-technology devices for sustainable energetics, sensorics and nanoelectronics" (project No. 2014-2020.4.01.15-0011) and the Estonian Research Council grant (PUT PRG 619). Partial support from the Ministry of Education, Youth and Sports of Czech Republic under projects LO1409 and CZ.02.1.01/0.0/0.0/16_013/0001406 and from the Polish National Science Centre (project no. 2018/31/B/ST8/00774) are also gratefully acknowledged.

Conflicts of Interest: The authors declare no conflict of interest. 


\section{Appendix A.}

\section{Appendix A.1. Bi ${ }^{3+}$-Doped Alkali Halides}

Luminescence characteristics of KCl:Bi were studied in [2,85,94,96,140,206,229-231]. In [85,94], different data were obtained on the emission and excitation bands positions, luminescence polarization characteristics, and decay kinetics (Table 1 ) indicating the possibility of formation of $\mathrm{Bi}^{3+}$ centers of different structure (e.g., $\mathrm{Bi}^{3+}$ ions located close to one or two cation vacancies, impurity anions like $\mathrm{O}^{2-}, \mathrm{S}^{2-}$, etc.). This effect is caused by a small solubility of trivalent $\mathrm{ns}^{2}$ ions as well as their twofold excess charge whose compensation can take place in different ways, depending on the conditions of the single crystal synthesis and quenching, the purification degree of the host salt, etc.

In [94], two emission bands were observed at $15 \mathrm{~K}$, peaking at $3.19 \mathrm{eV}$ and $2.88 \mathrm{eV}$. Only the fast component $(\approx 15 \mathrm{~ns})$ was observed in the $3.19 \mathrm{eV}$ emission decay, while the slow component $(0.55 \mathrm{~ms})$ dominates in the decay kinetics of the $2.88 \mathrm{eV}$ emission. The decay time of the slow component remains constant up to about $70 \mathrm{~K}$ and then decreases exponentially. The value of $\mathrm{D}=59 \mathrm{meV}$ was obtained. A noticeable difference in the excitation spectra of the two emissions as well as temperature variations of the emission spectra indicate that the $3.19 \mathrm{eV}$ and $2.88 \mathrm{eV}$ emission bands arise from different $\mathrm{Bi}^{3+}$ centers.

In [85], the complex emission band located around $2.5 \mathrm{eV}$ was observed in the emission spectrum of KCl:Bi (Figure 8a). Two fast (17 ns and $27 \mathrm{~ns}$ ) and two slow (1.38 ms and $2.8 \mathrm{~ms}$ ) components were observed at $4.2 \mathrm{~K}$ in the emission decay (Figure 9a). Their excitation spectra practically coincide. The emission spectra of two fast decay components are shifted to lower energy with respect to the spectra of two slow components. The analysis of the temperature dependences of the decay times allows to conclude that the emission of $\mathrm{Bi}^{3+}$ centers arises from the triplet RES and that the theoretical model $[135,137]$ is still valid in the case of $\mathrm{KCl}: \mathrm{Bi}$, despite the strong spin-orbit interaction.

\section{Appendix A.2. $\mathrm{Bi}^{3+}$-Doped Alkaline-Earth Oxides, Sulfides, and Fluorides}

Luminescence properties of all $\mathrm{Bi}^{3+}$-doped alkaline-earth oxides [79,84,85,88,89,91,133,232-239], sulfides [84,86-90] and fluorides [92] are similar (Table 1). The triplet emission of $\mathrm{Bi}^{3+}$ ions in these materials shows the extremely small Stokes shift and FWHM and the extremely large energy D of the spin-orbit splitting of the triplet RES (up to $265 \mathrm{meV}$ in $\mathrm{CaF}_{2}$ [92]). In the luminescence decay kinetics, the slow decay component at low temperatures is much stronger than the fast component. This indicates that mainly the metastable minima of the triplet RES are populated in the process of the excited state relaxation. In many systems, vibronic structure of the emission band and the lowest-energy excitation band was observed at low temperatures (see, e.g., $[84,86,88-92,133,234]$ ). All the observed features are caused by an extremely weak electron-phonon interaction characteristic for these materials.

As an example, the characteristics of triplet luminescence of $\mathrm{CaO}: \mathrm{Bi}$ are presented in Figures $8 \mathrm{~b}$ and $9 \mathrm{~b}$. At $4.2 \mathrm{~K}$, the strong slow $3.1 \mathrm{eV}$ emission and weak fast $3.3 \mathrm{eV}$ emission were observed, arising from the radiative decay of two triplet RES, corresponding to the ${ }^{3} \mathrm{P}_{0}$ and ${ }^{3} \mathrm{P}_{1}$ excited levels of a $\mathrm{Bi}^{3+}$, respectively [85]. It was concluded that the model [134], considering the spin-orbit interaction being dominant in the triplet RES, should be used for the description of the luminescence characteristics of the systems of this type.

In addition to the triplet emission, a new $4.15 \mathrm{eV}$ emission was found in [85] and ascribed to the electron transitions from the singlet excited state of a $\mathrm{Bi}^{3+}$ ion related to the ${ }^{1} \mathrm{P}_{1}$ excited state of a free $\mathrm{Bi}$ ion. At the temperatures around $30 \mathrm{~K}$, the intensity redistribution takes place between the $4.15 \mathrm{eV}$ and $3.1 \mathrm{eV}$ emissions indicating thermal transitions between the singlet and triplet excited levels of the same luminescence center. No such emission was observed in other $\mathrm{Bi}^{3+}$-doped compounds. 


\section{Appendix A.3. $\mathrm{Bi}^{3+}$-Doped Lanthanide Oxides}

The luminescence of $\mathrm{Y}_{2} \mathrm{O}_{3}: \mathrm{Bi}, \mathrm{Lu}_{2} \mathrm{O}_{3}: \mathrm{Bi}$, and $\mathrm{Gd}_{2} \mathrm{O}_{3}: \mathrm{Bi}$ arises from the triplet $\mathrm{RES}$ of $\mathrm{Bi}^{3+}$ ions located in two different crystal lattice sites of the $S_{6}$ and the $C_{2}$ symmetry (see, e.g., $[1,3,71,80,112]$ and references therein). The $\mathrm{Bi}\left(\mathrm{S}_{6}\right)$ and $\mathrm{Bi}\left(\mathrm{C}_{2}\right)$ centers reveal a very weak and a relatively strong electron-phonon interaction of an optical electron with the surrounding oxygen ion. This allowed to suggest [71] that these centers should be described within different models of RES: the Seitz model [134] for $\mathrm{Bi}\left(\mathrm{S}_{6}\right)$ centers and the model of Hizhnyakov [135] for $\mathrm{Bi}\left(\mathrm{C}_{2}\right)$ centers. The competition between the radiative and thermally stimulated and tunneling nonradiative processes in the triplet RES was considered in [71] to explain the low-temperature quenching of the triplet luminescence of $\mathrm{Bi}^{3+}$ found in [112], as well as the absence of the $\mathrm{Bi}^{3+}$-related exciton-like emission in $\mathrm{Y}_{2} \mathrm{O}_{3}: \mathrm{Bi}$ (for more details, see [71]).

In $\mathrm{La}_{2} \mathrm{O}_{3}: \mathrm{Bi}$, the $2.63 \mathrm{eV}$ emission band was ascribed to the ${ }^{3} \mathrm{P} \rightarrow{ }^{1} \mathrm{~S}_{0}$ transitions of a free $\mathrm{Bi}^{3+}$ ion [3,80]. In [112], two emission bands, $2.58 \mathrm{eV}$ and $2.18 \mathrm{eV}$, were observed and ascribed to single and dimer $\mathrm{Bi}^{3+}$ centers, respectively. However, it is not excluded that the $2.18 \mathrm{eV}$ emission $(\mathrm{S} \approx 1.47 \mathrm{eV})$ arises from excitons localized around $\mathrm{Bi}^{3+}$. If so, the presence of the exciton-like emission in $\mathrm{La}_{2} \mathrm{O}_{3}: \mathrm{Bi}$, unlike in $\mathrm{Y}_{2} \mathrm{O}_{3}: \mathrm{Bi}$ and $\mathrm{Lu}_{2} \mathrm{O}_{3}: \mathrm{Bi}$, and the absence of the low-temperature luminescence quenching in $\mathrm{La}_{2} \mathrm{O}_{3}: \mathrm{Bi}$ could be connected (see [71]).

\section{Appendix A.4. Bi ${ }^{3+}$-Doped Garnets}

In $\mathrm{Y}_{3} \mathrm{Al}_{5} \mathrm{O}_{12}$ : $\mathrm{Bi}$ and $\mathrm{Lu}_{3} \mathrm{Al}_{5} \mathrm{O}_{12}: \mathrm{Bi}$, the co-existence of the triplet $\mathrm{UV}$ emission of $\mathrm{Bi}^{3+}$ ions and the VIS emission of excitons localized around $\mathrm{Bi}^{3+}$ ions was found in $[17,18]$.

The luminescence of $\mathrm{Bi}^{3+}$-doped gallate garnets $\mathrm{Y}_{3} \mathrm{Ga}_{5} \mathrm{O}_{12}$ and $\mathrm{Gd}_{3} \mathrm{Ga}_{5} \mathrm{O}_{12}$ was found in [12] and suggested to be of an exciton origin. In $\mathrm{Gd}_{3} \mathrm{Ga}_{5} \mathrm{O}_{12}: \mathrm{Bi}_{1}$, no $\mathrm{Bi}^{3+}$-related $\mathrm{UV}$ emission was observed in $[12,74,75,240,241]$. The exciton-like origin of the VIS emission was confirmed in [74,75]. The close to linear dependence of the VIS emission intensity on the $\mathrm{Bi}^{3+}$ content indicates that two VIS emission bands observed in [75] are connected with the excitons localized around the single $\mathrm{Bi}^{3+}$ ions and $\left\{\mathrm{Bi}^{3+}\right.$ d\} centers.

Unlike the above-mentioned works, both the UV and VIS emissions were reported $[14,110]$ for $\mathrm{Y}_{3} \mathrm{Ga}_{5} \mathrm{O}_{12}$ :Bi and $\mathrm{Gd}_{3} \mathrm{Ga}_{5} \mathrm{O}_{12}$ :Bi. The UV emission was ascribed to the ${ }^{3} \mathrm{P}_{1,0} \rightarrow{ }^{1} \mathrm{~S}_{0}$ transitions of $\mathrm{Bi}^{3+}$ ions, while the VIS emission was attributed to $\mathrm{Bi}^{3+}$ pairs and/or clusters. In $\mathrm{Y}_{3} \mathrm{Ga}_{5} \mathrm{O}_{12}$ : $\mathrm{Bi}$, the UV/VIS emission intensity ratio was found to be $\approx 17$ in [14] and $\approx 2$ in [110]. No VIS emission was observed in [13] despite a large Bi content (10\%).

In all these cases, the lowest excitation bands of the UV and VIS emissions were found to be close (compare Table 1, Table 2, and Table 4). In [10], this band was ascribed to the ${ }^{1} \mathrm{~S}_{0} \rightarrow{ }^{3} \mathrm{P}_{1}$ transitions of $\mathrm{Bi}^{3+}$ ions and the VIS emission of $\mathrm{Y}_{3} \mathrm{Ga}_{5} \mathrm{O}_{12}: \mathrm{Bi}$ and $\mathrm{Gd}_{3} \mathrm{Ga}_{5} \mathrm{O}_{12}: \mathrm{Bi}$, to the $\mathrm{CT}$ transitions. It was not excluded in [7] that the lowest-energy excitation band of $\mathrm{Y}_{3} \mathrm{Ga}_{5} \mathrm{O}_{12}: \mathrm{Bi}$ and $\mathrm{Gd}_{3} \mathrm{Ga}_{5} \mathrm{O}_{12}: \mathrm{Bi}$ arises from the MMCT transitions and that their VIS luminescence is of the MMCT origin. However, it should be noted that the VIS emission of $\mathrm{Gd}_{3} \mathrm{Ga}_{5} \mathrm{O}_{12}$ : $\mathrm{Bi}$ is excited at much lower energy $(4.0-4.3 \mathrm{eV}[12,74,75])$ as compared with the lowest-energy MMCT transition (4.59 eV [10]). The same is true also for $\mathrm{Y}_{3} \mathrm{Al}_{5} \mathrm{O}_{12}: \mathrm{Bi}$ and $\mathrm{Lu}_{3} \mathrm{Al}_{5} \mathrm{O}_{12}$ :Bi. These data induce some doubts about the MMCT origin of the lowest excitation band of the VIS emission.

\section{Appendix A.5. Bi ${ }^{3+}$-Doped Aluminum Perovskites YAlO3 and GdAlO3}

The crystal structures of $\mathrm{YAlO}_{3}$ and $\mathrm{GdAlO}_{3}$ are different. The band gap $\mathrm{E}_{\mathrm{g}}$ in $\mathrm{YAlO}_{3}$ is about $8.5 \mathrm{eV}$ [154] or $8.8 \mathrm{eV}$ [242], and in $\mathrm{GdAlO}_{3}, \mathrm{E}_{\mathrm{g}} \approx 7.8 \mathrm{eV}$ [154]. In $\mathrm{YAlO}_{3}: \mathrm{Bi}$, only the UV emission was observed, located at $4.2 \mathrm{~K}$ at $3.76 \mathrm{eV}$ and excited at $4.43 \mathrm{eV}$ [22]. In $\mathrm{GdAlO}_{3}: \mathrm{Bi}$ [109], both the UV emission $(3.72 \mathrm{eV})$ and the VIS emissions (2.50 and $2.58 \mathrm{eV}$, see Table 4) were observed. In both papers, the UV emission was ascribed to the transitions from the triplet excited state of $\mathrm{Bi}^{3+}$ ions. In [109], the VIS emission was concluded to arise from $\mathrm{Bi}^{3+}$ dimers (although the concentration dependence 
of the emission intensity was not measured). In [10], the visible emission was ascribed to the CT transitions and in [154], it was interpreted in terms of IVCT in $\mathrm{Bi}^{3+}$ pairs. It is not excluded that the broad VIS emission band of $\mathrm{GdAlO}_{3}: \mathrm{Bi}$ consists of the emission bands of excitons localized around single and dimer $\mathrm{Bi}^{3+}$ centers. This could explain the dependence of its position and shape on the $\mathrm{Bi}^{3+}$ content.

\section{Appendix A.6. $\mathrm{Bi}^{3+}$-Doped Oxyorthosilicates}

For the first time, the luminescence of $\mathrm{Lu}_{2} \mathrm{SiO}_{5}: \mathrm{Bi}$ and $\mathrm{Y}_{2} \mathrm{SiO}_{5}: \mathrm{Bi}$ was detected in $[20,21]$. The characteristics of $\mathrm{Bi}^{3+}$-doped $\mathrm{Lu}_{2} \mathrm{SiO}_{5}$ and $\mathrm{Y}_{2} \mathrm{SiO}_{5}$ were found to be similar. In the emission spectrum of $\mathrm{Lu}_{2} \mathrm{SiO}_{5}: \mathrm{Bi}$, a strong $\mathrm{UV}$ band $(3.455 \mathrm{eV})$, much weaker $3.3 \mathrm{eV}$ band, and two visible bands $\left(2.2 \mathrm{eV}\right.$ and $2.3 \mathrm{eV}$ ) are observed at $4.2 \mathrm{~K}$. In $\mathrm{Y}_{2} \mathrm{SiO}_{5}$ : $\mathrm{Bi}$, only the $3.56 \mathrm{eV}$ band can surely be ascribed to $\mathrm{Bi}^{3+}$ centers. The low-temperature luminescence decay kinetics clearly indicates that the UV emission of both $\mathrm{Lu}_{2} \mathrm{SiO}_{5}$ : $\mathrm{Bi}$ and $\mathrm{Y}_{2} \mathrm{SiO}_{5}$ : $\mathrm{Bi}$ arises from the triplet $\mathrm{RES}$ of $\mathrm{Bi}^{3+}$ ions. The light sum of the VIS emission of $\mathrm{Bi}^{3+}$-doped silicates is in at least two orders of magnitude smaller as compared with the light sum of the UV emission of the main $\mathrm{Bi}^{3+}$ centers. Temperature dependences of decay times of both VIS emissions of $\mathrm{Lu}_{2} \mathrm{SiO}_{5}$ : $\mathrm{Bi}$ are similar to those observed for the VIS emission of other $\mathrm{Bi}^{3+}$-doped compounds and allow to connect them with the $\mathrm{Bi}^{3+}$-related localized excitons.

\section{Appendix A.7. Bi $i^{3+}$-Doped Tungstates}

Spectroscopic studies of $\mathrm{Bi}^{3+}$-doped tungstates (except $\mathrm{PbWO}_{4}$ ) were carried out [122-124,146-148]. In these papers, the well-separated lowest-energy $\mathrm{Bi}^{3+}$-related absorption (excitation) band was ascribed to the ${ }^{1} \mathrm{~S}_{0} \rightarrow{ }^{3} \mathrm{P}_{1}$ transitions of a free $\mathrm{Bi}^{3+}$ ion. In [124,146-148], the $\mathrm{Bi}^{3+}$-related luminescence was connected with the radiative decay of the triplet RES of $\mathrm{Bi}^{3+}$. From the analysis of the low-temperature decay kinetics of the $2.75 \mathrm{eV}$ emission of $\mathrm{CaWO}_{4}: \mathrm{Bi}$, the conclusion on the excitonic origin of this luminescence was made [122,123]. Similar decay kinetics was later observed for $\mathrm{CaWO}_{4}: \mathrm{Bi}[147]$ and for $\mathrm{CdWO}_{4}$ : $\mathrm{Bi}[148]$.

The luminescence of $\mathrm{PbWO}_{4}$ :Bi crystals was studied in detail in [73]. The $2.2 \mathrm{eV}$ emission was ascribed to the excitons localized around the $\mathrm{Bi}^{3+}$-related centers of two types. Three possibilities were considered for the interpretation of the lowest absorption (excitation) band of $\mathrm{PbWO}_{4}: \mathrm{Bi}$ :

(i) This band arises from the electron transitions from the ground state to the lowest-energy triplet excited state of $\mathrm{Bi}^{3+}$, corresponding to the ${ }^{1} \mathrm{~S}_{0} \rightarrow{ }^{3} \mathrm{P}_{1}$ transitions of a free $\mathrm{Bi}^{3+}$ ion. As the emission from the triplet RES of $\mathrm{Bi}^{3+}$ is absent, the ${ }^{3} \mathrm{P}_{1}$-related level of $\mathrm{Bi}^{3+}$ should be located inside $\mathrm{CB}$, and the electron transitions result in the ionization of $\mathrm{Bi}^{3+}$ and release of electrons into $\mathrm{CB}$. Similarly to the undoped $\mathrm{PbWO}_{4}$ crystal, the subsequent fast electron-hole recombination followed by vibronic relaxation results in the formation of the $\left(\mathrm{WO}_{4}\right)^{2-}$-type exciton localized around the $\mathrm{Bi}^{3+}$ ion. The optically released electrons can also be trapped at different traps (e.g., around oxygen vacancies $\mathrm{V}_{\mathrm{O}}$ or at $\mathrm{Bi}^{3+}$ and $\mathrm{Bi}^{5+}$ ions), producing stable paramagnetic electron $\left\{\mathrm{Pb}^{+}-\mathrm{V}_{\mathrm{O}}\right\}, \mathrm{Bi}^{2+}$, and $\mathrm{Bi}^{4+}$ centers.

(ii) Similar absorption band observed in $\mathrm{PbWO}_{4}: \operatorname{Pr}[243]$ was explained by the $\mathrm{Pr}^{3+} / \mathrm{W}^{6+} \rightarrow$ $\mathrm{Pr}^{4+} / \mathrm{W}^{5+}$ electron-transfer transitions proposed in [142]. The $\mathrm{Bi}^{3+} \rightarrow \mathrm{W}^{6+}$ charge-transfer transitions in $\mathrm{Y}_{2} \mathrm{WO}_{6}$ :Bi were suggested to occur in [1]. In tungstates, the transfer of an electron from the ground state of a $\mathrm{Bi}^{3+}$ ion to the nearest host $\mathrm{W}^{6+}$ ion: $\mathrm{Bi}^{3+}\left(6 \mathrm{~s}^{2}\right) / \mathrm{W}^{6+}\left(5 \mathrm{~d}^{0}\right) \rightarrow \mathrm{Bi}^{4+}\left(6 \mathrm{~s}^{1}\right) / \mathrm{W}^{5+}\left(5 \mathrm{~d}^{1}\right)$ was concluded to result in the formation of the hole $\mathrm{Bi}^{4+}$ and electron $\mathrm{W}^{5+}$ centers. Their subsequent fast recombination and the following relaxation results in the creation of the exciton localized around the $\mathrm{Bi}^{3+}$ ion and its subsequent radiative decay. With the use of the equation presented in [7], the MMCT energy in $\mathrm{PbWO}_{4}: \mathrm{Bi}$ was estimated to be $\approx 4.2 \mathrm{eV}$. This value is close to the suggested position of the $\mathrm{Bi}^{3+}$-related absorption band maximum $(\approx 4 \mathrm{eV})$.

(iii) A trivalent $\mathrm{Bi}^{3+}$ ion in the $\mathrm{PbWO}_{4}$ crystal lattice, substituting for a divalent $\mathrm{Pb}^{2+}$ ion, has an excess positive charge. By analogy with some other materials (see, e.g., [244]), it is not excluded that under photoexcitation of $\mathrm{PbWO}_{4}: \mathrm{Bi}$, the photostimulated electron transfer from the valence band $(\mathrm{VB})$ to the ground state of a single $\mathrm{Bi}^{3+}$ ion can also take place, resulting in creation of an electron 
$\mathrm{Bi}^{2+}$ center and a mobile hole in VB. The hole can be trapped by oxygen ions located close to the $\mathrm{Bi}^{3+}$ - related center and/or lead vacancy $\mathrm{V}_{\mathrm{Pb}}$. The subsequent fast recombination in close pairs of the optically created electron and hole centers is suggested to result in the creation of excitons localized around $\mathrm{Bi}^{3+}$-related centers. The presence of two types of excitons in $\mathrm{PbWO}_{4}: \mathrm{Bi}$, probably, $\mathrm{ex}^{0} \mathrm{Bi}^{3+}$ and $\mathrm{ex}^{0}\left\{\mathrm{Bi}^{3+}-\mathrm{V}_{\mathrm{Pb}}\right\}$ with strongly different thermal stabilities is suggested. The radiative decay of these excitons is accompanied with the $2.2 \mathrm{eV}$ emission. Similar processes were proposed to explain the appearance of the localized exciton emission and creation of the impurity-related electron centers $\left(\mathrm{Tl}^{0}\right.$, $\left.\mathrm{Pb}^{+}\right)$and self-trapped holes $\left(\mathrm{V}_{\mathrm{K}}\right.$ centers) in the $\mathrm{UV}$-irradiated $\mathrm{Tl}^{+}$- and $\mathrm{Pb}^{2+}$-doped caesium halides (see, e.g., [245] and references therein).

The data obtained by the TSL and EPR methods on the origin of stable electron and hole centers created under photoexcitation of $\mathrm{PbWO}_{4}$ :Bi crystals in the lowest-energy absorption band $[73,193]$ indicate that, in principle, all the above-mentioned processes can take place. As both the single $\mathrm{Bi}^{3+}$ ions and the $\mathrm{Bi}^{3+}$ ions associated with lead vacancies can exist in $\mathrm{PbWO}_{4}$, the process (ii) seems to be more preferable for $\left\{\mathrm{Bi}^{3+}-\mathrm{V}_{\mathrm{Pb}}\right\}$ centers with a negative excess charge, but the process (iii), for single $\mathrm{Bi}^{3+}$ centers with a positive excess charge.

It should be noted that the same processes can also take place in other materials where a $\mathrm{Bi}^{3+}$ ion is substituting for mono- or divalent host lattice ion.

\section{Appendix A.8. $\mathrm{Bi}^{3+}$-Doped Phosphates}

In $\mathrm{Bi}^{3+}$-doped $\mathrm{LiLaP}_{4} \mathrm{O}_{12}$ glasses and powders, two emission bands were registered at $4.2 \mathrm{~K}$. The $3.02 \mathrm{eV}$ emission was observed under the $5.28 \mathrm{eV}$ excitation while the $2.78 \mathrm{eV}$ emission was observed under the $4.95 \mathrm{eV}$ excitation. In [102], these bands were ascribed to single $\mathrm{Bi}^{3+}$ ions and $\mathrm{Bi}^{3+}$ dimers, respectively. In [246], both these bands were ascribed to single $\mathrm{Bi}^{3+}$ ions. To explain this fact, the presence of two crystallographic positions for a $\mathrm{Bi}^{3+}$ ion in the phosphate host was suggested. However, a later work [247] on the single crystal X-ray diffraction excluded such possibility.

In [72], the $\mathrm{LiLaP}_{4} \mathrm{O}_{12}: \mathrm{Bi}$ with different $\mathrm{Bi}$ contents and the undoped $\mathrm{LiLaP}_{4} \mathrm{O}_{12}$ were investigated. Only the $2.95 \mathrm{eV}$ emission of $\mathrm{LiLaP}_{4} \mathrm{O}_{12}$ : $\mathrm{Bi}$ was shown to arise from $\mathrm{Bi}^{3+}$-related centers and ascribed to an exciton localized around a single $\mathrm{Bi}^{3+}$ ion. The characteristics of this emission are similar to the characteristics of the $2.8 \mathrm{eV}$ emission of undoped $\mathrm{LiLaP}_{4} \mathrm{O}_{12}$. The absence of the UV emission was explained by the location of the lowest-energy excited state of $\mathrm{Bi}^{3+}$ inside $\mathrm{CB}$. Owing to a close position of the lowest excitation band of the $2.95 \mathrm{eV}$ emission (5.4 eV) to the estimated (according to [7]) value of the $\mathrm{Bi}^{3+} \rightarrow \mathrm{La}^{3+}$ charge transfer energy $(\approx 5.5 \mathrm{eV})$, it was suggested that under the $5.4 \mathrm{eV}$ excitation, an electron transfer from the ground state of a $\mathrm{Bi}^{3+}$ ion to the nearest host $\mathrm{La}^{3+}$ ion, $\mathrm{Bi}^{3+}\left(6 \mathrm{~s}^{2}\right) / \mathrm{La}^{3+}\left(5 \mathrm{~d}^{0}\right)$ $\rightarrow \mathrm{Bi}^{4+}\left(6 \mathrm{~s}^{1}\right) / \mathrm{La}^{2+}\left(5 \mathrm{~d}^{1}\right)$, takes place. The subsequent fast electron-hole recombination at the $\mathrm{Bi}^{3+}$ ion and the following relaxation result in the formation of the exciton localized around $\mathrm{Bi}^{3+}$ whose radiative decay is accompanied with the $2.95 \mathrm{eV}$ emission.

The same interpretation can be given to both broad visible emission bands of $\mathrm{LiLaP}_{4} \mathrm{O}_{12}$ : $\mathrm{Bi}$ located at $2.78 \mathrm{eV}(\mathrm{S}=2.17 \mathrm{eV})$ and $3.02 \mathrm{eV}(\mathrm{S}=2.25 \mathrm{eV})$ and ascribed to the triplet emission of $\mathrm{Bi}^{3+}$ [102]. Based on the concentration dependence reported in [102], the $2.78 \mathrm{eV}$ emission can be assumed to arise from an exciton localized around a $\mathrm{Bi}^{3+}$ dimer.

In $\mathrm{YPO}_{4}: \mathrm{Bi}, \mathrm{LuPO}_{4}: \mathrm{Bi}$, two emission bands, an intense narrow band at about 5.12-5.17 eV and a weak broad band at about 3.7-3.8 eV, were observed under excitation around 5.37-5.45 eV. The higher-energy band was ascribed to isolated $\mathrm{Bi}^{3+}$ ions $[7,24,113,128,154,248]$ while the lower-energy band, to $\mathrm{Bi}^{3+}$ dimers $[24,113,128]$, MMCT transitions $[7,128]$, or to the electron transfer in the $\mathrm{Bi}^{2+}-\mathrm{Bi}^{4+}$ pairs [154]. In our opinion, the lower-energy broad 3.7-3.8 eV emission band with the large Stokes shift $(\mathrm{S}=1.75-1.79 \mathrm{eV})$ can arise from the excitons localized around $\mathrm{Bi}^{3+}$-related centers.

From the temperature dependence of the decay time of the broad (FWHM $=0.6 \mathrm{eV}$ ) $2.75 \mathrm{eV}$ emission band of $\mathrm{LaPO}_{4}: \mathrm{Bi}$ with the large Stokes shift $(\mathrm{S}=2.4 \mathrm{eV})$ measured in [83], the value of $\mathrm{D}$ $=2.05 \mathrm{meV}$ was obtained. Such small $\mathrm{D}$ value allows to make a reliable conclusion that the $2.75 \mathrm{eV}$ emission of $\mathrm{LaPO}_{4}: \mathrm{Bi}$ arises from an exciton localize around a $\mathrm{Bi}^{3+}$ ion. 
In [111], the $\mathrm{Bi}^{3+}$-doped metaphosphates $\mathrm{LnP}_{3} \mathrm{O}_{9}(\mathrm{Ln}=\mathrm{Sc}, \mathrm{Lu}, \mathrm{Y}, \mathrm{Gd}, \mathrm{La})$ were studied. $\mathrm{In}_{\mathrm{Sc}} \mathrm{P}_{3} \mathrm{O}_{9}: \mathrm{Bi}$, $\mathrm{LuP}_{3} \mathrm{O}_{9}: \mathrm{Bi}$, and $\mathrm{YP}_{3} \mathrm{O}_{9}: \mathrm{Bi}$ with relatively small Stokes shifts $(0.56 \mathrm{eV}, 0.86 \mathrm{eV}$, and $0.92 \mathrm{eV}$, respectively) the excitation band was ascribed to the ${ }^{1} \mathrm{~S}_{0} \rightarrow{ }^{3} \mathrm{P}_{1}$ transitions and the emission, to the ${ }^{3} \mathrm{P}_{1,0} \rightarrow{ }^{1} \mathrm{~S}_{0}$ transitions of $\mathrm{Bi}^{3+}$. However, the $2.72 \mathrm{eV}$ emission of $\mathrm{LaP}_{3} \mathrm{O}_{9}$ :Bi has much larger Stokes shift $(\mathrm{S}=2.54 \mathrm{eV})$. This means that this emission can arise from the exciton localized around $\mathrm{a} \mathrm{Bi}^{3+}$ ion.

\section{Appendix A.9. Bi $i^{3+}$-Doped Rare-Earth Orthovanadates}

The study of luminescence characteristics of the undoped and $\mathrm{Bi}^{3+}$-doped orthovanadates started in $[1,3,166]$. In [166], temperature dependences of the luminescence decay time were measured for $\mathrm{YVO}_{4}$ and $\mathrm{YVO}_{4}: \mathrm{Bi}$ and found to be similar. The decay time of the $\mathrm{Bi}^{3+}$-related emission decreases drastically from $165 \mu$ s at $4 \mathrm{~K}$ to $4.5 \mu$ s at $\sim 20 \mathrm{~K}$. This effect was explained by the presence of two close excited state levels separated by only about $0.62 \mathrm{meV}$. However, the origin of these states was not discussed. In $[3,26,29,36,39,40,42,43,143-145]$, the $\mathrm{Bi}^{3+}$-related spectral bands of $\mathrm{YVO}_{4}$ : $\mathrm{Bi}$ were ascribed to the electronic transitions between the ground and excited states of a $\mathrm{Bi}^{3+}$ ion, while in $[7,27,33,34,38$, $41,44,128,141,156,249-253]$, to the charge transfer transitions between $\mathrm{Bi}$ and $\mathrm{V}$ ions. In the latter set of works, the lowest-energy absorption band was connected with the $\mathrm{Bi}^{3+}\left(6 \mathrm{~s}^{2}\right) \rightarrow \mathrm{V}^{5+}\left(3 \mathrm{~d}^{0}\right)$ transitions and the emission band, with the $\mathrm{V}^{4+}\left(3 \mathrm{~d}^{1}\right) \rightarrow \mathrm{Bi}^{4+}\left(6 \mathrm{~s}^{1}\right)$ transitions. Luminescence of $\mathrm{LuVO}_{4}: \mathrm{Bi}$ and $\mathrm{GdVO}_{4}$ :Bi was much less studied and mainly at $295 \mathrm{~K}$ (see, e.g., $[3,28,29,35,37,38,41,64,65,143,144]$ ).

In [76], the conclusion on the exciton-like origin of both the intrinsic blue emission and the $\mathrm{Bi}^{3+}$-related yellow emission in $\mathrm{Bi}^{3+}$-doped rare-earth orthovanadates was made based on the analysis of temperature dependences of their decay times. It was suggested that the $\mathrm{Bi}^{3+}$-related absorption (excitation) band around 3.73-3.79 eV arises from the electronic transition from the ground ${ }^{1} \mathrm{~S}_{0}$ state to the excited ${ }^{3} \mathrm{P}_{1}$ state of $\mathrm{Bi}^{3+}$ located inside $\mathrm{CB}$. The excitation in this band was suggested to result in an electron release from the ${ }^{3} \mathrm{P}_{1}$ level into $\mathrm{CB}$ and its subsequent immediate recombination with the hole remained at the $\mathrm{Bi}^{3+}$ ion. As a result, an exciton localized around the single $\mathrm{Bi}^{3+}$ ion is created whose radiative decay is accompanied with the $2.12-2.19 \mathrm{eV}$ emission. No other VIS emissions, which could arise, e.g., from the excitons localized around dimer $\left\{\mathrm{Bi}^{3+}-\mathrm{Bi}^{3+}\right\}$ centers, and no UV emission, which could arise from the triplet excited state of $\mathrm{Bi}^{3+}$ ions, were found in $\mathrm{YVO}_{4}: \mathrm{Bi}, \mathrm{LuVO}_{4}: \mathrm{Bi}$, and $\mathrm{GdVO}_{4}$ :Bi.

\section{Appendix A.10. $B i^{3+}$-Doped Lanthanide Niobates}

Luminescence of $\mathrm{Bi}^{3+}$-doped niobates was studied mainly at $295 \mathrm{~K}$. Not only the interpretation of experimental results but also positions of the emission and excitation bands reported in different papers were different. For $\mathrm{YNbO}_{4}: \mathrm{Bi}$, the MMCT origin of the spectral bands was suggested in $[1,7,64,65,157]$. The lowest-energy absorption band was connected with the $\mathrm{Bi}^{3+}\left(6 \mathrm{~s}^{2}\right) \rightarrow \mathrm{Nb}^{5+}\left(3 \mathrm{~d}^{0}\right)$ transitions and the emission band, with the $\mathrm{Nb}^{4+}\left(3 \mathrm{~d}^{1}\right) \rightarrow \mathrm{Bi}^{4+}\left(6 \mathrm{~s}^{1}\right)$ transitions. However, in [149-153], the excitation and emission bands of $\mathrm{YNbO}_{4}$ : $\mathrm{Bi}$ were ascribed to the electron transitions between the ground state $\left({ }^{1} \mathrm{~S}_{0}\right)$ and the triplet excited state $\left({ }^{3} \mathrm{P}_{1}\right)$ of a single $\mathrm{Bi}^{3+}$ ion. In [254], the absorption of $\mathrm{YNbO}_{4}: \mathrm{Bi}$ was ascribed to the charge transfer transitions from $\mathrm{O}^{2-} 2 \mathrm{p}$ to the excited $6 \mathrm{p}$ levels of $\mathrm{Bi}^{3+}$. The energies of the ${ }^{1} \mathrm{~S}_{0} \rightarrow$ ${ }^{3} \mathrm{P}_{1}$ transitions $(3.91 \mathrm{eV})$ and the MMCT transitions $(3.91 \mathrm{eV})$ calculated in [65] were found to be close to the position of the lowest-energy excitation band maximum in $\mathrm{YNbO}_{4}: \mathrm{Bi}$ and $\mathrm{GdNbO}_{4}$ :Bi. This means that, in principle, the appearance of both these types of transitions is possible in the absorption (and luminescence) spectra of $\mathrm{YNbO}_{4}: \mathrm{Bi}$.

In [77], two $\mathrm{Bi}^{3+}$-related emission bands were observed in $\mathrm{YNbO}_{4}$ :Bi. Based on detailed and systematic investigation of the intrinsic and $\mathrm{Bi}^{3+}$-related luminescence in $\mathrm{YNbO}_{4}$ : $\mathrm{Bi}$ powders with different Bi content, carried out by the methods of the steady-state and time-resolved luminescence spectroscopy in the 4.2-500 K temperature range, the conclusion on their exciton-like origin was made. The most intense emission band peaking at about $2.53 \mathrm{eV}$ and excited around $4.09 \mathrm{eV}$ was ascribed to the radiative decay of an exciton localized around a single $\mathrm{Bi}^{3+}$ ion. The weaker $2.41 \mathrm{eV}$ emission with the superlinear dependence of intensity on the impurity concentration was ascribed to an exciton 
localized around a dimer $\mathrm{Bi}^{3+}$ center. No ultraviolet emission arising from the ${ }^{3} \mathrm{P}_{1,0} \rightarrow{ }^{1} \mathrm{~S}_{0}$ transition of a $\mathrm{Bi}^{3+}$ ion was found. This fact as well as the exciton-like origin of the $\mathrm{Bi}^{3+}$-related emission bands indicate that the triplet excited level of $\mathrm{Bi}^{3+}$ ion is located inside $\mathrm{CB}$ of $\mathrm{YNbO}_{4}$.

Appendix A.11. $\mathrm{Bi}^{3+}$-Doped Borates

In $[1,78,95]$, the luminescence characteristics of $\mathrm{Bi}^{3+}$-doped lanthanide orthoborates $\mathrm{LnBO}_{3}(\mathrm{Ln}$ : $\mathrm{Sc}, \mathrm{Y}, \mathrm{La}, \mathrm{Gd}, \mathrm{Lu}$ ) of different structure and coordination numbers were investigated. In $\mathrm{ScBO}_{3}: \mathrm{Bi}$, the appearance of the vibronic structure of the emission and excitation spectra of $\mathrm{Bi}^{3+}$ centers at low temperatures and the small Stokes shift $(0.22 \mathrm{eV})$ indicate a very small electron-phonon interaction. The energy distance between the emitting and metastable minima of the triplet RES is large $(D=120 \mathrm{meV})$ indicating a strong spin-orbit interaction. For the UV $(3.46 \mathrm{eV})$ emission of $\mathrm{LaBO}_{3}: \mathrm{Bi}$, which also arises from $\mathrm{Bi}^{3+}$ centers, the Stokes shift is much larger $(1.16 \mathrm{eV})$, the decay time at $4.2 \mathrm{~K}$ is several times shorter, and the $\mathrm{D}$ value is about two times smaller $(55 \mathrm{meV})$. These features are caused by much stronger electron-phonon interaction with respect to the spin-orbit interaction in this compound as well as an increase of the probability of the radiative decay of the metastable minima of the triplet RES. Thus, the variation of luminescence characteristics in the sequence of the orthoborates $\mathrm{ScBO}_{3}$ $\rightarrow \mathrm{LuBO}_{3} \rightarrow \mathrm{YBO}_{3} \rightarrow \mathrm{LaBO}_{3}$ is caused by the increasing electron-phonon interaction. The broad VIS emission of $\mathrm{LaBO}_{3}: \mathrm{Bi}(2.69 \mathrm{eV})$ with the large Stokes shift $(1.84 \mathrm{eV})$ ascribed in [78] to $\mathrm{Bi}^{3+}$ pairs or clusters arises most probably from the $\mathrm{Bi}^{3+}$-related localized exciton. Indeed, as follows from the temperature dependence of its decay time, the $\mathrm{D}$ value for the corresponding triplet RES is in an order of magnitude smaller ( $5.7 \mathrm{meV}$ ) as compared to that of the UV emission ( $55 \mathrm{meV}$ ) and is characteristic for the exciton-like states.

Similar broad emission band of $\operatorname{InBO}_{3}$ : $\mathrm{Bi}$ with the large Stokes shift $(1.41 \mathrm{eV})$ was ascribed to the impurity-bound exciton [155]. It was suggested that the lowest excited level of $\mathrm{Bi}^{3+}$ is located inside or close to $\mathrm{CB}$ of $\mathrm{InBO}_{3}$. The excitation of $\mathrm{Bi}^{3+}$ results in the release of an electron into $\mathrm{CB}$ with the subsequent recombination with the hole on the luminescence center and formation of an impurity-trapped exciton.

\section{References}

1. Blasse, G.; Bril, A. Investigations on $\mathrm{Bi}^{3+}$-activated phosphors. J. Chem. Phys. 1968, 48, 217-222. [CrossRef]

2. Lushchik, C.; Gindina, R.; Zazubovich, S.; Lushchik, N. Nature of the luminescence centers in ionic crystals. Czechoslov. J. Phys. 1970, 20B, 585-604. [CrossRef]

3. Boulon, G. Processus de photoluminescence dans les oxydes et les orthovanadates de terres rares polycristallins actives par l'ion Bi ${ }^{3+}$. J. de Physique (France) 1971, 32, 333-347. [CrossRef]

4. Boulon, G. Spectroscopy of post-transition metal ions. In Spectroscopy of Solid-State Laser-Type Materials; Di Bartolo, B., Ed.; Plenum Press: New York, NY, USA, 1987; Volume 30, pp. 223-266.

5. Blasse, G. Luminescence of inorganic solids: From isolated centers to concentrated systems. Prog. Solid State Chem. 1988, 18, 79-171. [CrossRef]

6. Blasse, G.; Grabmaier, B.C. Luminescent Materials; Springer: Berlin, Germany, 1994.

7. Boutinaud, P. Revisiting the spectroscopy of the $\mathrm{Bi}^{3+}$ ion in oxide compounds. Inorg. Chem. 2013, 52, 6028-6038. [CrossRef]

8. Sun, H.-T.; Zhou, J.; Qui, J. Recent advances in bismuth activated photonic materials. Prog. Mater. Sci. 2014, 64, 1-72. [CrossRef]

9. Zazubovich, S.; Krasnikov, A.; Zorenko, Y.; Gorbenko, V.; Babin, V.; Mihokova, E.; Nikl, M. Luminescence of $\mathrm{Pb}$ - and Bi-related centers in aluminum garnet, perovskite and orthosilicate single crystalline films. In Nanocomposite, Ceramic and Thin Film Scintillators; Nikl, M., Ed.; Pan Stanford Publishing Pte. Ltd.: Singapore, 2016; Chapter 6; pp. 227-302.

10. Awater, R.H.P.; Dorenbos, P. The $\mathrm{Bi}^{3+} 6 \mathrm{~s}$ and $6 \mathrm{p}$ electron binding energies in relation to the chemical environment of inorganic compounds. J. Lumin. 2017, 184, 221-231. [CrossRef]

11. Swart, H.C.; Kroon, R.E. Ultraviolet and visible luminescence from bismuth doped materials. Opt. Mater. X 2019, 2, 100025. [CrossRef] 
12. Ilmer, M.; Grabmaier, B.C.; Blasse, G. Luminescence of $\mathrm{Bi}^{3+}$ in gallate garnets. Chem. Mat. 1994, 6, $204-206$. [CrossRef]

13. Nikl, M.; Novoselov, A.; Mihokova, E.; Polak, K.; Dusek, M.; McClune, B.; Yoshikawa, A.; Fukuda, T. Photoluminescence of $\mathrm{Bi}^{3+}$ in $\mathrm{Y}_{3} \mathrm{Ga}_{5} \mathrm{O}_{12}$ single-crystal host. J. Phys. Condens. Matter 2005, 17, 3367-3375. [CrossRef]

14. Setlur, A.A.; Srivastava, A.M. The nature of $\mathrm{Bi}^{3+}$ luminescence in garnet hosts. Opt. Mater. 2006, $29,410-415$. [CrossRef]

15. Zorenko, Y.; Gorbenko, V.; Voznyak, T.; Vistovsky, V.; Nedilko, S.; Nikl, M. Luminescence of $\mathrm{Bi}^{3+}$ ions in $\mathrm{Y}_{3} \mathrm{Al}_{5} \mathrm{O}_{12}$ :Bi single crystalline films. Radiat. Meas. 2007, 42, 882-886. [CrossRef]

16. Babin, V.; Gorbenko, V.; Krasnikov, A.; Makhov, A.; Mihokova, E.; Nikl, M.; Zazubovich, S.; Zorenko, Y. Origin of $\mathrm{Bi}^{3+}$-related luminescence centers in $\mathrm{Lu}_{3} \mathrm{Al}_{5} \mathrm{O}_{12}$ : $\mathrm{Bi}$ and $\mathrm{Y}_{3} \mathrm{Al}_{5} \mathrm{O}_{12}$ : $\mathrm{Bi}$ single crystalline films and the structure of their relaxed excited states. Phys. Status Solidi B 2012, 249, 1039-1045. [CrossRef]

17. Babin, V.; Gorbenko, V.; Krasnikov, A.; Makhov, A.; Nikl, M.; Zazubovich, S.; Zorenko, Y. Photoluminescence of $\mathrm{Lu}_{3} \mathrm{Al}_{5} \mathrm{O}_{12}: \mathrm{Bi}$ and $\mathrm{Y}_{3} \mathrm{Al}_{5} \mathrm{O}_{12}$ :Bi single crystalline films. Radiat. Meas. 2010, 45, 331-335. [CrossRef]

18. Babin, V.; Gorbenko, V.; Krasnikov, A.; Makhov, A.; Nikl, M.; Polak, K.; Zazubovich, S.; Zorenko, Y. Peculiarities of excited state structure and photoluminescence in $\mathrm{Bi}^{3+}$-doped $\mathrm{Lu}_{3} \mathrm{Al}_{5} \mathrm{O}_{12}$ single-crystalline films. J. Phys. Condens. Matter 2009, 21, 415502. [CrossRef]

19. Zorenko, Y.; Mares, J.A.; Kucerkova, R.; Gorbenko, V.; Savchun, V.; Voznyak, T.; Nikl, M.; Beitlerova, A.; Jurek, K. Optical, luminescence and scintillation characteristics of Bi-doped LuAG and YAG single crystalline films. J. Phys. D Appl. Phys. 2009, 42, 075501. [CrossRef]

20. Babin, V.; Gorbenko, V.; Krasnikov, A.; Mihokova, E.; Nikl, M.; Zazubovich, S.; Zorenko, Y. Photoluminescence and excited state structure in $\mathrm{Bi}^{3+}$-doped $\mathrm{Y}_{2} \mathrm{SiO}_{5}$ single crystalline films. Radiat. Meas. 2013, 56, 90-93. [CrossRef]

21. Gorbenko, V.; Krasnikov, A.; Mihokova, E.; Nikl, M.; Zazubovich, S.; Zorenko, Y. Photoluminescence and excited state structure of $\mathrm{Bi}^{3+}$-related centers in $\mathrm{Lu}_{2} \mathrm{SiO}_{5}$ :Bi single crystalline films. J. Lumin. 2013, 134, 469-476. [CrossRef]

22. Krasnikov, A.; Lipińska, L.; Mihokova, E.; Nikl, M.; Shalapska, T.; Suchocki, A.; Zazubovich, S.; Zhydachevskii, Y. Time-resolved photoluminescence and excited state structure of $\mathrm{Bi}^{3+}$ center in $\mathrm{YAlO}_{3}$. Opt. Mater. 2014, 36, 1705-1708. [CrossRef]

23. Chen, L.; Zheng, H.; Cheng, J.; Song, P.; Yang, G.; Zhang, G.; Wu, C. Site-selective luminescence of Bi ${ }^{3+}$ in the YBO3 host under vacuum ultraviolet excitation at low temperature. J. Lumin. 2008, 128, 2027-2030. [CrossRef]

24. Srivastava, A.M.; Camardello, S.J. Concentration dependence of the $\mathrm{Bi}^{3+}$ luminescence in $\mathrm{LnPO}_{4}\left(\mathrm{Ln}=\mathrm{Y}^{3+}\right.$, $\left.\mathrm{Lu}^{3+}\right)$. Opt. Mater. 2015, 39, 130-133. [CrossRef]

25. $\mathrm{Mu}, \mathrm{Z}$;; $\mathrm{Hu}, \mathrm{Y}$.; Chen, L.; Wang, X. Enhanced luminescence of $\mathrm{Dy}^{3+}$ in $\mathrm{Y}_{3} \mathrm{Al}_{5} \mathrm{O}_{12}$ by $\mathrm{Bi}^{3+}$ co-doping. J. Lumin. 2011, 131, 1687-1691. [CrossRef]

26. Chen, L.; Chen, K.J.; Lin, C.C.; Chu, C.I.; Hu, S.F.; Lee, M.H.; Liu, R.S. Combinatorial approach to the development of a single mass $\mathrm{YVO}_{4}: \mathrm{Bi}^{3+}, \mathrm{Eu}^{3+}$ phosphor with red and green dual colors for high color rendering white light-emitting diodes. J. Comb. Chem. 2010, 12, 587-594. [CrossRef] [PubMed]

27. Xia, Z.; Chen, D.; Yang, M.; Ying, T. Synthesis and luminescence properties of $\mathrm{YVO}_{4}: \mathrm{Eu}^{3+}, \mathrm{Bi}^{3+}$ phosphor with enhanced photoluminescence by $\mathrm{Bi}^{3+}$ doping. J. Phys. Chem. Sol. 2010, 71, 175-180. [CrossRef]

28. Kang, F.; Peng, M.; Zhang, Q.; Qiu, J. Abnormal anti-quenching and controllable multi-transitions of $\mathrm{Bi}^{3+}$ luminescence by temperature in a yellow-emitting $\mathrm{LuVO}_{4}: \mathrm{Bi}^{3+}$ phosphor for UV-converted white LEDs. Chem. Eur. J. 2014, 20, 11522-11530. [CrossRef] [PubMed]

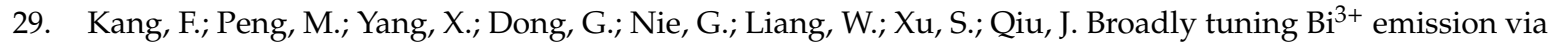
crystal field modulation in solid solution compounds $(\mathrm{Y}, \mathrm{Lu}, \mathrm{Sc}) \mathrm{VO}_{4}: \mathrm{Bi}$ for ultraviolet converted white LEDs. J. Mater. Chem. C 2014, 2, 6068-6076. [CrossRef]

30. Kang, F.; Yang, X.; Peng, M.; Wondraczek, L.; Ma, Z.; Zhang, Q.; Qiu, J. Red photoluminescence from Bi ${ }^{3+}$ and the influence of the oxygen-vacancy perturbation in $\mathrm{ScVO}_{4}$ : A combined experimental and theoretical study. J. Phys. Chem. C 2014, 118, 7515-7522. [CrossRef]

31. Kang, F.; Zhang, Y.; Wondraczek, L.; Zhu, J.; Yang, X.; Peng, M. Processing-dependence and the nature of the blue-shift of $\mathrm{Bi}^{3+}$-related photoemission in $\mathrm{ScVO}_{4}$ at elevated temperatures. J. Mater. Chem. 2014, 2, 9850-9857. 
32. Kang, F.; Zhang, Y.; Peng, M. Controlling the energy transfer via multiluminescent centers to achieve white light/tunable emissions in a single-phased $\mathrm{X} 2$-type $\mathrm{Y}_{2} \mathrm{SiO}_{5}: \mathrm{Eu}^{3+}, \mathrm{Bi}^{3+}$ phosphor for ultraviolet converted LEDs. Inorg. Chem. 2015, 54, 1462-1473. [CrossRef]

33. Huang, X.Y.; Wang, J.X.; Yu, D.C.; Ye, S.; Zhang, Q.Y.; Sun, X.W. Spectral conversion for solar cell efficiency enhancement using $\mathrm{YVO}_{4}: \mathrm{Bi}^{3+}, \mathrm{Ln}^{3+}(\mathrm{Ln}=\mathrm{Dy}, \mathrm{Er}, \mathrm{Ho}, \mathrm{Eu}, \mathrm{Sm}$, and $\mathrm{Yb})$ phosphors. J. Appl. Phys. 2011, 109, 113526. [CrossRef]

34. Chen, D.; Yu, Y.; Huang, P.; Lin, H.; Shan, Z.; Zeng, L.; Yang, A.; Wang, Y. Color-tunable luminescence for $\mathrm{Bi}^{3+} / \mathrm{Ln}^{3+}: \mathrm{YVO}_{4}(\mathrm{Ln}=\mathrm{Eu}, \mathrm{Sm}, \mathrm{Dy}, \mathrm{Ho})$ nanophosphors excitable by near-ultraviolet light. Phys. Chem. Chem. Phys. 2010, 12, 7775-7778. [CrossRef] [PubMed]

35. Zeng, L.; Tang, Q.; Lin, B.; Zhou, H.; Liu, G.; Li, Y.; Chen, D. Fabrication of $\mathrm{Bi}^{3+} / \mathrm{Ln}^{3+}: \mathrm{LuVO}_{4}(\mathrm{Ln}=\mathrm{Eu}, \mathrm{Sm}$, Dy, Ho) nanophosphors and its color-tunable optical performance. J. Lumin. 2018, 194, 667-674. [CrossRef]

36. Park, W.J.; Jung, M.K.; Im, S.J.; Yoon, D.H. Photoluminescence characteristics of energy transfer between Bi ${ }^{3+}$ and $\mathrm{Eu}^{3+}$ in $\mathrm{LnVO}_{4}$ : Eu, Bi (Ln = Y, La, Gd). Colloids Surf. A Physicochem. Eng. Asp. 2008, 313-314, 373-377. [CrossRef]

37. Lenczewska, K.; Tomala, R.; Hreniak, D. Near-UV sensitized NIR emission in $\mathrm{Nd}^{3+}$ and $\mathrm{Bi}^{3+}$ co-doped $\mathrm{GdVO}_{4}$ phosphors. Opt. Mater. 2017, 74, 12-15. [CrossRef]

38. Zeng, L.; Liu, Y.; Lin, B.; Tang, Q.; Zhou, H.; Zeng, J.; Liu, G.; Chen, D. Rational design of $\mathrm{Bi}^{3+} / \mathrm{Ln}^{3+}: \mathrm{GdVO}_{4}$ $(\mathrm{Ln}=\mathrm{Eu}, \mathrm{Sm}, \mathrm{Dy}, \mathrm{Ho})$ nanophosphor: Synthesis, characterization and color-tunable property. Opt. Mater. 2018, 77, 204-210. [CrossRef]

39. Natarajan, V.; Dhobale, A.R.; Lu, C.-H. Preparation and characterization of tunable $\mathrm{YVO}_{4}: \mathrm{Bi}^{3+}, \mathrm{Sm}^{3+}$ phosphors. J. Lumin. 2009, 129, 290-293. [CrossRef]

40. Zhao, M.; Li, G.; Zheng, J.; Li, L.; Yang, L. Fabrication of assembled-spheres $\mathrm{YVO}_{4}:\left(\mathrm{Ln}^{3+}, \mathrm{Bi}^{3+}\right)$ towards optically tunable emission. CrystEngComm. 2012, 14, 2062-2070. [CrossRef]

41. Lenczewska, K.; Gerasymchuk, Y.; Vu, N.; Liem, N.Q.; Boulon, G.; Hreniak, D. The size effect on the energy transfer in $\mathrm{Bi}^{3+}-\mathrm{Eu}^{3+}$ co-doped $\mathrm{GdVO}_{4}$ nanocrystals. J. Mater. Chem. C 2017, 5, 3014-3023. [CrossRef]

42. Matos, M.G.; Rocha, L.A.; Nassar, E.J.; Verelst, M. Influence of $\mathrm{Bi}^{3+}$ ions on the excitation wavelength of the $\mathrm{YVO}_{4}: \mathrm{Eu}^{3+}$ matrix. Opt. Mater. 2016, 62, 12-18.

43. Yang, L.; Mi, X.; Su, J.; Zhang, X.; Bai, Z.; Wang, N.; Lin, J. Tunable luminescence and energy transfer properties in $\mathrm{YVO}_{4}: \mathrm{Bi}^{3+}, \mathrm{Ln}^{3+}(\mathrm{Ln}=\mathrm{Dy}, \mathrm{Sm}, \mathrm{Eu})$ phosphors prepared by microwave sintering method. J. Mater. Sci. Mater. Electron. 2018, 29, 7941-7951. [CrossRef]

44. Cavalli, E.; Angiuli, F.; Belletti, A.; Boutinaud, P. Luminescence spectroscopy of $\mathrm{YVO}_{4}: \mathrm{Ln}^{3+}, \mathrm{Bi}^{3+}\left(\mathrm{Ln}^{3+}=\right.$ $\mathrm{Eu}^{3+}, \mathrm{Sm}^{3+}, \mathrm{Dy}^{3+}$ ) phosphors. Opt. Mater. 2014, 36, 1642-1648. [CrossRef]

45. Park, W.J.; Jung, M.K.; Yoon, D.H. Influence of $\mathrm{Eu}^{3+}, \mathrm{Bi}^{3+}$ co-doping content on photoluminescence of $\mathrm{YVO}_{4}$ red phosphors induced by ultraviolet excitation. Sens. Actuators B 2007, 126, 324-327. [CrossRef]

46. Zhydachevskii, Y.; Lipińska, L.; Baran, M.; Berkowski, M.; Suchocki, A.; Reszka, A. Broadband down-conversion in $\mathrm{Bi}^{3+}-\mathrm{Yb}^{3+}$-codoped yttrium and yttrium-aluminum oxides. Mater. Chem. Phys. 2014, 143, 622-628. [CrossRef]

47. Huang, X.Y.; Zhang, Q.Y. Near-infrared quantum cutting via cooperative energy transfer in $\mathrm{Gd}_{2} \mathrm{O}_{3}: \mathrm{Bi}^{3+}$, $\mathrm{Yb}^{3+}$ phosphors. J. Appl. Phys. 2010, 107, 063505. [CrossRef]

48. Zhydachevskyy, Y.; Tsiumra, V.; Baran, M.; Lipińska, L.; Sybilski, P.; Suchocki, A. Quantum efficency of the down-conversion process in $\mathrm{Bi}^{3+}-\mathrm{Yb}^{3+}$ co-doped $\mathrm{Gd}_{2} \mathrm{O}_{3}$. J. Lumin. 2018, 196, 169-173. [CrossRef]

49. Zhuang, Y.; Ueda, J.; Tanabe, S. Photochromism and white long-lasting persistent luminescence in $\mathrm{Bi}^{3+}$-doped $\mathrm{ZnGa}_{2} \mathrm{O}_{4}$ ceramics. Opt. Mater. Express 2012, 2, 1378-1383. [CrossRef]

50. Wang, S.; Chen, W.; Zhou, D.; Qui, J.; Xu, X.; Yu, X. Long persistent properties of $\mathrm{CaGa}_{2} \mathrm{O}_{4}: \mathrm{Bi}^{3+}$ at different ambient temperature. J. Am. Ceram. Soc. 2017, 100, 3514-3521. [CrossRef]

51. Wang, T.; Xu, X.; Zhou, D.; Yang, Y.; Qui, J.; Yu, X. Effect of defect distribution on the optical storage properties of strontium gallates with a low-dimensional chain structure. Inorg. Chem. 2016, 55, 894-901. [CrossRef]

52. Jia, D.D.; Zhu, J.; Wu, B.Q. Improvement of persistent phosphorescence of $\mathrm{Ca}_{0.9} \mathrm{Sr}_{0.1} \mathrm{~S}_{\mathrm{Bi}^{3+}}$ by codoping $\mathrm{Tm}^{3+}$. J. Lumin. 2000, 91, 59-65. [CrossRef]

53. Sun, W.; Pang, R.; Li, H.; Li, D.; Jiang, L.; Zhang, S.; Fu, J.; Li, C. Investigation of a novel color tunable long afterglow phosphor $\mathrm{KGaGeO}_{4}: \mathrm{Bi}^{3+}$ : Luminescence properties and mechanism. J. Mater. Chem. C 2017, 5, 1346-1355. [CrossRef] 
54. Jin, Y.; Hu, Y.; Chen, L.; Wang, X.; Ju, G.; Mu, Z. Persistent luminescence in $\mathrm{Bi}^{3+}$ doped $\mathrm{CaWO}_{4}$ matrix. Radiat. Meas. 2013, 51-52, 18-24. [CrossRef]

55. Yang, Z.; Liao, J.; Wang, T.; Wu, H.; Qiu, J.; Song, Z.; Zhou, D. Ultraviolet long afterglow emission in $\mathrm{Bi}^{3+}$ doped $\mathrm{CdSiO}_{3}$ phosphors. Mater. Express 2014, 4, 172-176. [CrossRef]

56. Liu, Z.; Ding, Y.; Meng, C.Z.Y.; Tang, J.; Qiu, Q. An efficient UV converted blue-emitting $\mathrm{Lu}_{2} \mathrm{CaGeO}_{6}: \mathrm{Bi}^{3+}$ persistent phosphor for potential application in photocatalysis. Ceramics. Int. 2018, 44, 14712-14716. [CrossRef]

57. Dou, X.; Xiang, H.; Wei, P.; Zhang, S.; Ju, G.; Meng, Z.; Chen, L.; Hu, Y.; Li, Y. A novel phosphor $\mathrm{CaZnGe}_{2} \mathrm{O}_{6}: \mathrm{Bi}^{3+}$ with persistent luminescence and photo-stimulated luminescence. Mater. Res. Bull. 2018, 105, 226-230. [CrossRef]

58. Wang, X.; Boutinaud, P.; Li, L.; Cao, J.; Xiong, P.; Li, X.; Luo, H.; Peng, M. Novel persistent and tribo-luminescence from bismuth ion pairs doped strontium gallate. J. Mater. Chem. C 2018, 6, 10367-10375. [CrossRef]

59. Wang, W.; Sun, Z.; He, X.; Wei, Y.; Zou, Z.; Zhang, J.; Wang, Z.; Zhang, Z.; Wang, Y. How to design ultraviolet emitting persistent materials for potential multifunctional applications: A living example of a $\mathrm{NaLuGeO}_{4}: \mathrm{Bi}^{3+}, \mathrm{Eu}^{3+}$ phosphor. J. Mater. Chem. C 2017, 5, 4310-4318. [CrossRef]

60. Feng, P.; Wei, Y.; Wang, Y.; Zhang, J.; Li, H.; Ci, Z.; Xie, R. Long persistent phosphor $\mathrm{CdSiO}_{3}: \mathrm{Gd}^{3+}, \mathrm{Bi}^{3+}$ and potential photocatalytic application of $\mathrm{CdSiO}_{3}: \mathrm{Gd}^{3+}, \mathrm{Bi}^{3+} @ \mathrm{TiO}_{2}$ in dark. J. Amer. Ceram. Soc. 2016, 99, 2368-2375. [CrossRef]

61. Lai, S.; Yang, Z.; Liao, J.; Qiu, J.; Song, Z.; Yang, Y.; Zhou, D. Investigation of persistent luminescence property of $\mathrm{Bi}^{3+}, \mathrm{Dy}^{3+}$ co-doped $\mathrm{CdSiO}_{3}$ phosphor. Mater. Res. Bull. 2014, 60, 714-718. [CrossRef]

62. Xiong, P.; Peng, M. Recent advances in ultraviolet persistent phosphors. Opt. Mater. X 2019, $2,100022$. [CrossRef]

63. Back, M.; Ueda, J.; Xu, J.; Asami, K.; Amidani, L.; Trave, E.; Tanabe, S. Uncovering the origin of the emitting states in $\mathrm{Bi}^{3+}$-activated $\mathrm{CaMO}_{3}(\mathrm{M}=\mathrm{Zr}, \mathrm{Sn}, \mathrm{Ti})$ perovskites: Metal-to-metal charge transfer versus $\mathrm{s}-\mathrm{p}$ transitions. J. Phys. Chem. C 2019, 123, 14677-14688. [CrossRef]

64. Boutinaud, P.; Cavalli, E. Predicting metal-to-metal charge transfer in closed-shell transition metal oxides doped with $\mathrm{Bi}^{3+}$ or $\mathrm{Pb}^{2+}$. Chem. Phys. Lett. 2011, 503, 239-243. [CrossRef]

65. Amer, M.; Boutinaud, P. On the character of the optical transitions in closed-shell transition metal oxides doped with $\mathrm{Bi}^{3+}$. Phys. Chem. Chem. Phys. 2017, 19, 2591-2596. [CrossRef] [PubMed]

66. Eucken, A. (Ed.) Landolt-Börnstein Zahlenwerte und Funktionen, I Band, Atom- und Molekularphysik, I Teil, Atome und Ionen; Springer: Berlin, Germany, 1950; p. 439.

67. Lushchik, N.E.; Lushchik, C.B. Spectroscopy of luminescence centers in alkali halides activated by gomological rows of ions. Sov. Phys. Opt. Spectrosc. 1960, 8, 839-846.

68. Blasse, G.; van der Steen, A.C. Luminescence characteristics of $\mathrm{Bi}^{3+}$-activated oxides. Solid St. Commun. 1979, 31, 993-994. [CrossRef]

69. Moncorge, R.; Jacquier, B.; Boulon, G. Temperature dependent luminescence of $\mathrm{Bi}_{4} \mathrm{Ge}_{3} \mathrm{O}_{12}$ : Discussion of possible models. J. Lumin. 1976, 14, 337-348.

70. Babin, V.; Lipińska, L.; Mihokova, E.; Nikl, M.; Shalapska, T.; Suchocki, A.; Zazubovich, S.; Zhydachevskii, Y. Time-resolved spectroscopy of $\mathrm{Bi}^{3+}$ centers in $\mathrm{Y}_{4} \mathrm{Al}_{2} \mathrm{O}_{9}$. Opt. Mater. 2015, 46, 104-108. [CrossRef]

71. Babin, V.; Chernenko, K.; Lipińska, L.; Mihokova, E.; Nikl, M.; Schulman, L.S.; Shalapska, T.; Suchocki, A.; Zazubovich, S.; Zhydachevskii, Y. Luminescence and excited state dynamics of $\mathrm{Bi}^{3+}$ centers in $\mathrm{Y}_{2} \mathrm{O}_{3}$. J. Lumin. 2015, 167, 268-277. [CrossRef]

72. Babin, V.; Chernenko, K.; Demchenko, P.; Mihokova, E.; Nikl, M.; Pashuk, I.; Shalapska, T.; Voloshinovskii, A.; Zazubovich, $\mathrm{S}$. Luminescence and excited state dynamics in $\mathrm{Bi}^{3+}$-doped $\mathrm{LiLaP}_{4} \mathrm{O}_{12}$ phosphates. J. Lumin. 2016, 176, 324-330. [CrossRef]

73. Buryi, M.; Bohacek, P.; Chernenko, K.; Krasnikov, A.; Laguta, V.V.; Mihokova, E.; Nikl, M.; Zazubovich, S. Luminescence and photo-thermally stimulated defect-creation processes in $\mathrm{Bi}^{3+}$-doped single crystals of lead tungstate. Phys. Status Solidi B 2016, 253, 895-910. [CrossRef]

74. Krasnikov, A.; Luchechko, A.; Mihokova, E.; Nikl, M.; Syvorotka, I.I.; Zazubovich, S.; Zhydachevskii, Y. Origin of $\mathrm{Bi}^{3+}$-related luminescence in $\mathrm{Gd}_{3} \mathrm{Ga}_{5} \mathrm{O}_{12}$ :Bi epitaxial films. J. Lumin. 2017, 190, 81-88. [CrossRef] 
75. Tsiumra, V.; Krasnikov, A.; Zazubovich, S.; Zhydachevskyy, Y.; Vasylechko, L.; Baran, M.; Wachnicki, L.; Lipinska, L.; Nikl, M.; Suchocki, A. Crystal structure and luminescence studies of microcrystalline GGG:Bi ${ }^{3+}$ and GGG:Bi ${ }^{3+}, \mathrm{Eu}^{3+}$ as UV-to-VIS converting phosphors for white LEDs. J. Lumin. 2019, 213, 278-289. [CrossRef]

76. Krasnikov, A.; Tsiumra, V.; Vasylechko, L.; Zazubovich, S.; Zhydachevskyy, Y. Photoluminescence origin in $\mathrm{Bi}^{3+}$-doped $\mathrm{YVO}_{4}, \mathrm{LuVO}_{4}$, and $\mathrm{GdVO}_{4}$ orthovanadates. J. Lumin. 2019, 212, 52-60. [CrossRef]

77. Baran, M.; Kissabekova, A.; Krasnikov, A.; Lushchik, A.; Suchocki, A.; Tsiumra, V.; Vasylechko, L.; Zazubovich, S.; Zhydachevskyy, Y. Exciton-like luminescence of $\mathrm{Bi}^{3+}$ - doped yttrium niobate. Nucl. Instrum. Meth. Phys. Res. B 2020, 463, 7-15. [CrossRef]

78. Wolfert, A.; Oomen, E.W.J.L.; Blasse, G. Host lattice dependence of the $\mathrm{Bi}^{3+}$ luminescence in orthoborates $\mathrm{LnBO}_{3}$ (with Ln = Sc, Y, La, Gd, or Lu). J. Solid St. Chem. 1985, 59, 280-290. [CrossRef]

79. Hughes, A.E.; Pells, G.P. The luminescence spectra of $\mathrm{Bi}^{3+}$ ions in $\mathrm{MgO}$ and CaO. Phys. Status Solidi B 1975, 71, 707-718. [CrossRef]

80. Boulon, G.; Pedrini, C.; Guidoni, M.; Pannel, C. Étude de la cinétique des centres luminogènes Bi ${ }^{3+}$ dans les cristaux. J. de Physique (France) 1975, 36, 267-278. [CrossRef]

81. Pedrini, C.; Boulon, G.; Gaume-Mahn, F. $\mathrm{Bi}^{3+}$ and $\mathrm{Pb}^{2+}$ centres in alkaline-earth antimonate phosphors. Phys. Status Solidi A 1973, 15, K15-K18. [CrossRef]

82. Moncorge, R.; Boulon, G.; Jacquier, B. Analysis of fluorescence processes of bismuth (3+) centers incorporated into lanthanum oxysulfate $\left(\mathrm{La}_{2} \mathrm{SO}_{6}\right)$. Compt. Rend. Acad. Sci. Paris Ser. B 1976, 282, 239-242.

83. Moncorge, R.; Boulon, G.; Denis, J. Fluorescence properties of bismuth-doped $\mathrm{LaPO}_{4}$. J. Phys. C Solid State Phys. 1979, 12, 1165-1171. [CrossRef]

84. Ellervee, A.F. Luminescence of $\mathrm{Pb}^{2+}$ and $\mathrm{Bi}^{3+}$ centres in alkali-earth sulphides and oxides. Phys. Status Solidi $B$ 1977, 82, 91-98. [CrossRef]

85. Aceves, R.; Barboza Flores, M.; Maaroos, A.; Nagirnyi, V.; Perez Salas, R.; Tsuboi, T.; Zazubovich, S.; Zepelin, V. RES structure of $\mathrm{Bi}^{3+}$ centres in $\mathrm{KCl}: \mathrm{Bi}, \mathrm{S}$ and CaO:Bi crystals. Phys. Status Solidi B 1996, 194, 619-631. [CrossRef]

86. Asano, S.; Nakao, Y.; Yamashita, N.; Matsuyama, I. Luminescence et transition non radiative ${ }^{3} \mathrm{~T}_{1 \mathrm{u}} \rightarrow{ }^{3} \mathrm{~A}_{1 \mathrm{u}}$ dans le luminophore BaS:Bi ${ }^{3+}$. Phys. Status Solidi B 1986, 133, 333-344. [CrossRef]

87. Donker, H.; Yamashita, N.; Smit, W.M.A.; Blasse, G. Luminescence decay times of the $\mathrm{Sb}^{2+}, \mathrm{Pb}^{2+}$, and $\mathrm{Bi}^{3+}$ ions in alkaline-earth sulfides. Phys. Status Solidi B 1989, 156, 537-544. [CrossRef]

88. Asano, S.; Yamashita, N. Luminescence et interaction phonon-electron dans le luminophore $\mathrm{MgS}: \mathrm{Bi}^{3+}$. Phys. Status Solidi B 1981, 105, 305-310. [CrossRef]

89. Asano, S.; Yamashita, N. Effect of magnetic field on luminescence of MgS, CaS and CaO phosphors activated with $\mathrm{Bi}^{3+}$ ions. Phys. Lett. A 1981, 86, 191-193. [CrossRef]

90. Yamashita, N.; Iwasaki, S.; Asano, S.; Ohishi, M.; Ohmori, K. Investigation of the luminescence in the SrS:Bi ${ }^{3+}$ phosphor by time-resolved emission spectroscopy. J. Phys. Soc. Japan 1984, 53, 4425-4431. [CrossRef]

91. Yamashita, N.; Ikeda, S.; Asano, S. Photoluminescence and excitation spectra of the SrO:Bi ${ }^{3+}$ phosphor. Phys. Lett. A 1987, 121, 94-96. [CrossRef]

92. Oboth, K.P.; Lohmeier, F.J.; Fisher, F. VUV and UV spectroscopy of $\mathrm{Pb}^{2+}$ and $\mathrm{Bi}^{3+}$ centres in alkaline-earth fluorides. Phys. Status Solidi B 1989, 154, 789-803. [CrossRef]

93. Wolfert, A.; Blasse, G. Luminescence of $\mathrm{Bi}^{3+}$-activated $\mathrm{LaOBr}$, a system with emission from different states. J. Lumin. 1985, 33, 213-226. [CrossRef]

94. Kang, J.G.; Yoon, H.M.; Chun, G.M.; Kim, Y.D.; Tsuboi, T. Spectroscopic studies of Bi ${ }^{3+}$ colour centres in $\mathrm{KCl}$ single crystals. J. Phys. Condens. Matter 1994, 6, 2101-2116. [CrossRef]

95. Wolfert, A.; Oomen, E.W.J.L.; Blasse, G. Host lattice dependence of the $\mathrm{Bi}^{3+}$ luminescence in orthoborates $\mathrm{LnBO}_{3}$. J. Lumin. 1984, 31-32, 308-310. [CrossRef]

96. Zazubovich, S.G.; Lushchik, N.E.; Lushchik, C.B. Polarized luminescence of KCl:Bi phosphor. Trudy IFA AN EstSSR 1961, 14, 292-293.

97. Wolfert, A.; Blasse, G. Luminescence of $\mathrm{B}^{\mathrm{i} 3+}$-doped crystals of $\mathrm{Cs}_{2} \mathrm{NaYBr}_{6}$ and $\mathrm{Cs}_{2} \mathrm{NaLaCl}_{6}$. J. Solid State Chem. 1985, 59, 133-142. [CrossRef]

98. van der Steen, A.C. Luminescence of $\mathrm{Cs}_{2} \mathrm{NaYCl}_{6}-\mathrm{Bi}^{3+}\left(6 \mathrm{~s}^{2}\right)$. Phys. Status. Solidi B 1980, 100, $603-611$. [CrossRef] 
99. Wolfert, A.; Blasse, G. Luminescence of the $\mathrm{Bi}^{3+}$ ion in compounds LnOCI ( $\left.\mathrm{Ln}=\mathrm{La}, \mathrm{Y}, \mathrm{Gd}\right)$. Mater. Res. Bull. 1984, 19, 67-75. [CrossRef]

100. Boulon, G.; Jorgensen, C.K.; Reisfeld, R. The two luminescent levels of $\mathrm{Bi}^{3+}$ in solids. Chem. Phys. Lett. 1980, 75, 24-26. [CrossRef]

101. Xiao, X.; Yan, B. Hybrid precursors synthesis and optical properties of $\mathrm{LnNbO}_{4}: \mathrm{Bi}^{3+}$ blue phosphors and $\mathrm{Bi}^{3+}$ sensitizing of on $\mathrm{Dy}^{3+}$ 's luminescence in $\mathrm{YNbO}_{4}$ matrix. J. Alloy. Compd. 2006, 421, 252-257. [CrossRef]

102. Blasse, G.; Dirksen, G.J. The luminescence of broad-band emitters in LiLaP $\mathrm{O}_{12}$. Phys. Status Solidi B 1982, 110, 487-494. [CrossRef]

103. Awater, R.H.P.; Dorenbos, P. X-ray induced valence change and vacuum referred binding energies of $\mathrm{Bi}^{3+}$ and $\mathrm{Bi}^{2+}$ in $\mathrm{Li}_{2} \mathrm{BaP}_{2} \mathrm{O}_{7}$. J. Phys. Chem. C 2016, 120, 15114-15118. [CrossRef]

104. Zhiran, H.; Blasse, G. Energy transfer phenomena in luminescent materials based on $\mathrm{GdB}_{3} \mathrm{O}_{6}$. Mater. Chem. Phys. 1985, 12, 257-274. [CrossRef]

105. Blasse, G.; Meijerink, A.; Nomes, M.; Zuidema, J. Unusual Bismuth Luminescence in Strontium Tetraborate (SrB4O7:Bi). J. Phys. Chem. Sol. 1994, 55, 171-174. [CrossRef]

106. Peng, M.; Sprenger, B.; Schmidt, M.A.; Schwefel, H.; Wondraczek, L. Broadband NIR photoluminescence from Bi-doped $\mathrm{Ba}_{2} \mathrm{P}_{2} \mathrm{O}_{7}$ crystals: Insights into the nature of NIR-emitting bismuth centers. Opt. Express 2010, 18, 12852-12863. [CrossRef] [PubMed]

107. Zheng, J.; Peng, M.; Kang, F.; Cao, R.; Ma, Z.; Dong, G.; Qiu, J.; Xu, S. Broadband NIR luminescence from a new bismuth doped $\mathrm{Ba}_{2} \mathrm{~B}_{5} \mathrm{O}_{9} \mathrm{Cl}$ crystal: Evidence for the $\mathrm{Bi}^{0}$ model. Opt. Express 2012, 20, 22569-22578. [CrossRef] [PubMed]

108. Zorenko, Y.; Gorbenko, V.; Voznyak, T.; Nikl, M.; Beitlerova, A.; Jary, V. Bi ${ }^{3+}-\mathrm{Ce}^{3+}$ energy transfer and luminescent properties of LuAG:Bi,Ce and YAG:Bi,Ce single crystalline films. J. Lumin. 2013, 134, 539-543. [CrossRef]

109. Srivastava, A.M.; Comanzo, H.A. The ultraviolet and visible luminescence of $\mathrm{Bi}^{3+}$ in the orthorhombic perovskite, $\mathrm{GdAlO}_{3}$. Opt. Mater. 2017, 63, 118-121. [CrossRef]

110. Zhu, N.-F.; Li, Y.-X.; Yu, X.-F. Luminescence spectra of $Y G G: R^{3+}, \mathrm{Bi}^{3+} \mathrm{RE}=\mathrm{Eu}$ and $\mathrm{Tb}$ ) and energy transfer from $\mathrm{Bi}^{3+}$ to $\mathrm{RE}^{3+}$. Chin. Phys. Lett. 2008, 25, 703-706.

111. Oomen, E.W.J.L.; Blasse, G. Luminescence of $\mathrm{Bi}^{3+}$ in the metaphosphates $\mathrm{LnP}_{3} 0_{9}(\mathrm{Ln}=\mathrm{Sc}, \mathrm{Lu}, \mathrm{Y}, \mathrm{Gd}, \mathrm{La}) . J$. Solid St. Chem. 1988, 75, 201-204. [CrossRef]

112. van de Craats, A.M.; Blasse, G. The quenching of bismuth(III) luminescence in yttrium oxide $\left(\mathrm{Y}_{2} \mathrm{O}_{3}\right)$. Chem. Phys. Lett. 1995, 243, 559-563. [CrossRef]

113. Awater, R.H.P.; Niemeijer-Berghuijs, L.C.; Dorenbos, P. Luminescence and charge carrier trapping in $\mathrm{YPO}_{4}: B i$. Opt. Mater. 2017, 66, 351-355. [CrossRef]

114. Srivastava, A.M. Luminescence of $\mathrm{Bi}^{3+}$ in the orthorhombic perovskites $\mathrm{CaB}^{4+} \mathrm{O}_{3}\left(\mathrm{~B}^{4+}=\mathrm{Zr}, \mathrm{Sn}\right)$ : Crossover from localized to D-state emission. Opt. Mater. 2016, 58, 89-92. [CrossRef]

115. Srivastava, A.M. Luminescence of $\mathrm{Bi}^{3+}$ in the orthorhombic perovskites, $\mathrm{SrB}^{4+} \mathrm{O}_{3}\left(\mathrm{~B}^{4+}=\mathrm{Zr}\right.$, Sn). Opt. Mater. 2017, 72, 313-315. [CrossRef]

116. Srivastava, A.M. Luminescence of $\mathrm{Bi}^{3+}$ in $\mathrm{LaGaO}_{3}$. Mater. Res. Bull. 1999, 34, 1391-1396. [CrossRef]

117. van Steensel, L.I.; Bokhove, S.G.; van de Craats, A.M.; de Blank, J.; Blasse, G. The luminescence of $\mathrm{Bi}^{3+}$ in $\mathrm{LaInO}_{3}$ and some other perovskites. Mater. Res. Bull. 1995, 30, 1359-1362. [CrossRef]

118. Srivastava, A.M.; Comanzo, H.A.; Brik, M.G. The nature of $\mathrm{Bi}^{3+}$ luminescence in the double perovskite $\mathrm{La}_{2} \mathrm{LiSbO}_{6}$. J. Lumin. 2017, 192, 620-625. [CrossRef]

119. Srivastava, A.M. On the luminescence of $\mathrm{Bi}^{3+}$ in the pyrochlore $\mathrm{Y}_{2} \mathrm{Sn}_{2} \mathrm{O}_{7}$. Mater. Res. Bull. 2002, 37, 745-751. [CrossRef]

120. Srivastava, A.M.; Beers, W.W. On the impurity trapped exciton luminescence in $\mathrm{La}_{2} \mathrm{Zr}_{2} \mathrm{O}_{7}: \mathrm{Bi}^{3+}$. J. Lumin. 1999, 81, 293-300. [CrossRef]

121. Kiliaan, H.S.; Blasse, G. A study of the sensitizer in the luminescent systems $\left(\mathrm{Y}, \mathrm{Gd}_{2} \mathrm{O}_{2} \mathrm{SO}_{4}: \mathrm{Bi}, \mathrm{Tb}\right.$ and $\mathrm{Li}_{6}(\mathrm{Y}, \mathrm{Gd})\left(\mathrm{BO}_{3}\right)_{3}: \mathrm{S}, \mathrm{Tb}\left(\mathrm{S}=\mathrm{Ce}^{3+}, \mathrm{Pr}^{3+}\right.$ or $\left.\mathrm{Bi}^{3+}\right)$. Mater. Chem. Phys. 1987, 18, 155-170. [CrossRef]

122. Nagirnyi, V.; Feldbach, E.; Jönsson, L.; Kirm, M.; Kotlov, A.; Svensson, G.; Asberg-Dahlborg, M. Relaxation of electronic excitations in $\mathrm{PbWO}_{4}$ and $\mathrm{CaWO}_{4}$ :Bi crystals. In Proceedings of the Fifth Int. Conf. on Inorganic Scintillators and Their Applications (SCINT99), Moscow, Russia, 16-20 August 1999; Mikhailin, V., Ed.; Moscow State University Press: Moscow, Russia, 2000; pp. 315-320. 
123. Nagirnyi, V.; Kotlov, A.; Jönsson, L.; Kirm, M.; Lushchik, A. Emission decay kinetics in a CaWO $\mathrm{CB}_{4}$ Bi crystal. Nucl. Instrum. Methods Phys. Res. A 2005, 537, 61-65. [CrossRef]

124. Zorenko, Y.; Pashkovsky, M.; Voloshinovskii, A.; Kuklinski, B.; Grinberg, M. The luminescence of $\mathrm{CaWO}_{4}: \mathrm{Bi}$ single crystals. J. Lumin. 2006, 116, 43-51. [CrossRef]

125. Park, T.-K.; Ahn, H.-C.; Mho, S.-I. High concentration of $\mathrm{Bi}^{3+}$ incorporated into $\mathrm{RNbO}_{4}: \mathrm{Eu}^{3+}(\mathrm{R}=\mathrm{La}, \mathrm{Y}, \mathrm{Gd})$ as red phosphors for white LED applications. J. Korean. Phys. Soc. 2008, 52, 431-434. [CrossRef]

126. Srivastava, A.M.; Comanzo, H.A.; Camardello, S.J. On the " $\mathrm{Bi}^{3+}-\mathrm{Ti}^{4+"}$ charge transfer transition in the pyrochlore $\mathrm{Y}_{2} \mathrm{Ti}_{2} \mathrm{O}_{7}: \mathrm{Bi}^{3+}$. Opt. Mater. 2015, 48, 31-35. [CrossRef]

127. Cao, R.; Fu, T.; Xu, H.; Luo, W.; Peng, D.; Chen, Z.; Fu, J. Synthesis and luminescence enhancement of $\mathrm{CaTiO}_{3}$ :Bi yellow phosphor by codoping $\mathrm{Al}^{3+} / \mathrm{B}^{3+}$ ions. J. Alloy. Comp. 2016, 674, 51-55. [CrossRef]

128. Cavalli, E.; Angiuli, F.; Mezzadri, F.; Trevisani, M.; Bettinelli, M.; Boutinaud, P.; Brik, M. Tunable luminescence of $\mathrm{Bi}^{3+}$-doped $\mathrm{YP}_{\mathrm{x}} \mathrm{V}_{1-\mathrm{x}} \mathrm{O}_{4}(0 \leq \mathrm{x} \leq 1)$. J. Phys. Condens. Matter 2014, 26, 385503. [CrossRef] [PubMed]

129. Madej, A.; Witkowski, M.E.; Wojtowicz, A.J.; Zych, E. Photo- and radioluminescent properties of undoped and Bi-doped $\mathrm{Lu}_{2} \mathrm{WO}_{6}$ powders at 10-300K. J. Lumin. 2015, 160, 50-56. [CrossRef]

130. Cao, R.; Quan, G.; Shi, Z.; Luo, Z.; Hu, Q.; Guo, S. A double perovskite $\mathrm{Ca}_{2} \mathrm{MgWO}_{6}$ :Bi yellow-emitting phosphor: Synthesis and luminescence properties. J. Lumin. 2017, 181, 332-336. [CrossRef]

131. Jacobs, P.W.M. Alkali halide crystals containing impurity ions with the $\mathrm{ns}^{2}$ ground-state electronic configuration. J. Phys. Chem. Solids 1991, 52, 35-67. [CrossRef]

132. Zazubovich, S. Polarization spectroscopy of $\mathrm{ns}^{2}$ impurity ions in alkali halides. Int. J. Mod. Phys. B 1994, 8 , 985-1031. [CrossRef]

133. Zavt, G.S.; Ellervee, A.F. $\mathrm{Pb}^{2+}$ and $\mathrm{Bi}^{3+}$ impurity centres in alkali-earth oxides: Vibronic spectra, lattice dynamics, and electron-phonon interaction. Phys. Status Solidi B 1979, 94, 757-768. [CrossRef]

134. Seitz, F. Interpretation of the properties of alkali halide-thallium phosphors. J. Chem. Phys. 1938, 6, 150-162. [CrossRef]

135. Hizhnyakov, V.V.; Kristoffel, N.N. Jahn-Teller mercury-like impurities in ionic crystals. In The Dynamical Jahn-Teller Effect in Localized Systems; Perlin, Y., Wagner, M., Eds.; Elsevier Publ. Co.: Amsterdam, The Netherlands, 1984; Chapter 9; pp. 383-437.

136. Hizhnyakov, V.; Zazubovich, S.; Soovik, T. Kinetics and temperature dependences of polarized emission of anisotropic tin centres in alkali halides. Phys. Status Solidi B 1974, 66, 727-738. [CrossRef]

137. Hizhnyakov, V.V. Adiabatic Potential Energy Surface and Luminescence CHARACTERISTICS of Impurity Centers with Two Optical Electrons; Preprint FI-36; Institute of Physics: Tartu, Estonia, 1975; 27p.

138. Zazubovich, S.G.; Hizhnyakov, V.V. Polarized luminescence and a new model of mercury-like centers in ionic crystals. Izv. Akad. Nauk SSSR Ser. Fiz. 1985, 49, 1874-1879.

139. Nagirnyi, V.; Soovik, T.; Vaino, P.; Zazubovich, S.; Jaanson, N. Triplet relaxed excited state structure and luminescence of thallium-doped alkali halides. Phys. Status Solidi B 1991, 164, 493-502. [CrossRef]

140. Zazubovich, S.G.; Lushchik, N.E. Spectra of luminescence centres of crystals doped with isoelectronic ions. Trudy IFA AN EstSSR 1961, 14, 283-285.

141. Blasse, G. Optical electron transfer between metal ions and its consequences. In Complex Chemistry (Structure and Bonding Series); Springer: Berlin, Germany, 1991; Volume 76, pp. 153-187.

142. Reut, E.G.; Ryskin, A.I. Virtual recharge: Mechanism of radiationless transition in scheelite and fergusonite type crystals doped with rare-earth ions. Phys. Status Solidi A 1973, 17, 47-57. [CrossRef]

143. Anitha, M.; Ramakrishnan, P.; Chatterjee, A.; Alexander, G.; Singh, H. Spectral properties and emission efficiencies of $\mathrm{GdVO}_{4}$ phosphors. Appl. Phys. A 2002, 74, 153-162. [CrossRef]

144. Mahalley, B.N.; Dhoble, S.J.; Pode, R.B.; Alexander, G. Photoluminescence in $\mathrm{GdVO}_{4}: \mathrm{Bi}^{3+}{ }^{3} \mathrm{Eu}^{3+}$ red phosphor. Appl. Phys. A Mater. Sci. Process. 2000, 70, 39-45. [CrossRef]

145. Xie, W.; Tian, C.; Lyu, F.; Wang, Z.; Zou, C.; Kang, F.; Dong, H.; Sun, G. Toward temperature-dependent $\mathrm{Bi}^{3+}$-related tunable emission in the $\mathrm{YVO}_{4}: \mathrm{Bi}^{3+}$ phosphor. J. Am. Ceram. Soc. 2019, 102, 3488-3497. [CrossRef]

146. Zorenko, Y.; Gorbenko, V.; Zorenko, T.; Savchun, V.; Voloshinovskii, A. Luminescent and scintillation properties of $\mathrm{CaWO}_{4}$ and $\mathrm{CaWO}_{4}$ :Bi single crystalline films. In Proceedings of the International Conference on Oxide Materials for Electronic Engineering-Fabrication, Properties and Applications, Lviv, Ukraine, 26-30 May 2014; pp. 253-254.

147. Kang, F.; Peng, M.M. A new study on the energy transfer in the color-tunable phosphor $\mathrm{CaWO}_{4}: \mathrm{Bi}$. Dalton. Trans. 2014, 43, 277-284. [CrossRef] 
148. Zorenko, Y.; Gorbenko, V.; Voznyak, T.; Konstankevych, I.; Savchyn, V.; Batentschuk, M.; Winnacker, A.; Brabec, C.J. Scintillators based on $\mathrm{CdWO}_{4}$ and $\mathrm{CdWO}_{4}$ :Bi single crystalline films. IEEE Trans. Nucl. Sci. 2012, 59, 2281-2285. [CrossRef]

149. Shin, S.H.; Jeon, D.Y.; Suh, K.S. Charge-transfer nature in luminescence of $\mathrm{YNbO}_{4}$ :Bi blue phosphor. J. Appl. Phys. 2001, 90, 5986-5990. [CrossRef]

150. Jiang, Z.; Yu, X.; Gou, J.; Duan, L.; Su, X.; Fan, G.; Duan, Y. Design, luminescence and energy transfer of single-phased color-tunable $\mathrm{YNbO}_{4}: \mathrm{Bi}^{3+}, \mathrm{Eu}^{3+}$, phosphor for UV pumped white light-emitting diodes. $J$. Mater. Sci. Mater. Electron. 2017, 28, 3630-3636. [CrossRef]

151. Zhou, R.; Kou, Y.; Wei, X.; Duan, C.; Chen, Y.; Yin, M. Broadband downconversion based near-infrared quantum cutting via cooperative energy transfer in $\mathrm{YNbO}_{4}: \mathrm{Bi}^{3+}, \mathrm{Yb}^{3+}$ phosphor. Appl. Phys. B 2012, 107, 483-487. [CrossRef]

152. Chen, X.; Li, S.; Salamo, G.J.; Li, Y.; He, L.; Yang, G.; Gao, Y.; Liu, Q. Sensitized intense near-infrared downconversion quantum cutting three-photon luminescence phenomena of the $\mathrm{Tm}^{3+}$ ion activator in $\mathrm{Tm}^{3+} \mathrm{Bi}^{3+}: \mathrm{YNbO}_{4}$ powder phosphor. Opt. Express 2015, 23, A51-A61. [CrossRef]

153. Bang, J.H.; Oh, E.S.; Seo, S.H.; Kim, J.S.; Lee, M.; Park, H.L.; Lee, C.-I.; Kim, C.C.; Kim, K.J. Cathodoluminescence study of $\mathrm{Bi}^{3+}$-doped $\mathrm{YNbO}_{4}$ phosphor. Phys. Status Solidi A 2002, 191, 291-295. [CrossRef]

154. Dorenbos, P. Charge transfer bands in optical materials and related defect level location. Opt. Mater. 2017, 69, 8-22. [CrossRef]

155. Blasse, G.; de Mello Donega, C.; Berezovskaja, I.; Dotsenko, V. The luminescence of bismuth (III) in indium orthoborate. Solid St. Commun. 1994, 91, 29-31. [CrossRef]

156. Tsiumra, V.; Zhyshkovych, A.; Malyi, T.; Chornodolskyy, Y.; Vistovskyy, V.; Syrotyuk, S.; Zhydachevskyy, Y.; Suchocki, A.; Voloshinovskii, A. Localized exciton luminescence in $\mathrm{YVO}_{4}: \mathrm{Bi}^{3+}$. Opt. Mater. 2019, 89, 480-487. [CrossRef]

157. Jing, X.; Gibbons, C.; Nicholas, D.; Silver, J.; Vecht, A.; Frampton, C.S. Blue luminescence in yttrium and gadolinium niobates caused by bismuth. The importance of non-bonding $\mathrm{ns}^{2}$ valence orbital electrons. J. Mater. Chem. 1999, 9, 2913-2918. [CrossRef]

158. Boutinaud, P. On the luminescence of $\mathrm{Bi}^{3+}$ pairs in oxidic compounds. J. Lumin. 2018, 197, 228-232. [CrossRef]

159. Awater, R.H.P.; Dorenbos, P.P. Towards a general concentration quenching model of $\mathrm{Bi}^{3+}$ luminescence. J. Lumin. 2017, 188, 487-489. [CrossRef]

160. Babin, V.; Fabeni, P.; Mihokova, E.; Nikl, M.; Stolovich, A.; Pazzi, G.P.; Zazubovich, S. Time-resolved spectroscopy of exciton states in undoped and doped CsI crystals. In Proceedings of the Fifth International Conference on Inorganic Scintillators and Their Applications (SCINT99), Moscow, Russia, 16-20 August 1999; Mikhailin, V., Ed.; Moscow State University Press: Moscow, Russia, 2000; pp. 544-549.

161. Zazubovich, S. Physics of halide scintillators. Radiat. Meas. 2001, 33, 699-704. [CrossRef]

162. Buth, A.H.; Blasse, G. Luminescence and energy transfer in yttrium niobate $\left(\mathrm{YNbO}_{4}\right)$. Phys. Status Solidi A 1981, 64, 669-676. [CrossRef]

163. Ding, S.; Zhang, H.; Liu, W.; Sun, D.; Zhang, Q. Experimental and first principle investigation the electronic and optical properties of $\mathrm{YNbO}_{4}$ and $\mathrm{LuNbO}_{4}$ phosphors. J. Mater. Sci. Mater. Electron. 2018, 29, 11878-11885. [CrossRef]

164. Liu, X.; Chen, C.; Li, S.; Dai, Y.; Guo, H.; Tang, X.; Xie, Y.; Yan, L. Host-sensitized and tunable luminescence of $\mathrm{GdNbO}_{4}: \mathrm{Ln}^{3+}\left(\mathrm{Ln}^{3+}=\mathrm{Eu}^{3+} / \mathrm{Tb}^{3+} / \mathrm{Tm}^{3+}\right)$ nanocrystalline phosphors with abundant color. Inorg. Chem. 2016, 55, 10383-10396. [CrossRef]

165. Blasse, G.; Bril, A. Luminescence phenomena in compounds with fergusonite structure. J. Lumin. 1970, 3 , 109-131. [CrossRef]

166. Moncorge, R.; Boulon, G. Investigations of the absorption and emission properties along with energy transfer in pure and $\mathrm{Bi}^{3+}$ doped $\mathrm{YVO}_{4}$. J. Lumin. 1979, 18-19, 376-380. [CrossRef]

167. Zorenko, Y.; Voloshinovskii, A.; Savchyn, V.; Voznyak, T.; Nikl, M.; Nejezchleb, K.; Mikhailin, V.; Kolobanov, V.; Spassky, D. Exciton and antisite defect-related luminescence in $\mathrm{Lu}_{3} \mathrm{Al}_{5} \mathrm{O}_{12}$ and $\mathrm{Y}_{3} \mathrm{Al}_{5} \mathrm{O}_{12}$ garnets. Phys. Status Solidi B 2007, 244, 2180-2189. [CrossRef]

168. Babin, V.; Bichevin, V.; Gorbenko, V.; Kink, M.; Makhov, A.; Maksimov, Y.; Nikl, M.; Stryganyuk, G.; Zazubovich, S.; Zorenko, Y. Time-resolved spectroscopy of exciton-related states in single crystals and single crystalline films of $\mathrm{Lu}_{3} \mathrm{Al}_{5} \mathrm{O}_{12}$ and $\mathrm{Lu}_{3} \mathrm{Al}_{5} \mathrm{O}_{12}$ :Ce. Phys. Status Solidi B 2011, 248, 1505-1512. [CrossRef] 
169. Babin, V.; Blazek, K.; Krasnikov, A.; Nejezchleb, K.; Nikl, M.; Savikhina, T.; Zazubovich, S. Luminescence of undoped LuAG and YAG crystals. Phys. Status Solidi 2005, C 2, 97-100. [CrossRef]

170. Mürk, V.; Yaroshevich, N. Exciton and recombination processes in YAG crystals. J. Phys. Condens. Matter 1995, 7, 5857-5864. [CrossRef]

171. Zorenko, Y.; Zorenko, T.; Vistovskyy, V.; Grinberg, M.; Łukasiewicz, T. Time-resolved spectroscopy of intrinsic luminescence of $\mathrm{Y}_{3} \mathrm{Ga}_{5} \mathrm{O}_{12}$ and $(\mathrm{LaLu})_{3} \mathrm{Lu}_{2} \mathrm{Ga}_{3} \mathrm{O}_{12}$ single crystals. Opt. Mater. 2009, 31, 1835-1838. [CrossRef]

172. Lammers, M.J.J.; Severin, J.M.; Blasse, G. The luminescence properties of unactivated and $\mathrm{Tb}^{3+}$-activated $\mathrm{Gd}_{3} \mathrm{Ga}_{5} \mathrm{O}_{12}$. J. Electrochem. Soc. Solid State Sci. Technol. 1987, 134, 2356-2358.

173. Babin, V.; Gorbenko, V.; Kondakova, I.; Kärner, T.; Laguta, V.V.; Nikl, M.; Zazubovich, S.; Zorenko, Y. Time-resolved spectroscopy of exciton states in single crystals and single crystalline films of $\mathrm{YAlO}_{3}$ and $\mathrm{YAlO}_{3}$ :Ce. J. Phys. D Appl. Phys. 2011, 44, 315402. [CrossRef]

174. Korzhik, M.V.; Trower, W.P. Origin of scintillation in cerium-doped oxide crystals. Appl. Phys. Lett. 1995, 66, 2327-2328. [CrossRef]

175. Zorenko, Y.; Gorbenko, V.; Voloshinovskii, A.; Vistovskii, V.; Nikl, M.; Mihokova, E.; Nejezchleb, K. Intrinsic and $\mathrm{Ce}^{3+}$-related luminescence of single crystals and single crystalline films of YAP perovskites: New results. IEEE Trans. Nucl. Sci. 2008, 55, 1186-1191. [CrossRef]

176. Zorenko, T.; Gorbenko, V.; Petrosyan, A.; Gieszczyk, W.; Bilski, P.; Zorenko, Y. Intrinsic and defect-related luminescence of $\mathrm{YAlO}_{3}$ and $\mathrm{LuAlO}_{3}$ single crystals and films. Opt. Mater. 2018, 86, 376-381. [CrossRef]

177. Zorenko, Y.; Gorbenko, V.; Voznyak, T.; Mikhailin, V.; Kolobanov, V.; Spassky, D.; Nikl, M. Intrinsic and $\mathrm{Ce}^{3+}$-related luminescence in single crystalline films and single crystals of LuAP and LuAP:Ce perovskites. IEEE Trans. Nucl. Sci. 2008, 55, 1192-1196. [CrossRef]

178. Nikl, M.; Bohacek, P.; Mihokova, E.; Kobayashi, M.; Ishii, M.; Usuki, Y.; Babin, V.; Stolovich, A.; Zazubovich, S.; Bacci, M. Excitonic emission of scheelite tungstates $\mathrm{AWO}_{4}(\mathrm{~A}=\mathrm{Pb}, \mathrm{Ca}, \mathrm{Ba}, \mathrm{Sr})$. J. Lumin. 2000, 87-89, 1136-1139. [CrossRef]

179. Babin, V.; Bohacek, P.; Bender, E.; Krasnikov, A.; Mihokova, E.; Nikl, M.; Senguttuvan, N.; Stolovits, A.; Usuki, Y.; Zazubovich, S. Decay kinetics of the green emission in tungstates and molybdates. Radiat. Meas. 2004, 38, 533-537. [CrossRef]

180. Babin, V.; Bohachek, K.; Krasnikov, A.; Nikl, M.; Stolovits, A.; Zazubovich, S. Origin of green luminescence in $\mathrm{PbWO}_{4}$ crystals. J. Lumin. 2007, 124, 113-119. [CrossRef]

181. Cooke, D.W.; Bennett, B.L.; Muenchausen, R.E.; Lee, J.-K.; Nastasi, M.A. Intrinsic ultraviolet luminescence from $\mathrm{Lu}_{2} \mathrm{O}_{3}, \mathrm{Lu}_{2} \mathrm{SiO}_{5}$ and $\mathrm{Lu}_{2} \mathrm{SiO}_{5}: \mathrm{Ce}^{3+}$. J. Lumin. 2004, 106, 125-132. [CrossRef]

182. Jacobsohn, L.G.; Lee, J.-K.; Bennett, B.L.; Muenchausen, R.E.; Nastasi, M.; Cooke, D.W. Effects of ion beam irradiation on self-trapped defects in single-crystal $\mathrm{Lu}_{2} \mathrm{SiO}_{5}$. J. Lumin. 2007, 124, 5-9. [CrossRef]

183. Zorenko, Y.; Zorenko, T.; Voznyak, T.; Sidletskiy, O. Intrinsic luminescence of $\mathrm{Lu}_{2} \mathrm{SiO}_{5}(\mathrm{LSO}) \mathrm{and}_{2} \mathrm{SiO}_{5}$ (YSO) orthosilicates. J. Lumin. 2013, 137, 204-207. [CrossRef]

184. Meunier-Beillard, P.; Moine, B.; Dujardin, C.; Cieren, X.; Pedrini, C.; Huguenin, D.; Archambault, V. Exciton trapping in $\mathrm{LaPO}_{4}$ doped with trivalent cerium and/or terbium ions. Rad. Eff. Def. Solids 1999, 149, 25-30. [CrossRef]

185. Wisniewski, D.; Tavernier, S.; Wojtowicz, A.J.; Wisniewska, M.; Bruyndonckx, P.; Dorenbos, P.; van Loef, E.; van Eijk, C.W.E.; Boatner, L.A. $\mathrm{LuPO}_{4}: \mathrm{Nd}$ and $\mathrm{YPO}_{4}: \mathrm{Nd}-$ new promising VUV scintillation materials. Nucl. Instrum. Meth. Phys. Res. A 2002, 486, 239-243. [CrossRef]

186. Mikhailin, V.V.; Spassky, D.A.; Kolobanov, V.N.; Meotishvili, A.A.; Permenov, D.G.; Zadneprovski, B.I. Luminescence study of the $\mathrm{LuBO}_{3}$ and $\mathrm{LuPO}_{4}$ doped with RE ${ }^{3+}$. Radiat. Meas. 2010, 45, 307-310. [CrossRef]

187. Knitel, M.J.; Dorenbos, P.; van Eijk, C.W.E.; Plasteig, B.; Viana, B.; Kahn-Harari, A.; Vivien, D. Photoluminescence, and scintillation/thermoluminescence yields of several $\mathrm{Ce}^{3+}$ and $\mathrm{Eu}^{2+}$ activated borates. Nucl. Instrum. Meth. Phys. Res. A 2000, 443, 364-374. [CrossRef]

188. Nagirnyi, V.; Stolovich, A.; Zazubovich, S.; Zepelin, V.; Mihokova, E.; Nikl, M.; Pazzi, G.P.; Salvini, L. Peculiarities of the triplet relaxed excited-state structure and luminescence of a CsI:Tl crystal. J. Phys. Condens. Matter 1995, 7, 3637-3653. [CrossRef]

189. Mihokova, E.; Nagirnyi, V.; Nikl, M.; Stolovich, A.; Pazzi, G.P.; Zazubovich, S.; Zepelin, V. Relaxed excited state structure and luminescence of thallium-doped caesium chloride and bromide. J. Phys. Condens. Matter 1996, 8, 4301-4314. [CrossRef] 
190. Aceves, R.; Babin, V.; Barboza Flores, M.; Fabeni, P.; Mihokova, E.; Nagirnyi, V.; Nikl, M.; Nitsch, K.; Pazzi, G.P.; Perez Salas, R.; et al. Coexistence of the impurity and perturbed exciton levels in the relaxed excited state of CsCl:Pb crystal. J. Phys. Condens. Matter 1998, 10, 5449-5461. [CrossRef]

191. Aceves, R.; Babin, V.; Barboza Flores, M.; Fabeni, P.; Mihokova, E.; Nikl, M.; Nitsch, K.; Pazzi, G.P.; Perez Salas, R.; Zazubovich, N.; et al. Relaxed excited states origin and structure in lead-doped caesium bromide. Phys. Status Solidi B 2001, 223, 745-756. [CrossRef]

192. Babin, V.; Krasnikov, A.; Nikl, M.; Nitsch, K.; Stolovitš, A.; Zazubovich, S. Luminescence and relaxed excited state origin in CsI:Pb crystals. J. Lumin. 2003, 101, 219-226. [CrossRef]

193. Vazhenin, V.A.; Potapov, A.P.; Asatryan, G.R.; Nikl, M. Photosensitive bismuth ions in lead tungstate. Phys. Solid St. 2013, 55, 803-806. [CrossRef]

194. Yadav, S.K.; Uberuaga, B.P.; Nikl, M.; Jiang, C.; Stanek, C.R. Band-gap and band-edge engineering of multicomponent garnet scintillators from first principles. Phys. Rev. Appl. 2015, 4, 054012. [CrossRef]

195. Babin, V.; Buryi, M.; Chlan, V.; Kamada, K.; Laguta, V.V.; Nikl, M.; Pejchal, J.; Štěpánková, H.; Yoshikawa, A.; Fomichov, Y.; et al. Influence of gallium content on $\mathrm{Ga}^{3+}$ position and photo- and thermally stimulated luminescence in $\mathrm{Ce}^{3+}$-doped multicomponent $\left(\mathrm{Y}, \mathrm{Lu}_{1}\right)_{3} \mathrm{Ga}_{\mathrm{x}} \mathrm{Al}_{5-\mathrm{x}} \mathrm{O}_{12}$ garnets. J. Lumin. 2018, 200, 141-150. [CrossRef]

196. Babin, V.; Hanus, M.; Krasnikov, A.; Kučera, M.; Nikl, M.; Zazubovich, S. Determination of the position of the $5 \mathrm{~d}$ excited levels of $\mathrm{Ce}^{3+}$ ions with respect to the conduction band in the epitaxial films of the multicomponent $(\mathrm{Lu}, \mathrm{Gd})_{3}(\mathrm{Ga}, \mathrm{Al})_{5} \mathrm{O}_{12}:$ Ce garnets. Opt. Mat. 2016, 62, 465-474. [CrossRef]

197. Babin, V.; Chernenko, K.; Kučera, M.; Nikl, M.; Zazubovich, S. Photostimulated luminescence and defects creation processes in $\mathrm{Ce}^{3+}$-doped epitaxial films of multicomponent $\mathrm{Lu}_{3-\mathrm{x}} \mathrm{Gd}_{\mathrm{x}} \mathrm{Ga}_{\mathrm{y}} \mathrm{Al}_{5-\mathrm{y}} \mathrm{O}_{12}$ garnets. J. Lumin. 2016, 179, 487-495. [CrossRef]

198. Ogiegło,J.M.; Katelnikovas, A.; Zych, A.; Jüstel, T.; Meijerink, A.; Ronda, C.R. Luminescence and luminescence quenching in $\mathrm{Gd}_{3}(\mathrm{Ga}, \mathrm{Al})_{5} \mathrm{O}_{12}$ scintillators doped with $\mathrm{Ce}^{3+}$. J. Phys. Chem. A 2013, 117, 2479-2484. [CrossRef]

199. Nikl, M.; Kamada, K.; Kurosawa, S.; Yokota, Y.; Yoshikawa, A.; Pejchal, J.; Babin, V. Luminescence and scintillation mechanism in $\mathrm{Ce}^{3+}$ and $\operatorname{Pr}^{3+}$ doped $(\mathrm{Lu}, \mathrm{Y}, \mathrm{Gd})_{3}(\mathrm{Ga}, \mathrm{Al})_{5} \mathrm{O}_{12}$ single crystal scintillators. Phys. Status Solidi C 2013, 10, 172-175. [CrossRef]

200. Yousif, A.; Vinod, K.; Seed Ahmed, H.A.A.; Som, S.; Noto, L.L.; Ntwaeaborwa, O.M.; Swart, H.C. Effect of $\mathrm{Ga}^{3+}$ doping on the photoluminescence properties of $\mathrm{Y}_{3} \mathrm{Al}_{5-\mathrm{x}} \mathrm{Ga}_{\mathrm{x}} \mathrm{O}_{12}: \mathrm{Bi}^{3+}$ phosphor. ECS J. Solid St. Sci. Technol. 2014, 3, R222-R227. [CrossRef]

201. Zorenko, Y.; Gorbenko, V.; Voznyak, T.; Jary, V.; Nikl, M. Luminescence spectroscopy of the $\mathrm{Bi}^{3+}$ single and dimer centers in $\mathrm{Y}_{3} \mathrm{Al}_{5} \mathrm{O}_{12}$ :Bi single crystalline films. J. Lumin. 2010, 130, 1963-1969. [CrossRef]

202. Zorenko, Y.; Gorbenko, V.; Zorenko, T.; Malinowski, P.; Jary, V.; Kucerkova, R.; Beitlerova, A.; Mares, J.A.; Nikl, M.; Fedorov, A. Luminescent and scintillation properties of $\mathrm{Bi}^{3+}$ doped $\mathrm{Y}_{2} \mathrm{SiO}_{5}$ and $\mathrm{Lu}_{2} \mathrm{SiO}_{5}$ single crystalline films. J. Lumin. 2014, 154, 525-530. [CrossRef]

203. Fukuda, A. Absorption bands of paired-ion centers $\left(\mathrm{Ga}^{+}\right)_{2},\left(\mathrm{In}^{+}\right)_{2}$ and $\left(\mathrm{Tl}^{+}\right)_{2}$ in KI. J. Phys. Soc. Jpn. 1969, 26, 1006-1013. [CrossRef]

204. Ermoshkin, A.; Evarestov, R.; Gindina, R.; Maaroos, A.; Osminin, V.; Zazubovich, S. Monovalent mercury-like ion dimer centres in alkali halide crystals. Phys. Status Solidi B 1975, 70, 749-758. [CrossRef]

205. Tsuboi, T. Geometrical structure of $\left(\mathrm{Tl}^{+}\right)_{2}$ luminescent center in alkali halides: Presence of $\mathrm{D}_{2 \mathrm{~h}}$ and $\mathrm{D}_{4 \mathrm{~h}}$ dimer centers. Phys. Rev. B 1984, 29, 1022-1029. [CrossRef]

206. Zazubovich, S.; Lushchik, N.E.; Lushchik, C.B. Optical structure of luminescence centres in ionic crystals doped with mercury-like ions. Soviet Phys. Opt. Spectrosc. 1963, 15, 381-388.

207. Tsuboi, T.; Jacobs, P.W.M. Optical studies of $\mathrm{s}^{2}$-ion dimer centers in alkali halide crystals. J. Phys. Chem. Solids 1991, 52, 69-80. [CrossRef]

208. de Vries, A.J.; Blasse, G. Energy migration in gadolinium compounds. J. de Phys. Colloq. 1985, 46, C7-C109. [CrossRef]

209. Nagli, L.E.; Dyachenko, S.V. Influence of $\mathrm{a} \mathrm{v}_{\mathrm{c}}{ }^{-}$Vacancy on Luminescence of $\mathrm{Pb}^{+}$Centres in Alkali Halides. Phys. Stat. Sol. B 1988, 146, 295-301. [CrossRef]

210. Mollenauer, L.F.; Vieira, N.D.; Szeto, L. Optical properties of the $\mathrm{Tl}^{0}(1)$ center in KCl. Phys. Rev. B 1983, 27, 5332-5346. [CrossRef]

211. Fockele, M.; Ahlers, F.J.; Lohse, F.; Spaeth, J.-M.; Bartram, R.H. Optical properties of atomic thallium centres in alkali halides. J. Phys. C Solid State Phys. 1985, 18, 1963. [CrossRef] 
212. Hamstra, M.A.; Folkerts, H.F.; Blasse, G. Red bismuth emission in alkaline-earth-metal sulfates. J. Mater. Chem. 1994, 4, 1349-1350. [CrossRef]

213. Srivastava, A.M. Luminescence of divalent bismuth in $\mathrm{M}^{2+} \mathrm{BPO}_{5}\left(\mathrm{M}^{2+}=\mathrm{Ba}^{2+}, \mathrm{Sr}^{2+}\right.$ and $\left.\mathrm{Ca}^{2+}\right)$. J. Lumin. 1998, 78, 239-243. [CrossRef]

214. Zeng, Q.; Zhang, T.; Pei, Z.; Qiang, S.U. Luminescence of unusual bismuth in barium borates $\left(\mathrm{BaB}_{8} \mathrm{O}_{13}: \mathrm{Bi}\right)$. J. Mater. Sci. Techn. 1999, 15, 282.

215. Gaft, M.; Reisfeld, R.; Panczer, G.; Boulon, G.; Saraidarov, T.; Erlish, S. The luminescence of Bi, Ag and Cu in natural and synthetic barite $\mathrm{BaSO}_{4}$. Opt. Mater. 2001, 16, 279-290. [CrossRef]

216. Peng, M.; Wondraczek, L. Photoluminescence of $\mathrm{Sr}_{2} \mathrm{P}_{2} \mathrm{O}_{7}: \mathrm{Bi}^{2+}$ as a red phosphor for additive light generation. Opt. Lett. 2010, 35, 2544-2546. [CrossRef]

217. Cao, R.; Shang, F.; Liao, C.; Qiu, J. Yellow-to-orange emission from $\mathrm{Bi}^{2+}$-doped $\mathrm{RF}_{2}(\mathrm{R}=\mathrm{Ca}$ and $\mathrm{Sr})$ phosphors. Opt. Express 2013, 21, 15728-15733. [CrossRef]

218. Zheng, J.; Li, L.; Peng, M. A New Red Aluminate Phosphor $\mathrm{CaAl}_{12} \mathrm{O}_{19}$ Activated by $\mathrm{Bi}^{2+}$ for White LEDs. Sci. Adv. Mater. 2017, 9, 485-489. [CrossRef]

219. Jong, M.; Meijerink, A.; Gordon, R.A.; Barandiaran, Z.; Seijo, L. Is Bi ${ }^{2+}$ Responsible for the Red-Orange Emission of Bismuth-Doped $\mathrm{SrB}_{4} \mathrm{O}_{7}$ ? J. Phys.Chem. C 2014, 118, 9696-9705. [CrossRef]

220. Peng, M.; Wondraczek, L. Bi ${ }^{2+}$-doped strontium borates for white-light-emitting diodes. Opt. Lett. 2009, 34, 2885-2887. [CrossRef]

221. Jong, M.; Meijerink, A.; Barandiaran, Z.; Seijo, L. Structure and Hindered Vibration of $\mathrm{Bi}^{2+}$ in the Red-Orange Phosphor $\mathrm{SrB}_{4} \mathrm{O}_{7}$ :Bi. J. Phys. Chem. C 2014, 118, 17932-17939. [CrossRef]

222. Peng, M.; Wondraczek, L. Orange-to-Red Emission from $\mathrm{Bi}^{2+}$ and Alkaline Earth Codoped Strontium Borate Phosphors for White Light Emitting Diodes. J. Am. Ceram. Soc. 2010, 93, 1437-1442. [CrossRef]

223. Li, L.; Peng, M.; Viana, B.; Wang, J.; Lei, B.; Liu, Y.; Zhang, Q.; Qiu, J. Unusual Concentration Induced Antithermal Quenching of the $\mathrm{Bi}^{2+}$ Emission from $\mathrm{Sr}_{2} \mathrm{P}_{2} \mathrm{O}_{7}: \mathrm{Bi}^{2+}$. Inorg. Chem. 2015, 54, 6028-6034. [CrossRef]

224. Cao, R.; Peng, M.; Qiu, J. Luminescence from $\mathrm{Bi}^{2+}$-doped $\mathrm{BaSO}_{4}$ for White LEDs. Opt. Express 2012, 20, A977-A983. [CrossRef] [PubMed]

225. Murata, K.; Fujimoto, Y.; Kanabe, T.; Fujita, H.; Nakatsuka, M. Bi-doped SiO as a new laser material for an intense laser. Fusion Eng. Des. 1999, 44, 437-439. [CrossRef]

226. Bjerrum, N.; Boston, C.; Smith, G. Lower oxidation states of bismuth. $\mathrm{Bi}^{+}$and $\mathrm{Bi}_{5}{ }^{3+}$ in molten salt solutions. Inorg. Chem. 1967, 6, 1162-1172. [CrossRef]

227. Zheng, J.; Tan, L.; Wang, L.; Peng, M.; Xu, S. Superbroad visible to NIR photoluminescence from $\mathrm{Bi}^{+}$ evidenced in $\mathrm{Ba}_{2} \mathrm{~B}_{5} \mathrm{O}_{9} \mathrm{Cl}: \mathrm{Bi}$ crystal. Opt. Express 2016, 24, 2830-2835. [CrossRef]

228. Lyu, T.; Dorenbos, ${\mathrm{P} . \mathrm{Bi}^{3+}}^{3}$ acting both as an electron and as a hole trap in La-, Y-, and LuPO4. J. Mater. Chem. C 2018, 6, 6240-6249. [CrossRef]

229. Zazubovich, S.G.; Lushchik, N.E. Alkali halide crystals doped with bismuth and antimony. Trudy IFA AN EstSSR 1961, 17, 50-66.

230. Lushchik, C.B.; Gindina, R.I.; Zazubovich, S.G.; Lushchik, N.E. Polarization characteristics of some alkali halide phosphors. Trudy IFA AN EstSSR 1961, 17, 38-49.

231. Zazubovich, S.G. Polarized luminescence of alkali halides doped with mercury-like ions. Trudy IFA AN EstSSR 1969, 36, 109-153.

232. Ewles, J.; Curry, C. Resolution and analysis of low temperature luminescent spectra of Bi and $\mathrm{Pb}$ activated solids of simple crystal structure. Proc. Phys. Soc. A 1950, 63, 708-715. [CrossRef]

233. Runciman, W.A. Absorption and emission spectra of bismuth-activated phosphors. Proc. Phys. Soc. A 1955, 68, 647-649. [CrossRef]

234. Lushchik, C.; Lushchik, N.; Muuga, I. Vibronic spectra of crystals activated with mercury-like ions. Trudy Ins. Fiz. Astron. Akad. Nauk EstSSR 1963, 23, 22-37.

235. Hughes, A.E.; Runciman, W.A. Stress and Zeeman spectra in bismuth-doped and undoped calcium oxide. J. Phys. C Solid State Phys. 1969, 2, 37-45. [CrossRef]

236. Lehmann, W. Calcium oxide phosphors. J. Lumin. 1973, 6, 455-470. [CrossRef]

237. Hughes, A.E.; Pells, G.P. Absorption and luminescence of bismuth ions implanted into $\mathrm{CaO}$ and $\mathrm{MgO}$ single crystals. Phys. Status Solidi A 1974, 25, 437-443. [CrossRef]

238. Runciman, W.A.; Manson, N.B.; Marshall, M. Magnetic effect on the emission of bismuth-doped calcium oxide. J. Lumin. 1976, 12/13, 413-417. [CrossRef] 
239. van der Steen, A.C.; Dijcks, L.T.F. The luminescence properties of alkaline-earth oxides activated with $6 s^{2}$ ions. Phys. Status Solidi B 1981, 104, 283-292. [CrossRef]

240. Randoshkin, V.V.; Vasil'eva, N.V.; Kolobanov, V.N.; Mikhailin, V.V.; Petrovin, N.N.; Spasskii, D.A.; Sysoev, N.N. Effect of $\mathrm{Gd}_{2} \mathrm{O}_{3}$ concentration in Bi-containing high-temperature solutions on the luminescence of epitaxial $\mathrm{Gd}_{3} \mathrm{Ga}_{5} \mathrm{O}_{12}$ films. Inorg. Mater. 2009, 45, 418-422. [CrossRef]

241. Luchechko, A.; Syvorotka, I.I.; Zakharko, Y.; Syvorotka, I.M. Growing features and luminescence of Bi ${ }^{3+}$ ions in $\mathrm{Gd}_{3} \mathrm{Ga}_{5} \mathrm{O}_{12}$ epitaxial films. Solid State Phenom. 2013, 200, 215-219.

242. Lushchik, C.; Feldbach, E.; Frorip, A.; Kirm, M.; Lushchik, A.; Maaroos, A.; Martinson, I. Multiplication of electronic excitations in $\mathrm{CaO}$ and $\mathrm{YAlO}_{3}$ crystals with free and self-trapped excitons. J. Phys. Condens. Matter 1994, 6, 11177-11187. [CrossRef]

243. Auffrey, E.; Korjik, M.; Shalapska, T.; Zazubovich, S. Photoluminescence and excited states dynamics in $\mathrm{PbWO}_{4}: \mathrm{Pr}^{3+}$ crystals. J. Lumin. 2014, 154, 381-386. [CrossRef]

244. Laguta, V.V.; Nikl, M.; Zazubovich, S. Photothermally stimulated creation of electron and hole centers in $\mathrm{Ce}^{3+}$-doped $\mathrm{Y}_{2} \mathrm{SiO}_{5}$ single crystals. Opt. Mater. 2014, 36, 1636-1641. [CrossRef]

245. Babin, V.; Kalder, K.; Krasnikov, A.; Zazubovich, S. Luminescence and defects creation under photoexcitation of CsI:Tl crystals in $\mathrm{Tl}^{+}$-related absorption bands. J. Lumin. 2002, 96, 75-85. [CrossRef]

246. Verwey, J.W.M.; Blasse, G. Luminescence efficiency of ions with broad-band excitation in lithium lanthanum phosphate glass. Chem. Mater. 1990, 2, 458-463. [CrossRef]

247. Boujelbene, M.; Mhiri, T. Synthesis and crystal structure of $\mathrm{LiLaP}_{4} \mathrm{O}_{12}$. X-ray Struct. Anal. Online 2011, 27, 21-22. [CrossRef]

248.

249. Dorenbos, P.; Krumpel, A.H.; van der Kolk, E.; Boutinaud, P.; Bettinelli, M.; Cavalli, E. Lanthanide level location in transition metal complex compounds. Opt. Mater. 2010, 32, 1681-1685. [CrossRef]

250. Newport, A.; Silver, J.; Vecht, A. The synthesis of fine particle yttrium vanadate phosphors from spherical powder precursors using urea precipitation. J. Electrochem. Soc. 2000, 147, 3944-3947. [CrossRef]

251. Takeshita, S.; Isobe, T.; Sawayama, T.; Niikura, S. Effects of the homogeneous $\mathrm{Bi}^{3+}$ doping process on photoluminescence properties of $\mathrm{YVO}_{4}: \mathrm{Bi}^{3+}, \mathrm{Eu}^{3+}$ nanophosphor. J. Lumin. 2009, 129, 1067-1072. [CrossRef]

252. Boutinaud, P. Optical processes in $(\mathrm{Y}, \mathrm{Bi}) \mathrm{VO}_{4}$ doped with $\mathrm{Eu}^{3+}$ or $\mathrm{Pr}^{3+}$. J. Phys. Condens. Matter 2014, 26, 405501. [CrossRef] [PubMed]

253. Mahlik, S.; Amer, M.; Boutinaud, P. Energy level structure of $\mathrm{Bi}^{3+}$ in zircon and scheelite polymorphs of $\mathrm{YVO}_{4}$. J. Phys. Chem. 2016, 120, 8261-8265. [CrossRef]

254. Lee, S.K.; Chang, H.; Han, C.H.; Kim, H.J.; Jang, H.G.; Park, H.D. Electronic structures and luminescence properties of $\mathrm{YNbO}_{4}$ and $\mathrm{YNbO}_{4}$ :Bi. J. Solid St. Chem. 2001, 156, 267-273. [CrossRef] 